\title{
DESIGN AND CONSTRUCTION OF 1800W MODULAR MULTIPLE INPUT SINGLE OUTPUT NON-ISOLATED DC-DC CONVERTERS
}

\author{
A Thesis \\ presented to \\ the Faculty of California Polytechnic State University, \\ San Luis Obispo
}

\author{
In Partial Fulfillment \\ of the Requirements for the Degree \\ Master of Science in Electrical Engineering
}

by

Angelo Miguel Asuncion Gallardo

June 2017 
(C) 2017

Angelo Miguel Asuncion Gallardo

ALL RIGHTS RESERVED 


\section{COMMITTEE MEMBERSHIP}

TITLE: Design and Construction of 1800W Modular Multiple Input Single Output Non-Isolated DC-DC Converters

AUTHOR: Angelo Miguel Asuncion Gallardo

DATE SUBMITTED: June 2017

COMMITTEE CHAIR: Taufik, Ph.D.

Professor of Electrical Engineering

COMMITTEE MEMBER: David Braun, Ph.D.

Professor of Electrical Engineering

COMMITTEE MEMBER: Helen Yu, Ph.D.

Professor of Electrical Engineering 


\begin{abstract}
Design and Construction of 1800W Modular Multiple Input Single Output Non-Isolated DC-DC Converters
\end{abstract}

Angelo Miguel Asuncion Gallardo

This thesis report details the design and construction of non-isolated DC-DC converters to create a Multiple Input Single Output (MISO) converter for combining multiple renewable energy sources into one single output. This MISO uses the fourswitch buck-boost topology to output a single $48 \mathrm{~V}$ from multiple nominal 24V inputs. The MISO converter implements a modular approach to deliver $1800 \mathrm{~W}$ output power. Each module in the MISO is rated at $600 \mathrm{~W}$ and they share the output power equally. Hardware results show that the converter produces $1800 \mathrm{~W}$ of output power from three sources with $96.4 \%$ efficiency. Each module also demonstrates equal sharing feature of the MISO converter.

Keywords: DC-DC converter, non-isolated, power electronics, four-switch buck-boost, multiple input single output 


\section{ACKNOWLEDGMENTS}

I would like to thank my parents for their unconditional love and support. They have always been supportive in my ambitions for more internships and more education and without them, I would not be where I am today. Their encouragement to achieve more in my life led me to pursue a Master's in Electrical Engineering, and ultimately write this thesis report.

In addition, I would like to thank all my friends who have helped and supported me throughout my five years here at Cal Poly. I would like to give a special thank you to all my fellow electrical engineering colleagues who I have struggled alongside with during my time in both the undergraduate and graduate EE program.

Lastly, I would like to thank three specific people who have been critical to the success of this thesis. I would like to thank Owen Jong for his help during the design process, Lu Li for his help during the layout process, and, finally, Dr. Taufik for his guidance and expertise in the field of power electronics. Dr. Taufik develops excellence for all his students and deserves more credit than he receives. I am grateful that he was my advisor for this thesis and that he has given me a bright future in power electronics. 


\section{TABLE OF CONTENTS}

Page

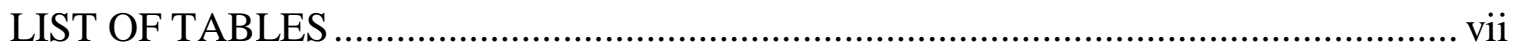

LIST OF FIGURES ................................................................................... viii

\section{CHAPTER}

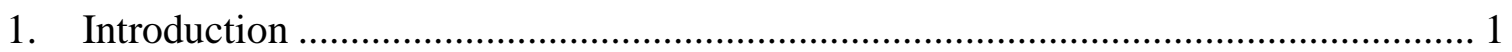

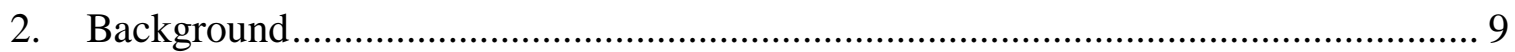

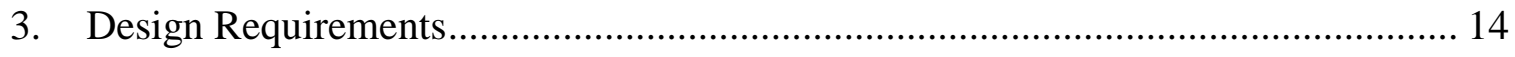

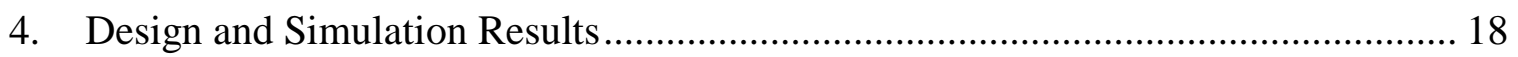

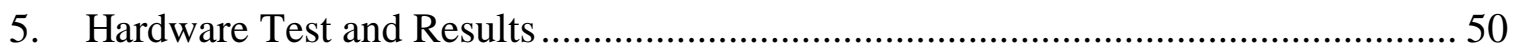

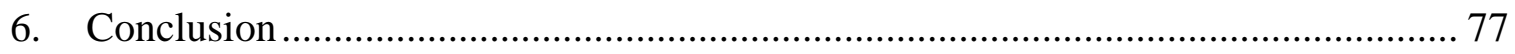

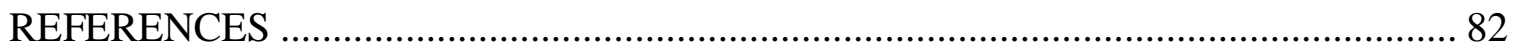

\section{APPENDICES}

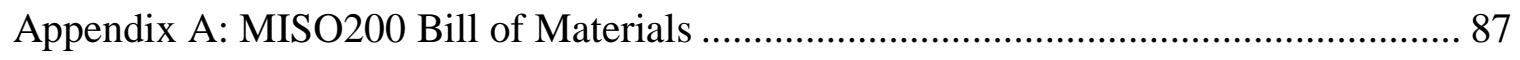

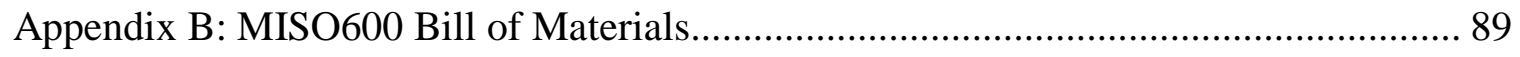

Appendix C: MISO200 Efficiency Raw Data ….................................................. 91

Appendix D: MISO600 Efficiency and Load Sharing Raw Data ................................ 92

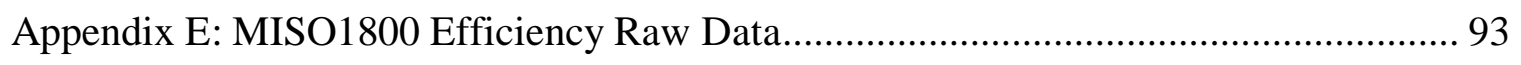

Appendix F: MISO1800 Load Sharing Raw Data ................................................ 94

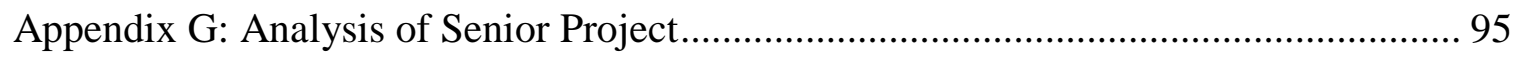




\section{LIST OF TABLES}

Page

Table 3-1: Summary of Design Specifications …………………………………...... 17

Table 5-1: List of Equipment for Test Setups.................................................................. 52

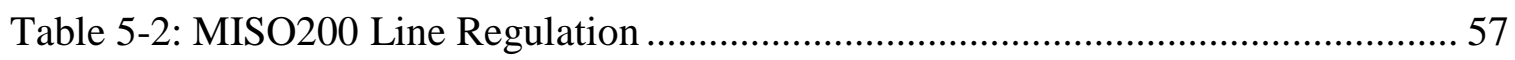

Table 5-3: MISO200 Output Voltage Ripple and Switch-Node Data .............................. 59

Table 5-4: MISO600 Load Sharing Per Channel............................................................. 64

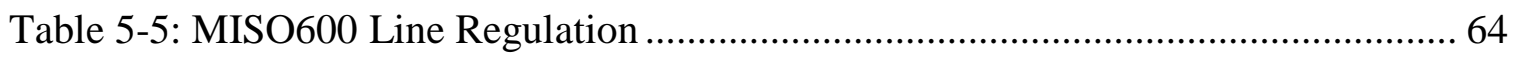

Table 5-6: MISO600 Output Voltage Ripple and Switch-Node Data .............................. 65

Table 5-7: MISO1800 Load Sharing Per Channel.......................................................... 71

Table 5-8: MISO1800 Output Voltage Ripple and Switch-Node Data ............................. 72

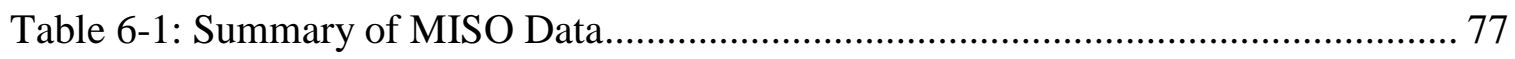




\section{LIST OF FIGURES}

Page

Figure 1-1: Projected World Population by 2050 [2] ................................................. 2

Figure 1-2: Projected World Consumption by 2040 [1] ............................................. 2

Figure 1-3: Projected Breakdown of Electricity Generation by Fuel [6]........................... 4

Figure 1-4: Block Diagram of DC House [5] ...................................................... 8

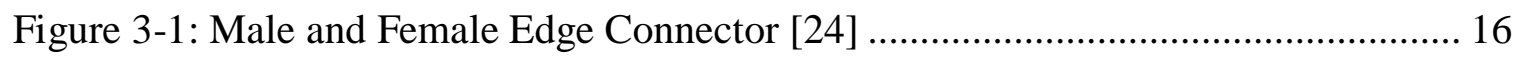

Figure 4-1: Simplified Circuit of Four-Switch Buck-Boost [32] ................................. 19

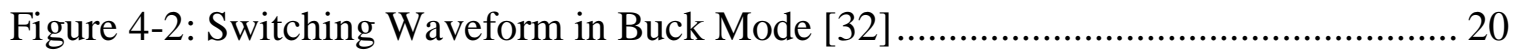

Figure 4-3: Switching Waveform in Boost Mode [32] ............................................ 20

Figure 4-4: Switching Waveform in Buck-Boost Mode [32] ....................................... 21

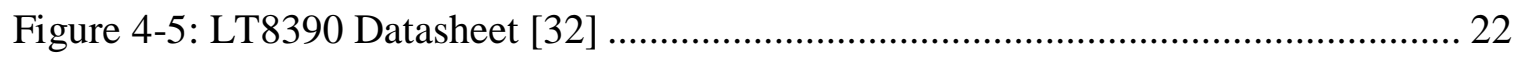

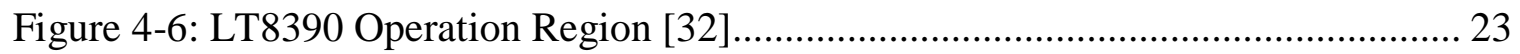

Figure 4-7: Buck-Boost Switching Waveform for Peak-Buck and Peak-Boost [32] ....... 24

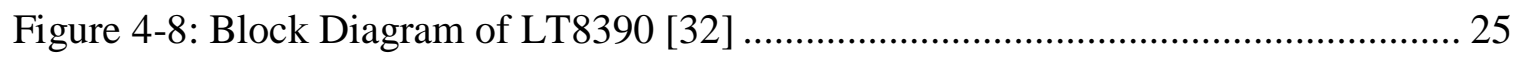

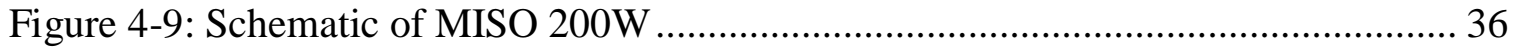

Figure 4-10: Block Diagram of Current Sharing .................................................... 37

Figure 4-11: Current Sharing Control Circuit Implementation ................................... 38

Figure 4-12: Complete Schematic of MISO 200W Module ........................................ 39

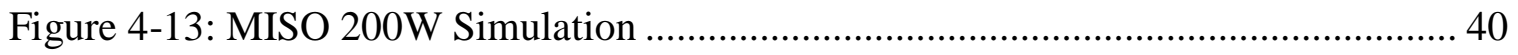

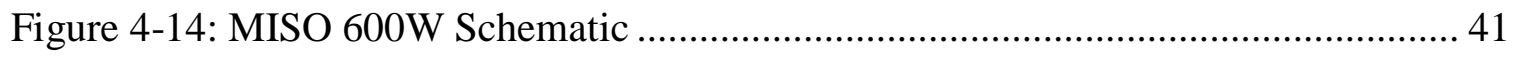

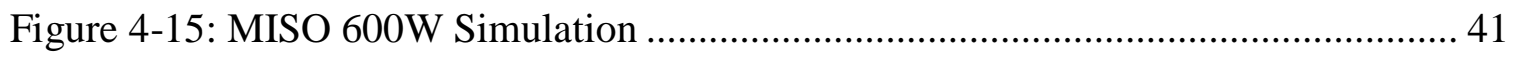

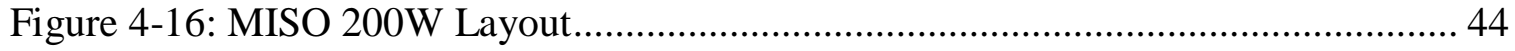




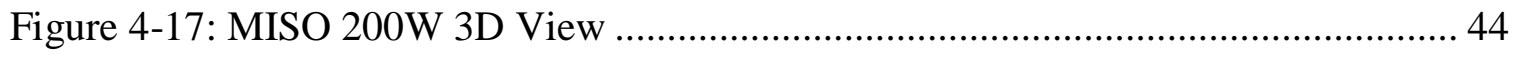

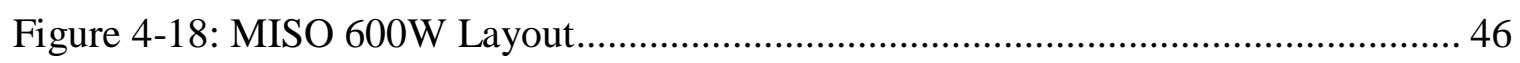

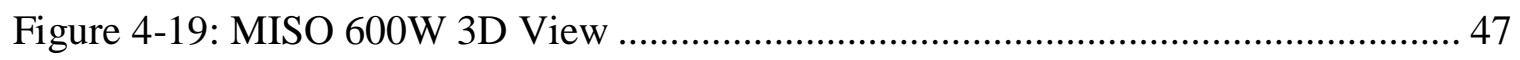

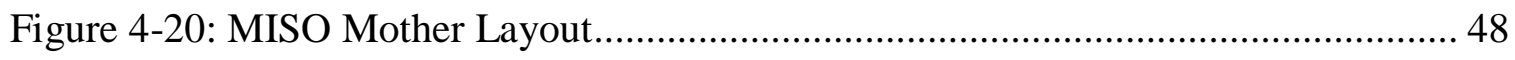

Figure 4-21: MISO Mother 3D View …………………........................................ 49

Figure 5-1: Block Diagram of Generic Test Setup ………………………………....... 52

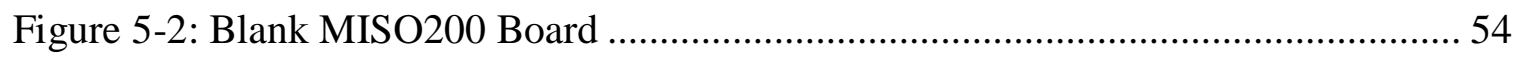

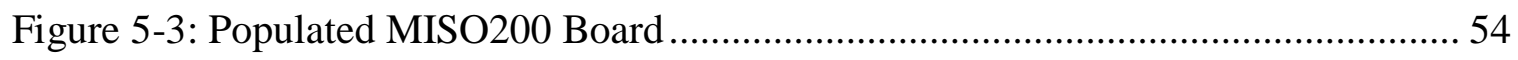

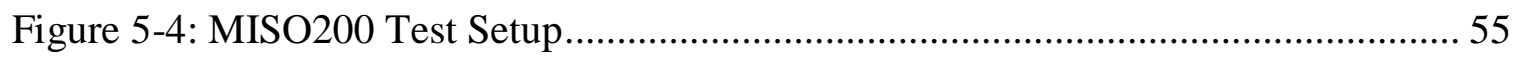

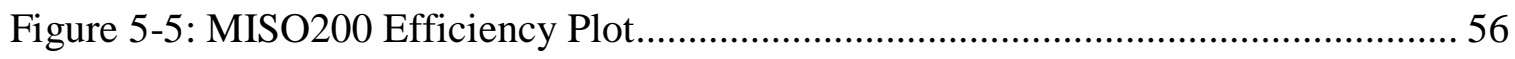

Figure 5-6: MISO200 Oscilloscope Probe Configuration ……......................................... 58

Figure 5-7: MISO200 Output Voltage Ripple and Switch-Node Waveform .................... 58

Figure 5-8: MISO200 Thermal Picture. M1: LS Boost FET, M2: LT8390 ..................... 59

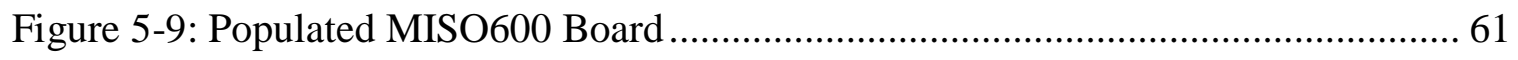

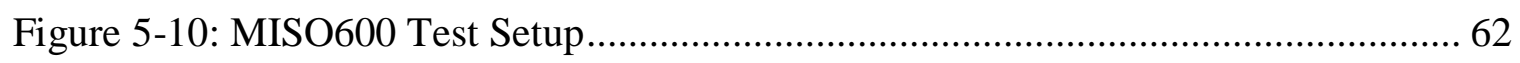

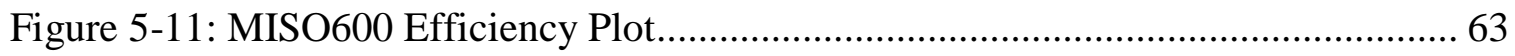

Figure 5-12: MISO600 Output Voltage Ripple and Switch-Node Waveform .................. 65

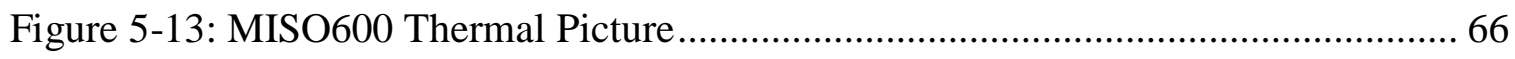

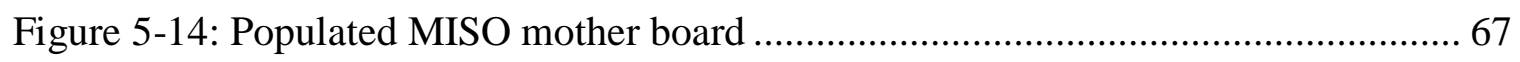

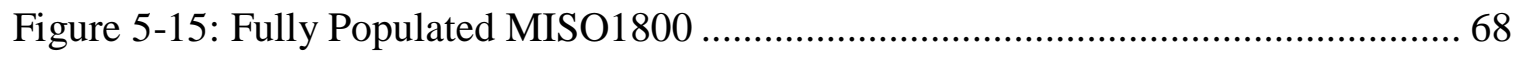

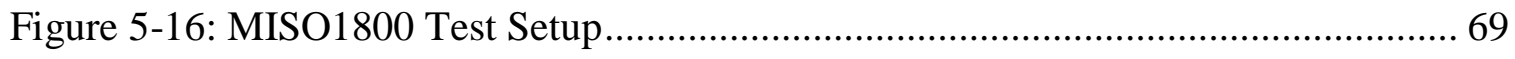

Figure 5-17: MISO1800 Efficiency Plot................................................................... 70

Figure 5-18: MISO1800 Output Voltage Ripple and Switch-Node Waveform ................ 72 
Figure 5-19: MISO1800 Thermal Picture Input Side

Figure 5-20: MISO1800 Thermal Picture Single Board .......................................... 73

Figure 5-21: MISO1800 Thermal Picture Top View.................................................. 74

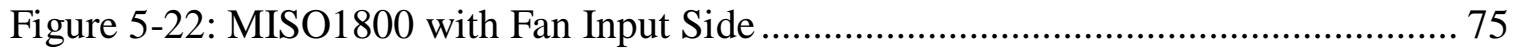

Figure 5-23: MISO1800 with Fan Single Board ..................................................... 75

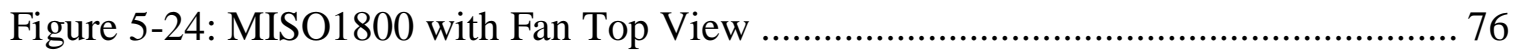




\section{Introduction}

Electricity has become an essential resource in everyday modern life. Houses need electricity to light up the house, run the HVAC system, and power up appliances. People surround themselves with all sorts of electronic devices like cellphones, computers or television to entertain themselves. Vehicles all use batteries and requires electricity to start up the engine and run the car. Life in the modern world becomes difficult without these things. Technology makes lives easier, but requires electricity for it to work. Because of all this, society needs readily available electricity to survive in the civilized world.

However, the world faces a dilemma where it cannot produce sufficient energy for everyone. The past 20 years have shown an increase in energy consumption which looks to continue increasing in the next 20 years [1]. Since the world population has increased as illustrated in Figure 1-1 [2], global energy consumption naturally increases as well.

Figure 1-2 reveals that the U.S. Census Bureau predicts the population to steadily increase through 2050 [2]. This population growth leads to more people consuming energy, which innately means more energy consumption. Population is not the only indicator of the increase in consumption. As countries become more developed, their technology advances and requires the use of electricity to accomplish their daily tasks. Figure 1-2 shows the projected world energy consumption in the next 20 years for both OECD and Non-OECD countries [1]. 


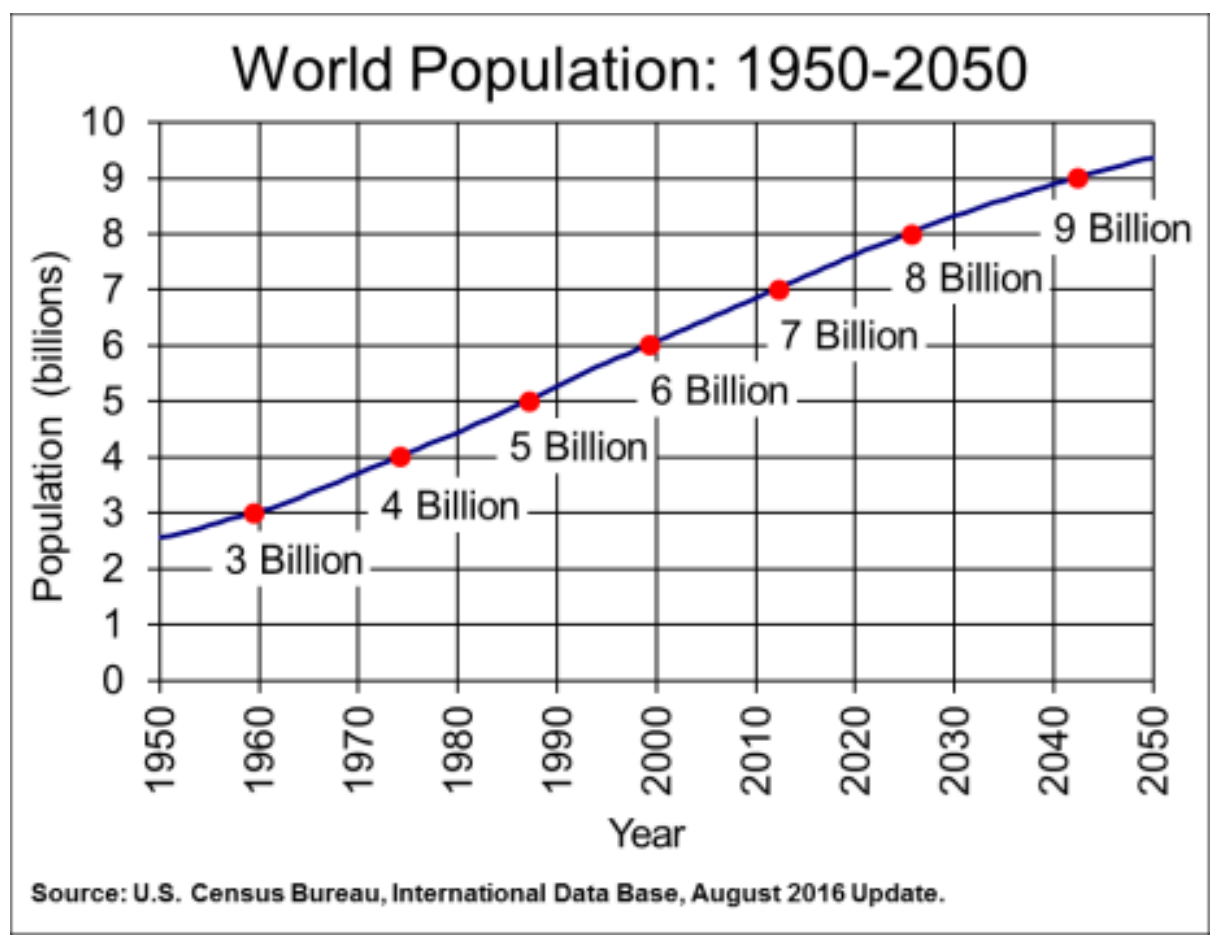

Figure 1-1: Projected World Population by 2050 [2]

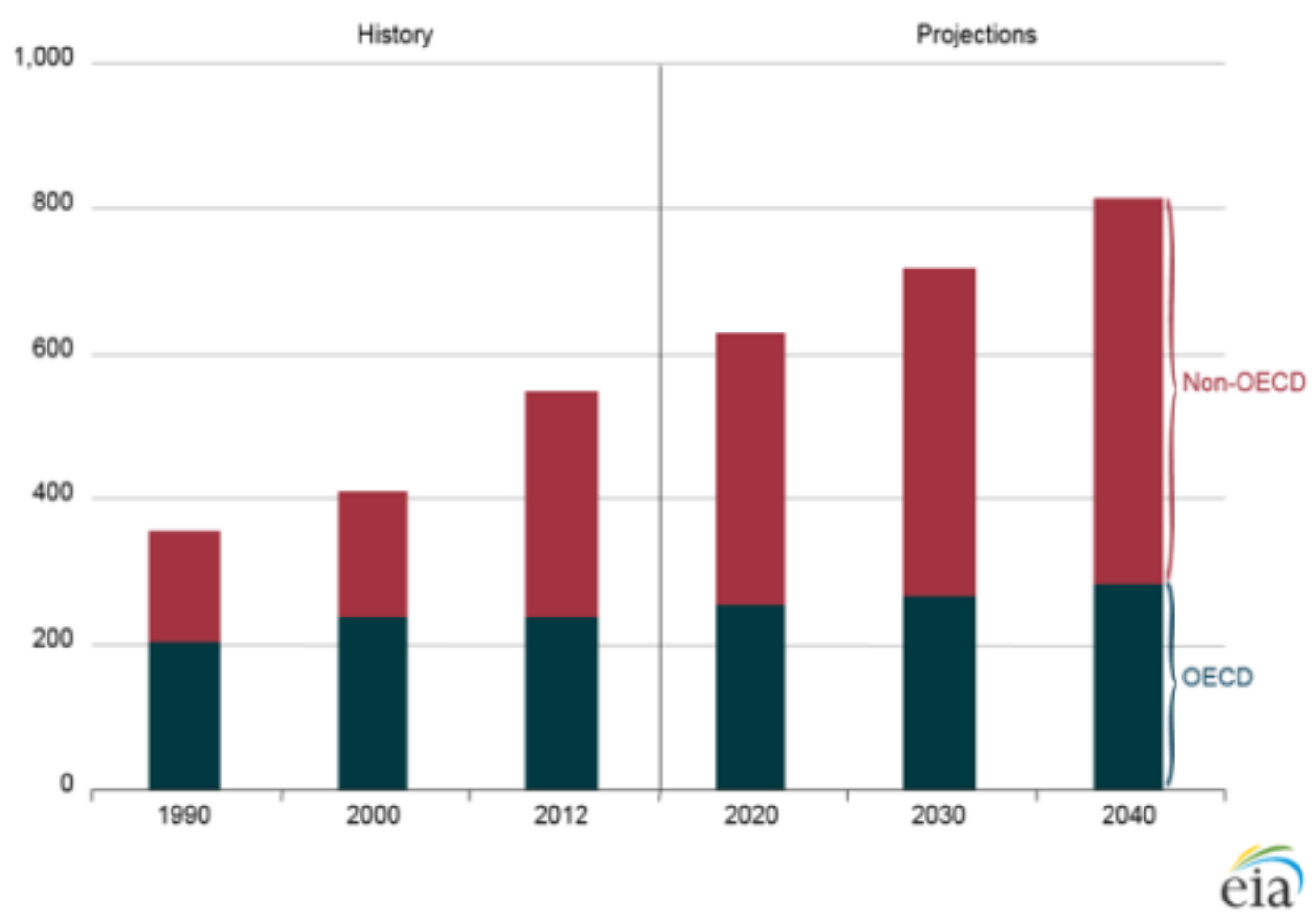

Figure 1-2: Projected World Consumption by 2040 [1] 
OECD (Organization for Economic Co-operation and Development) countries refers to 35 developed countries in the world. These countries have projected low growth in the next 20 years since they have already grown and developed. Non-OECD countries, which include rapidly growing countries like China and India, contribute a substantial portion of growth in energy consumption [2]. As these countries grow and become more industrialized, they plan to use more electricity. Their existing population consumes more energy than they did before, and their growing population continues that trend of energy consumption. Providing sufficient energy for this growth becomes a potential issue in the next 20 years.

Despite all the growth in energy consumption, there's still approximately 1.2 billion to 1.3 billion people in the world without electricity, according to the International Energy Agency [3-4]. This nearly equates to one fifth of the entire world population. Most of these people live in rural areas without electricity, which contrasts to more urbanized areas that have electricity. These rural societies inhibit themselves from growing and developing by not having readily available energy. Solving the inability to access a power grid in rural areas can greatly help billions of people to have access to electricity and thus help their country become a developed nation.

The continuous growth of energy consumption and generation can bring about a huge environmental impact. Figure 1-3 shows the breakdown of electricity generation by fuel today along with its projected breakdown in the next 20 years. 


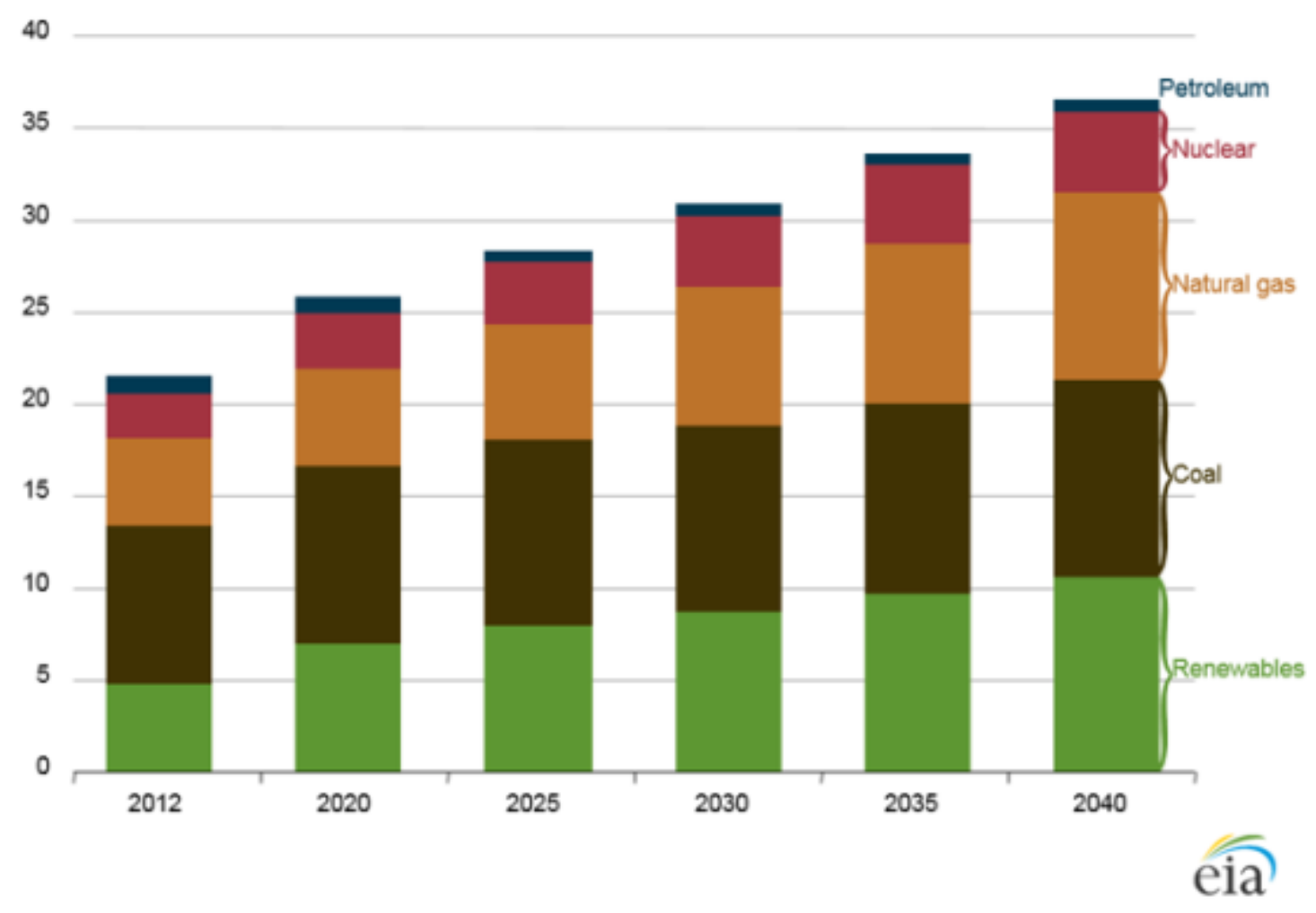

Figure 1-3: Projected Breakdown of Electricity Generation by Fuel [6]

Figure 1-3 demonstrates and projects fossil fuel as the leader of all energy generation. This dependency on fossil fuels has proven to have devastating effects on the environment [7]. Using and burning fossil fuels causes greenhouse gas emissions, which can lead to catastrophic changes in the earth's climate. Also, only a finite amount of fossil fuels exists on Earth, making it not sustainable for future generations to use. A push away from fossil fuels and toward cleaner fuels is needed. The need for a sustainable alternative to fossil fuels helped renewables make strides into the electricity breakdown [6]. Wind, solar and hydro forces generate renewable energy with minimal effect to the environment. Also, the fear of running out of renewable energy does not exist because wind, sunlight, and water replenish themselves. Actions to produce more clean and renewable energy for everyone can help the world stay healthy for future generations. 
The rise in renewables also makes power systems that run independent from the power grid possible [8]. Energy can be generated from anywhere using an available renewable energy source. If a solar panel makes sufficient energy then people can create these systems that generate enough power to remove the need for the utility power grid. This makes it possible to create homes that operate without connecting to the power grid. Harnessing power through renewables helps take a great step towards having a greener Earth, since renewables exhibit minimum negative environmental impacts compared to fossil fuels.

However, off-grid systems have a steep cost and run inefficiently because of the many components needed to have a working off-grid system. These components include a renewable source (such as solar panel or wind turbine), battery storage unit, and inverter. The purpose of the first two components are self-explanatory; the renewable source unit gathers energy, and the batteries stores the energy for future use. The inverter converts generated energy from renewable sources to alternating current (AC) power, which most houses use. However, most devices run off direct current (DC) power produced from solar panels. This means that to charge a phone, energy needs to convert from its original DC power from the solar panels into AC power to connect to the whole house, and then back to DC power to finally charge a phone. The additional steps to convert from $\mathrm{DC}$ to $\mathrm{AC}$ back to $\mathrm{DC}$ causes unnecessary power losses and additional costs to a system.

The purpose of having houses run off AC power versus DC power dates to the "War of Currents" [9]. During the $20^{\text {th }}$ century, Nikola Tesla and Thomas Edison debated whether AC or DC current should become the standard in America. At the time, Edison's 
DC system was the standard. However, Tesla argued that his AC system would solve the problem of long distance power transmission, something that Edison's DC system could not do. With the development of a transformer, which easily steps up and down AC voltage, Telsa's AC system won the war and reigned as the standard in power systems. Despite the standard in AC, electronics until now run on DC power. Devices that directly plug into a wall outlet, like a television or lighting fixture, have a system that performs $\mathrm{AC}$ to $\mathrm{DC}$ conversion to convert the $\mathrm{AC}$ power from the wall outlet to $\mathrm{DC}$ power to physically power up the device. Mobile devices such as laptops and cellphones use batteries, which store DC power. These batteries use an adapter to charge when connected to a wall outlet and convert AC power to DC power. Every time a device needs to convert from $\mathrm{AC}$ to $\mathrm{DC}$, its system grows in both size and in price. AC power acts as a middle-man in power where, if removed, would improve the efficiency of a power system in a home. With advances in technology towards high efficient DC-DC converters [10], the elimination of $\mathrm{AC}$ power is possible within a home that does not take power transmission into consideration. So ideally, especially in an off-grid condition, a house is powered best with only DC power. This idea leads to the creation of the DC House Project.

The DC House Project, which originated in California Polytechnic State University, started as a project with the goal of providing electricity for people living in rural areas not connected to the grid [5]. The project seeks to create a house that runs solely on DC power generated by renewable energy sources such as wind, solar, hydro, and even human power. By having a DC power system, it eliminates the constraint of having to convert from the renewable energy source to AC power back to DC power. 
This reduces the cost and size, when compared to a traditional AC power system, and increases the efficiency of power delivered from the source to the load. With these considerations, the DC House provides a great way to create an affordable and efficient power system for off the grid rural communities.

The DC House Project also aim solves the problem of alternative energy sources for homes all over the world. Since the house generates energy through renewable energy sources, it cuts out the dependency on fossil fuels and all other non-renewable energy sources. This can eventually help the world by both providing clean energy to people and providing energy from an infinite source of energy. Renewable energy generation solves the energy crisis, since the world cannot run out of solar and wind energy. Since this energy generation is clean, environmental impacts will go down due to reduction in greenhouse gas emissions.

The DC House consists of four different blocks: renewable sources, MISO, battery storage, and loads as shown in Figure 1-4. The renewable energy sources provide DC power, which then gets clumped into the Multiple Input, Single Output (MISO) DCDC converter. The MISO receives all the generated energy, converts to 48V DC, and delivers it to a single bus. The single 48VDC bus connects to both the battery storage unit and the loads on the house. As seen in Figure 1-4, no AC power exists at all in the house, which prevents the house from losing unnecessary energy for converting between AC and DC. Overall, utilizing the DC House system can provide power to a house in a much cheaper and more efficient way than the standard off-grid AC power house can. 


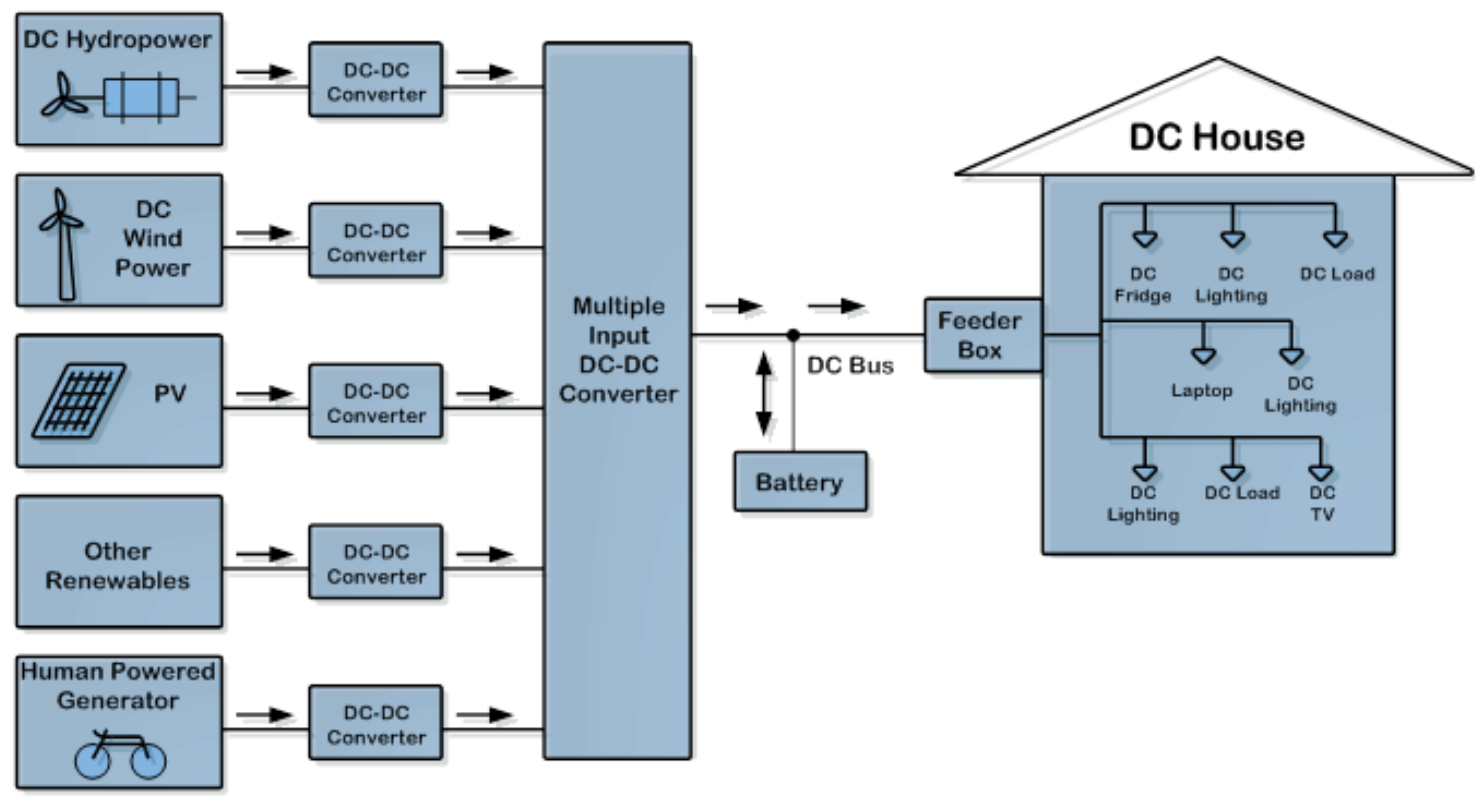

Figure 1-4: Block Diagram of DC House [5]

Chapter 1 of this thesis discusses the energy crisis and environmental issues that come with the current worldwide energy generation system and how the DC House project helps to improve and fix these issues. It also describes how much of the world population does not have power, and how the DC House project can provide power to these people and their homes. Chapter 2 discusses the MISO block of the DC House project, prior research work on MISOs, and how this thesis aims to solve the issues encountered in the previous designs. Chapter 3 discusses the design parameters and specifications of the proposed MISO. Chapter 4 details the design, development, and testing of the proposed converter. Chapter 5 presents data from the proposed MISO testing along with the analysis of its performance. Finally, Chapter 6 summarizes the findings and discusses further improvement of the proposed MISO converter. 


\section{Background}

This thesis project focuses on the Multiple-Input Single-Output (MISO) DC-DC converter, an essential part of the DC House system. It harvests energy through renewable sources, and then convert it to power the house. Since the DC House accommodates any available renewable energy sources in a flexible manner, the MISO must reliably take multiple sources and create a single output voltage to provide to the DC bus to distribute power to all loads in the DC house. Theoretically, the multiple inputs combine into a single output by placing them either in series or in parallel. However, several implications come from this. If the inputs are placed in series, then their currents must match. Solar panels are typically connected in series to create a higher voltage; however, the unit that gives the smallest current drives the overall power produced by the series connection. This remains true for any series connection to work since all components must have the same current. For optimal output power throughout a day, sources should not connect in series since the sources, such as solar panel and wind generator, do not generate power simultaneously throughout the day. If the inputs are directly placed in parallel, then their voltages must match. This also becomes difficult to operate especially with different types of sources. Using OR-ing diodes can overcome to problem of connecting multiple sources in parallel. This method works effectively, since the diode that has the highest anode potential turns on and connects the corresponding source to the output. As the diode conducts, its current causes a forward voltage drop which consequently reduces its anode voltage to less than the non-conducting diode further disconnecting its source and allowing another diode/source to take on the load. However, despite its functionality, the OR-ing diode method suffers from many technical 
issues. As presented in [31], the use of simple OR-ing diode method decreases system efficiency, increases discrete component cost and input THD, and reduces the functional life of the EMS. Because of these reasons, the MISO converter should utilize a more effective and efficient solution.

Previous engineers have studied and researched the idea of having a MISO converter for multiple sources in the past. A typical design of a MISO utilizes power electronics to successfully create a single output from multiple inputs. [23] explores the feasibility of the use of power electronics for MISO. This paper found that the most feasible topologies for a MISO are the buck and buck-boost. From this, many engineers have tried to make MISOs with either of these two topologies depending on their application [11 -22]. The DC House project theoretically could use any of the previously designed MISOs. However, the previous MISO approaches still contain flaws that make them unappealing and unsuitable for the DC House project.

Generally, the previous MISO research consists of two categories: isolated and non-isolated topologies. The isolated topologies employ a high frequency transformer to isolate the grounds of the primary side and the secondary side. For the non-isolated MISO methodologies, papers [11 - 13] discuss the design of a buck-boost MISO and [15] uses a SEPIC topology, which relates to buck and buck-boost topologies Papers [16 - 18] discuss novel converter MISOs made specifically for their needs. [16] shows a novel buck-like converter, [17] shows a novel buck-boost-like converter, and [18] discussed a z-sourced converter, which differs slightly from buck and buck-boost topologies. All these converters have their own flaws that make them unsuitable for the DC House project. For example, MISOs proposed in $[11,12,15,16,18]$ reveal their limitation to 
only 2 sources, which does not fit the DC House's source generation, as seen in Figure 14. Some MISOs design specifically for inverter or AC loads $[11-14,17]$. This does not work for the DC House, since it does not use AC power and an inverter. Paper [18] presents a MISO that connects the same sources in series, instead of in parallel. This means that either the current through each source must match, or that a weak source gets bypassed. Bypassing the weak source allows the other source to operate at its own current, rather than following the current of the weakest source, which would result in a lower generation efficiency. As stated before, this does not work for the DC House since different types of sources may provide the energy to the house.

This paragraph considers isolated topologies as the solution for the MISO converter as proposed in [19-22]. [19] does not use a specific isolated topology. Rather it uses a transformer and adds on a buck-boost topology on the primary side and a buck topology on the secondary side. The MISO proposed in [20] employs a common isolated topology called the flyback converter. Its sources get combined through multiple primary windings and one single secondary winding. Previous Cal Poly San Luis Obispo students have designed MISOs with isolated topologies. One design, proposed by Chin Kin Taffy Wong's thesis, creates the MISO with the full bridge topology to aim for a high output power [21]. With this topology, the primary side connects the sources together, while one secondary winding combines the energy from the multiple sources to a single load at 48VDC. The MISO worked, but with poor operation. Efficiencies never reached above $80 \%$ and its output power only hit about a peak of $80 \mathrm{~W}$ for three input sources, which cannot power up a home. Another MISO, proposed by Owen Jong [22], uses a flyback converter, which improves the efficiency and increases the output power of the MISO. 
The final design has a maximum output power of $145.5 \mathrm{~W}$ while operating with an efficiency of $92.35 \%$, which demonstrates a great improvement from the previous design.

Although Jong's isolated MISOs performed well, the flyback topology has a serious drawback when it comes to larger output power applications. More specifically, its transformer size becomes relatively large compared to other topologies at the larger power level (>150W). This limitation poses a technical challenge for the DC House, as the power level of the MISO increases to approximately $600 \mathrm{~W}$ and $1800 \mathrm{~W}$ for potential adoption in urban homes. Unlike the rural areas, urban areas in developing countries typically have larger electrical loads [31] and need about 600W from the utility company. Therefore, for the DC House technology to work for this setting, a larger sized MISO converter must be developed. However, the use of DC House technology contains a different purpose in rural areas compared to urban areas. For homes in cities, the DC House technology complements the $\mathrm{AC}$ grid and provides a more efficient use of electricity, which reduces the electricity cost. This may happen by having two electrical system in the house: AC to power large loads such as refrigerators, and DC to power light loads such as lighting and portable device charging. This concept, called the Hybrid System, is currently under investigation by the DC House project team at Cal Poly.

Another potential drawback of the isolated topologies lies in cost, especially due to the use of transformer. In addition, commercially available transformers are limited in selection; thus, this thesis must custom make a transformer. The losses incurred by the converter makes the use of a single converter solution to provide the $600 \mathrm{~W}$ less desirable. Reliability becomes another concern at $600 \mathrm{~W}$. A single $600 \mathrm{~W}$ converter that takes in multiple inputs and outputs one voltage suffers in reliability, since any failure within the 
converter affects all inputs connected, and power delivery to the load must come to a halt. Based on these considerations, the MISO converter should follow the modular approach, where each source has its own dedicated sub-MISO unit. With this approach, the operation of one source and its sub-MISO unit acts independently from the other such that when the sub-MISO breaks, the other units can continue to carry load to the output. In addition, with multiple modular sub-MISOs, the heat generated from the entire MISO distributes across multiple modules, compared to the heat dissipating on one single MISO module.

This thesis demonstrates a modular non-isolated MISO converter designed to perform equal load sharing while delivering $1800 \mathrm{~W}$ of output power at an efficiency higher than $90 \%$.

With the modular solution, the potential adoption of the DC House system expands from homes in rural areas to homes in any setting. The MISO must handle the 600W from a single source. This way, the MISO can scale easily, enabling the DC House system to have power capacity of multiples of $600 \mathrm{~W}$. This thesis follows the design and simulation of the proposed MISO to ensure the feasibility of the $600 \mathrm{~W}$ power. The final design of the proposed MISO includes a circuit layout for hardware prototyping. This thesis project also performs bench level tests on the prototype to evaluate the proposed MISO performance. 


\section{Design Requirements}

Achieving the goal of creating a higher power and efficient MISO for the DC House project requires making design specifications. For the DC House to work at its optimal efficiency, each component must operate optimally, including the input renewable energy sources. Previous DC House studies have shown the precise output voltage of all the DC House renewable sources (solar panel, DC wind turbine, and DC hydro-turbine) equals $24 \mathrm{~V}$ to generate energy in the most efficient manner [25 - 27]. Therefore, this MISO specifies the nominal input voltage of the proposed MISO to $24 \mathrm{~V}$. However, sometimes renewable sources can have a swing in voltage, or perhaps future revisions of the DC House may have a higher input voltage. Thus, to keep the design of the MISO flexible, it sets the input voltage range to $10 \mathrm{~V}-60 \mathrm{~V}$. As for the average output voltage of the proposed MISO, this thesis sets it to $48 \mathrm{~V}$. This MISO aims to provide an average of $48 \mathrm{~V}$ at its output, and therefore its design tailors for this voltage. Again, this voltage value comes from previous studies of the DC House, which show the most efficient bus voltage for the house [28-29]. In return, all loads designed for the DC House currently interface with the $48 \mathrm{~V}$ bus.

Previous MISOs made for the DC House project operate at $150 \mathrm{~W}-200 \mathrm{~W}$. Homes in urban settings require more power than what previous MISOs can provide [30]. Therefore, for this thesis, the designed MISO should operate at an output power of $600 \mathrm{~W}$ for a single module. The $600 \mathrm{~W}$ module should also have the capability to connect in parallel with other MISO modules to create an even greater output power. The proposed MISO uses up to three modules operating simultaneously, generating a maximum output power of $1800 \mathrm{~W}$. The proposed $600 \mathrm{~W}$ module aims to operate with an efficiency of at 
least 90\% at full load. The design must achieve this efficiency, since the DC House provides energy to homes in a more efficient manner compared to regular AC homes. This gives the incentives and motivation for people to stray away from AC homes and start using DC homes. A high efficiency system does not require a cooling system, since power should not be lost in the system. With efficiency as high as 90\%, the MISO converter should not need an internal fan to provide airflow as a cooling system.

The design specifies additional parameters, so the MISO produces a clean $48 \mathrm{~V}$ output. Line regulation demonstrates the ability of a power converter to maintain its output voltage with changes to the input voltage. Since renewable energy sources vary throughout the day, the input voltage can swing dramatically, and the MISO must maintain $48 \mathrm{~V}$ output voltage with any change in the input. Therefore, the proposed MISO specifies a line regulation of $3 \%$ for an input voltage change of $12 \mathrm{~V}$ to $36 \mathrm{~V}$ at full load. Load regulation demonstrates the ability of a power converter to maintain its output voltage when changes occur at the load. Since different loads can operate at any given time in the DC House, the MISO must maintain 48V output voltage, while the load ranges from no load (idling) to full load. Therefore, the proposed MISO specifies a load regulation of $3 \%$ from $10 \%$ load to $90 \%$ load, when the input equals $24 \mathrm{~V}$. Finally, output voltage ripple shows how much variation the output voltage has while the power converter operates in steady state. A high output voltage ripple means that the instantaneous output voltage exists too far from the specified 48V. Therefore, this thesis specifies an output voltage ripple of $3 \%$.

The proposed MISO aims to create a product with easy installation. This way, anyone can purchase and install it in their home without the knowledge and expertise of 
an electrician. To make it simple to install, the proposed MISO uses an edge connector for the input and output buses. Edge connectors, like the one shown in Figure 3-1, makes the MISO easily pluggable and removable without the use of any tools. It also allows users to place multiple MISO modules in parallel onto a single motherboard which holds all the female connectors. Therefore, this thesis also considers the initial design of a motherboard to host parallel connection of several MISOs that can output $1800 \mathrm{~W}$ total power. Chapter 4 of this thesis report discusses the use of edge connectors and motherboards for the MISO.

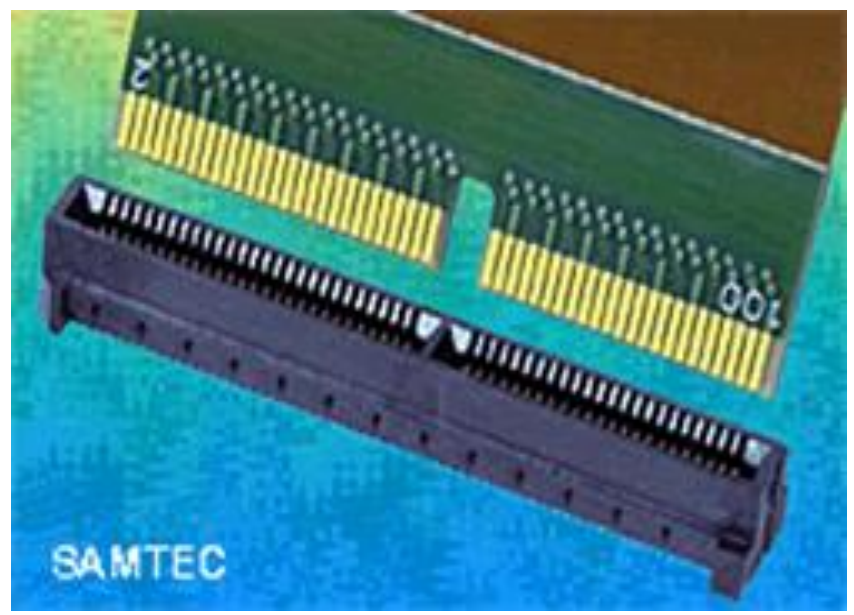

Figure 3-1: Male and Female Edge Connector [24]

As a subset of this thesis involves the redesigning of the $200 \mathrm{~W}$ version of the MISO converter. The new layout serves as the basis for the larger 600W MISO layout design. This provides more scalability in the use of MISO, since users may choose to combine MISO converters at two different power levels, instead of just having the $600 \mathrm{~W}$ option. Both the 200W and 600W MISO designs require construction on a Printed Circuit Board (PCB). 
Table 3-1 summarizes all design specifications explained in this chapter. The following chapter discusses the design process of the proposed MISO with the specifications listed in Table 3-1 kept in mind.

Table 3-1: Summary of Design Specifications

\begin{tabular}{|c|c|}
\hline Type & Rating \\
\hline Input Voltage & $10 \mathrm{~V}-60 \mathrm{~V}, 24 \mathrm{~V}$ nominal \\
\hline Average Output Voltage & $48 \mathrm{~V}$ \\
\hline Maximum Output Power & $\begin{array}{l}\text { 600W for } 1 \text { module, } 1800 \mathrm{~W} \text { for } 3 \text { modules } \\
\text { Standalone } 200 \mathrm{~W} \text { module }\end{array}$ \\
\hline Number of Parallel Modules & Up to $3600 \mathrm{~W}$ modules \\
\hline Efficiency & $\geq 90 \%$ \\
\hline Airflow & 0 LFM \\
\hline Line Regulation & $3 \%$ with $12 \mathrm{~V}-36 \mathrm{~V}$ input \\
\hline Load Regulation & $3 \%$ \\
\hline Output Voltage Ripple & $3 \%$ \\
\hline Input and Output Connection & Edge Connectors \\
\hline
\end{tabular}




\section{Design and Simulation Results}

This chapter discusses the design of the proposed MISO outlined in the previous chapters. To reach the desired $600 \mathrm{~W}$ for a single MISO module, the design process entails creating a $200 \mathrm{~W}$ converter, and then placing it in parallel with two identical $200 \mathrm{~W}$ modules. The division into three $200 \mathrm{~W}$ modules to produce the $600 \mathrm{~W}$ output is done for several reasons. One reason is to provide components' stress and thermal relief on the 600W system. The size of components diminishes by having three parallel modules. Another reason involves reliability of performance over time, since components in a 600W converter do a better job of withholding stress when divided into multiple modules.

The first step in the design of the $200 \mathrm{~W}$ module is choosing a power converter topology. This dictates the rest of the design. Per the discussion in Chapter 2 and from [23], the two most feasible non-isolated topologies are buck and buck-boost. Therefore, this thesis uses a buck-boost topology for its flexibility of input voltage values ranging above and below the output voltage value. However, a standard buck-boost converter brings inherent disadvantages. This includes its discontinuous input and output current waveforms as well as its negative output voltage polarity. Because of these two issues, the designed converter must use a more advanced version of the buck-boost converter that does not have these same disadvantages. This advanced version is called the fourswitch buck-boost, which uses four switches rather than the conventional buck-boost converter which uses two switches. The additional switches allow the four-switch buckboost converter to operate as a boost converter, buck converter, and a buck-boost converter. By doing so, it maintains the flexibility of having any input voltage while 
eliminating the original disadvantages that a standard buck-boost converter has. Figure 41 shows the simplified circuit of the four-switch buck-boost.

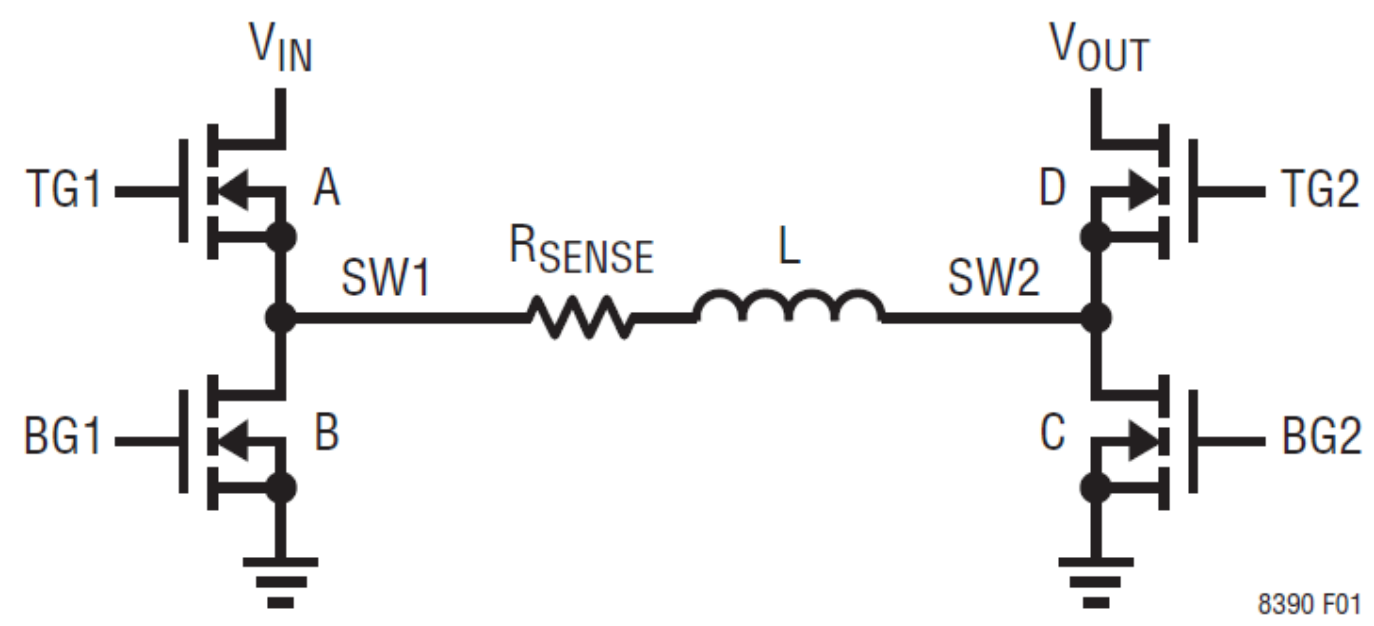

Figure 4-1: Simplified Circuit of Four-Switch Buck-Boost [32]

A four-switch buck-boost can operate in boost, buck, and buck-boost mode by use of the four switches. The following operation refers to the switches A, B, C, and D as depicted in Figure 4-1. When the input voltage exceeds the output voltage, the converter enters buck mode. This occurs by always keeping switch $\mathrm{C}$ off and switch $\mathrm{D}$ on, while using switch A and B to create the PWM signal that gets delivered to the inductor. Node SW1 acts as the switch-node in this mode. The input current waveform functions discontinuously, since the input and the switch-node connect in this setup. However, the output current waveform functions continuously. Figure 4-2 shows the switching waveform diagram.

Similarly, the converter can also act solely as a boost converter by always keeping switch A on and switch B off, while using switch C and D to create the PWM signal. This occurs when the output voltage exceeds the input voltage. In this mode, the output current 
waveform functions discontinuously, and the input current waveform functions continuously. Figure 4-3 shows the switching waveform diagram.

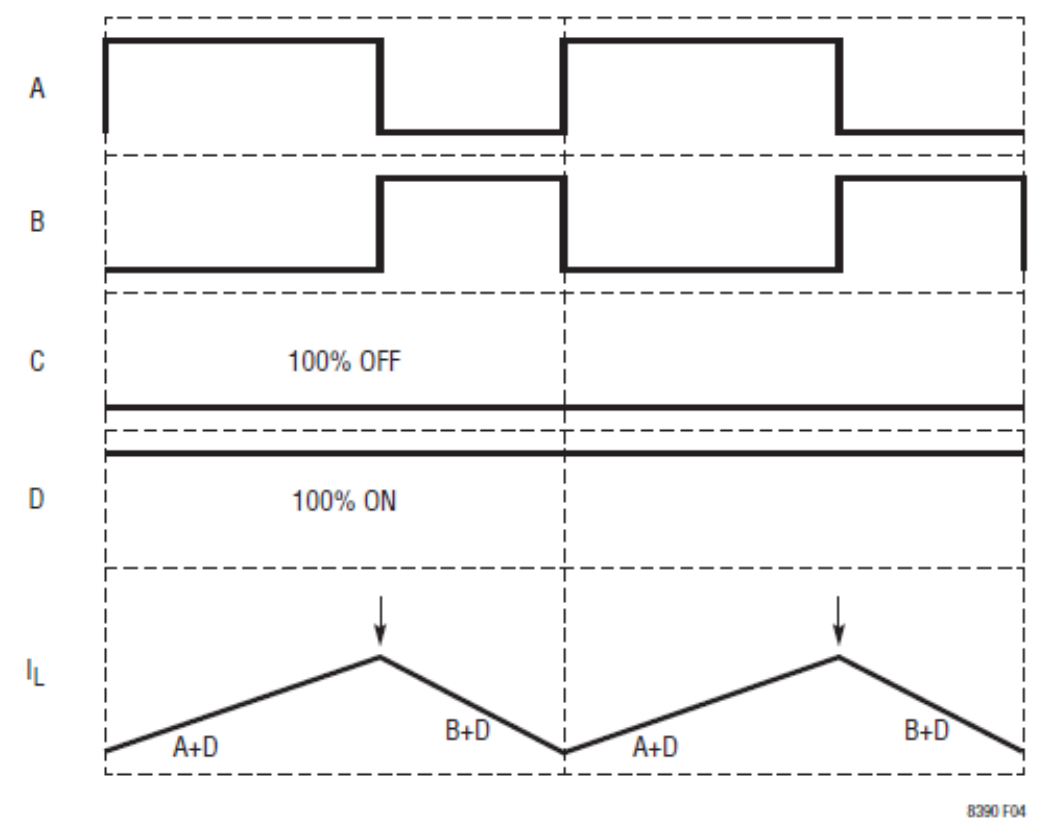

Figure 4-2: Switching Waveform in Buck Mode [32]

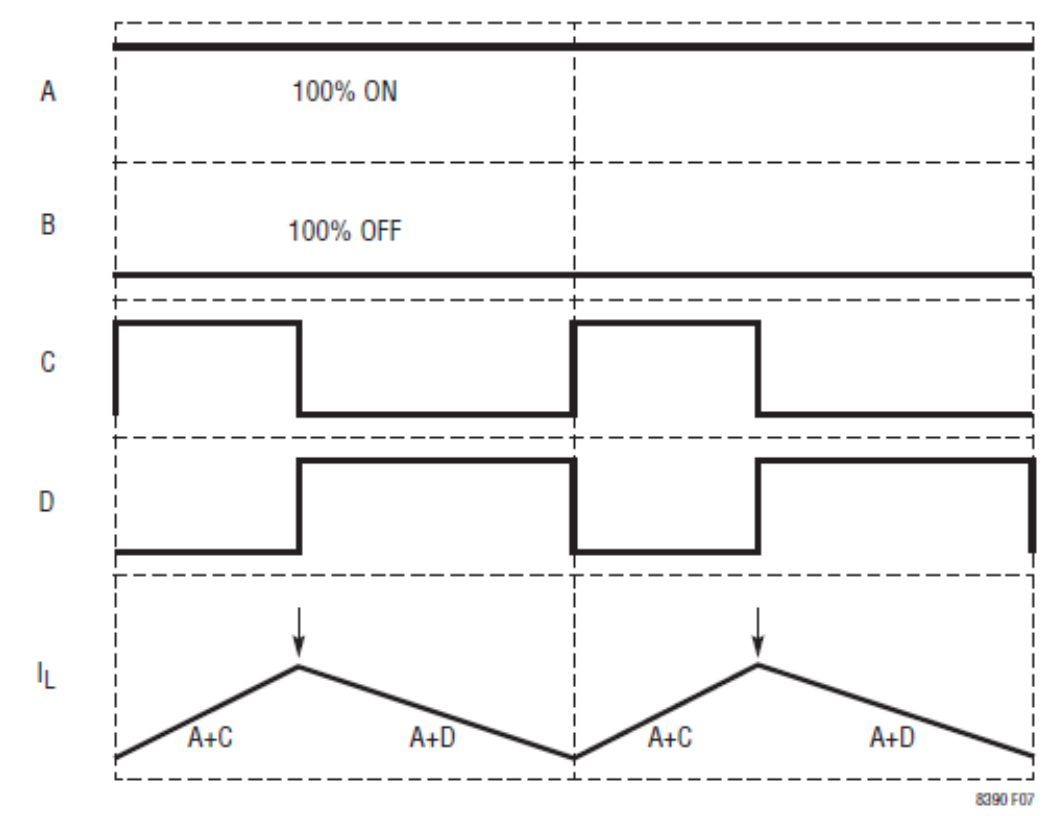

Figure 4-3: Switching Waveform in Boost Mode [32] 
Finally, the four-switch buck-boost acts as a buck-boost converter by switching all four switches. Although this mode contains the discontinuous input and output current waveforms as mentioned earlier, it only enters this mode when the input voltage almost equals the output voltage. Figure 4-4 shows the switching waveform.

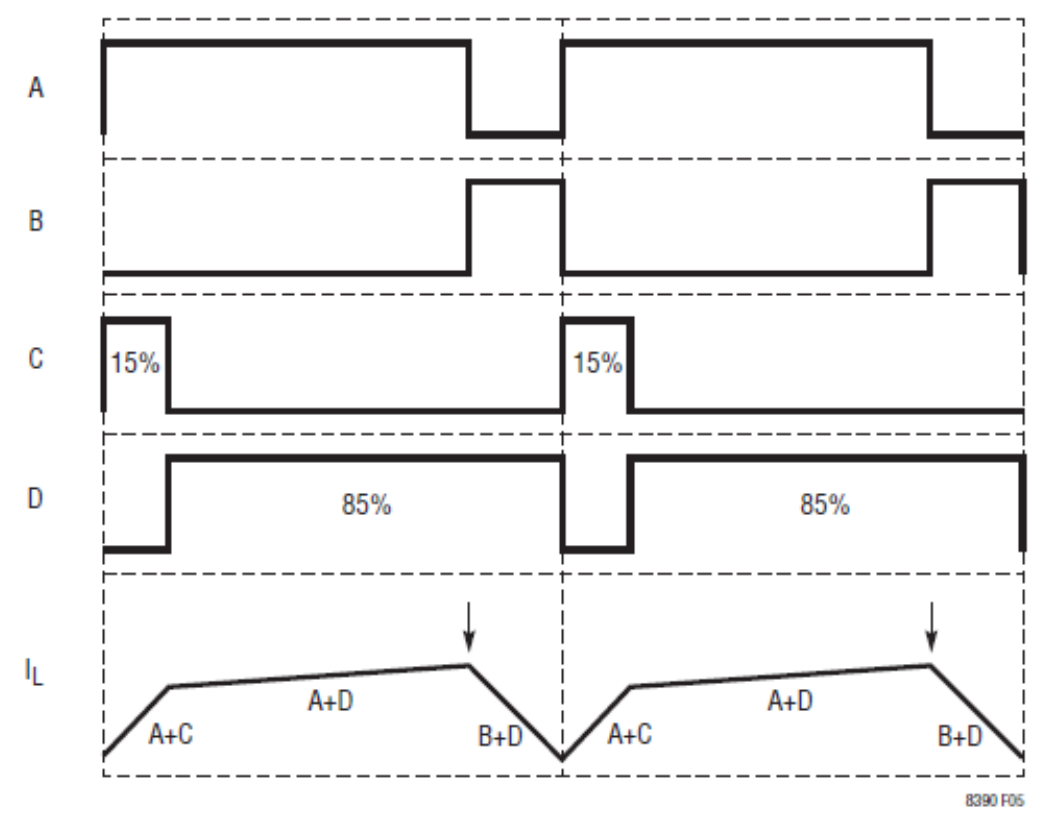

Figure 4-4: Switching Waveform in Buck-Boost Mode [32]

This thesis focuses on the boost mode, since the input voltage is specified nominally at $24 \mathrm{~V}$, as described in Chapter 3 . Despite this, the input voltage can still range from $10 \mathrm{~V}-60 \mathrm{~V}$, and for a $48 \mathrm{~V}$ output, the MISO designs for all three modes.

Since the MISO must operate in parallel with other sub-MISO modules to create a higher power system, the designed MISO requires current sharing feature. Without this, a single module could overload with power, which leads to modular failure. Therefore, the selected controller for this MISO must have the ability to control either the input or 
output current so that an external logic circuit manipulate this feature to allow equal

current sharing.

This thesis selects the LT8390 as the controller for the MISO. This controller meets all the specified requirements for the proposed MISO, which gives reason for its choice. It is a four-switch buck-boost controller that can monitor either input or output current. The datasheet states it can operate up to $60 \mathrm{~V}$ at both input and output, which meets the specified input and output voltage requirements for the proposed MISO. The datasheet advertises that the controller can operate up to $98 \%$ efficiency, which falls well above the $90 \%$ specified efficiency of this MISO. Figure 4-5 shows a glimpse of the datasheet.

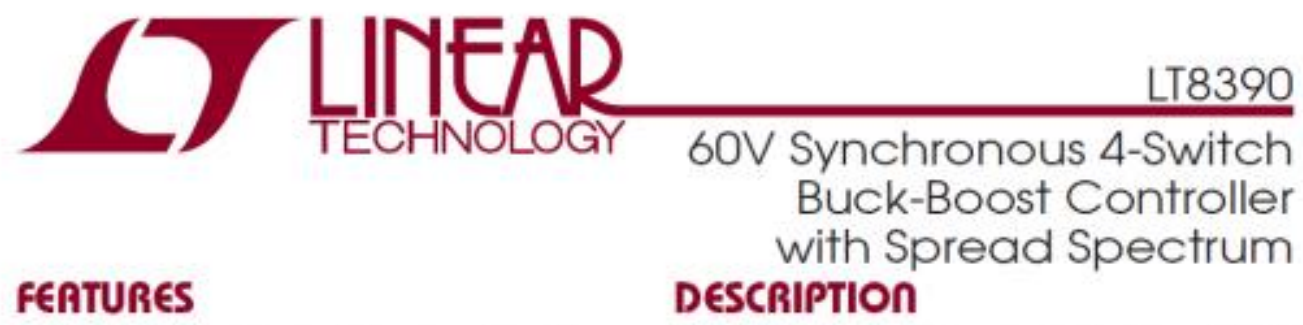

- 4-Switch Single Inductor Architecture Allows $V_{1 M}$ Above, Below or Equal to $V_{\text {OUt }}$

- Synchronous Switching: Up to $98 \%$ Efficiency

- Proprietary Peak-Buck Peak-Boost Current Mode

- Wide VIN Range: $4 V$ to $60 \mathrm{~V}$

- $\pm 1.5 \%$ Output Voltage Accuracy: $1 \mathrm{~V} \leq V_{\text {OUT }} \leq 60 \mathrm{~V}$

- $\pm 3 \%$ Input or Output Current Accuracy with Monitor

- Spread Spectrum Frequency Modulation for Low EMI

- High Side PMOS Load Switch Driver

- Integrated Bootstrap Diodes

- No Top MOSFET Refresh Noise in Buck or Boost

- Adjustable and Synchronizable: $150 \mathrm{kHz}$ to $650 \mathrm{kHz}$

- Vout Disconnected from ViN During Shutdown

- Available in 28-Lead TSSOP with Exposed Pad and 28-Lead QFN ( $4 \mathrm{~mm} \times 5 \mathrm{~mm})$

\section{APPLICATIONS}

- Automotive, Industrial, Telecom Systems

- High Power Battery-Powered System
The LT 8390 is a synchronous 4 -switch buck-boost DC/DC controller that regulates output voltage, input or output current from an input voltage above, below, or equal to the output voltage. The proprietary peak-buck/peak-boost current mode control scheme allows adjustable and synchronizable $150 \mathrm{kHz}$ to $650 \mathrm{kHz}$ fixed frequency operation, or internal $\pm 15 \%$ triangle spread spectrum frequency modulation for low EMI. With a $4 \mathrm{~V}$ to $60 \mathrm{~V}$ input voltage range, $0 \mathrm{~V}$ to $60 \mathrm{~V}$ output voltage capability, and seamless low-noise transitions between operation regions, the LT 8390 is ideal for voltage regulator, battery and supercapacitor charger applications in automotive, industrial, telecom, and even battery-powered systems.

The LT8390 provides input or output current monitor and power good flag. Fault protection is also provided to detect output short-circuit condition, during which the LT8390 retries, latches off, or keeps running.

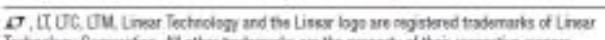

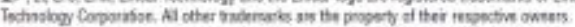

Figure 4-5: LT8390 Datasheet [32] 
This controller operates like any other four-switch buck-boost converter.

Depending on the ratio of input voltage to output voltage, the LT8390 turns on and off certain switches so it can operate in the buck, boost, or buck-boost mode. Figure 4-6 shows the different modes at certain input and output voltage ratios.

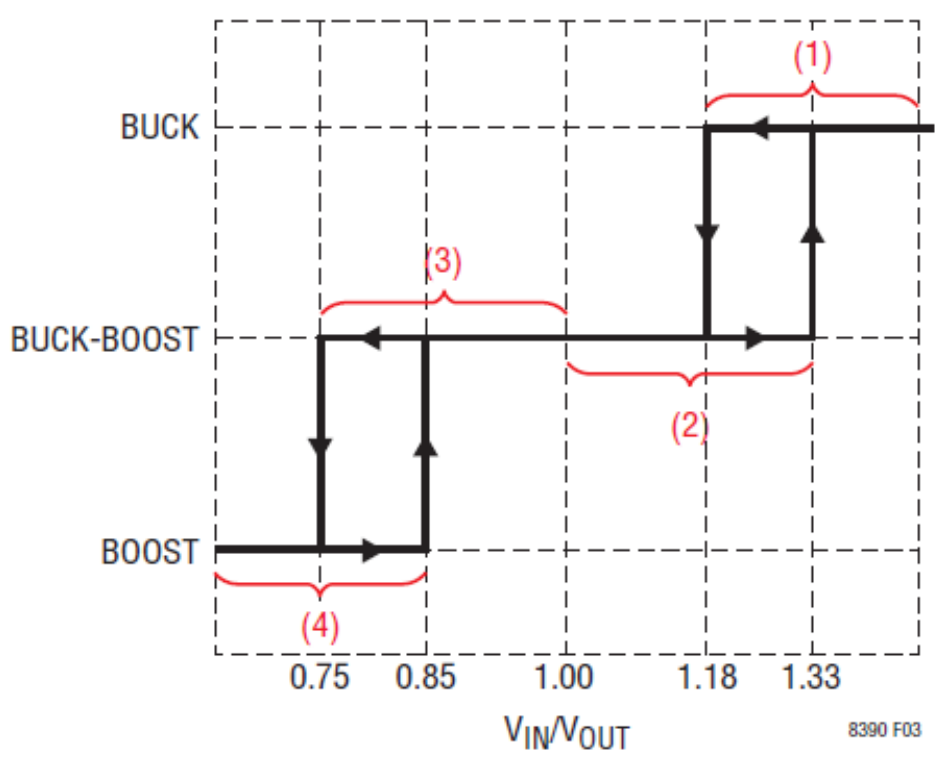

Figure 4-6: LT8390 Operation Region [32]

When the input voltage equals 1.33 times the output voltage, the controller operates in buck mode, and when the input voltage equals 0.75 times the output voltage, the controller operates in boost mode. Regions 2 and 3 of Figure 4-6 shows where the converter operates in buck-boost mode. The four switches operate as described in Figures 4-2, 4-3, and 4-4 per mode the controller is in. The LT8390 operates as a current mode controller, which means that it watches the inductor current and reacts accordingly. Figure 4-2, 4-3, and 4-4 shows the behavior of the inductor current and the timing of the switches for each mode. For all modes, the controller continuously monitors the inductor current until it reaches a peak current threshold, which gets determined by the 
compensation voltage pin, $\mathrm{V}_{\mathrm{C}}$. When it reaches the peak current threshold through the inductor, the controller changes which switch turns on and which switch turns off, depending on the mode. For buck and boost mode, it alternates the switches that connect to the switch node (A and B for buck, C and D for boost) while maintaining the state of the other two switches. For buck-boost mode, it designates the peak current location based on whether the input voltage is only slightly greater than (region 3 of Figure 4-6) or less than (region 2 of Figure 4-6) the output voltage. Figure 4-7 illustrates the switching waveforms.
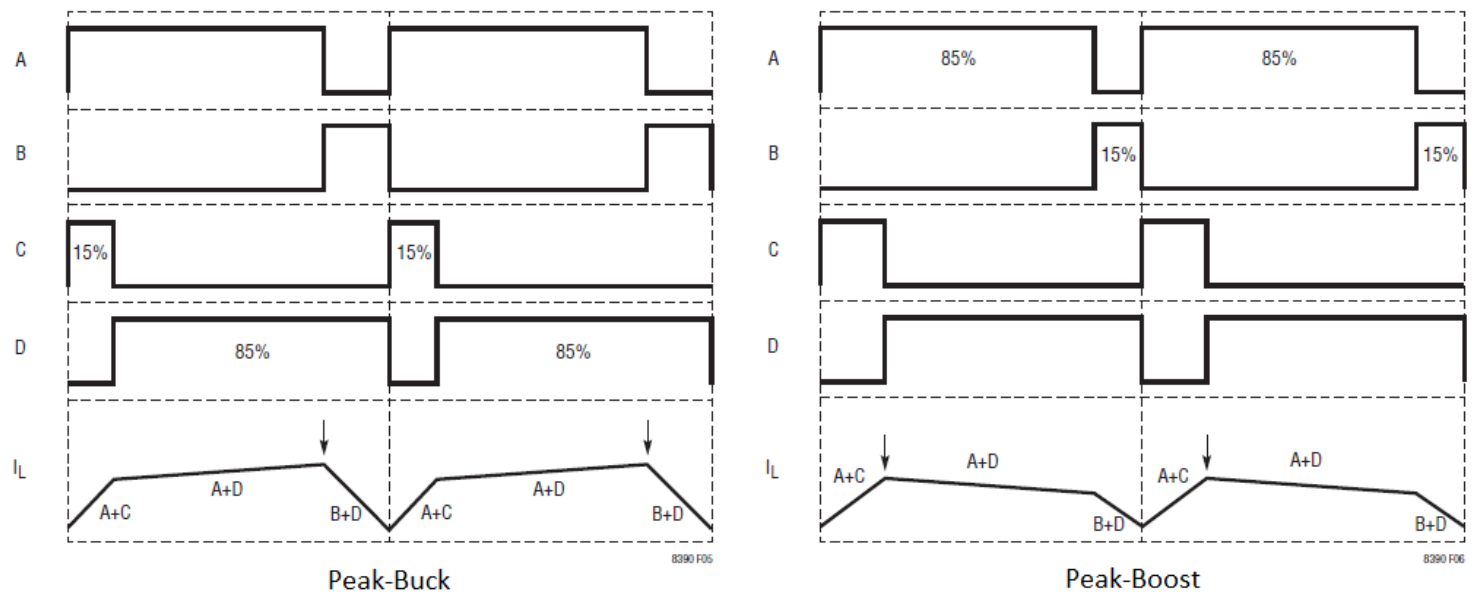

Figure 4-7: Buck-Boost Switching Waveform for Peak-Buck and Peak-Boost [32]

The other features of the LT8390 are standard amongst most power controllers made by Linear Technology. The controller has a FB pin that regulates to $1 \mathrm{~V}$. A resistor divider connects the FB pin to the converter's output. Therefore, this resistor divider sets the average output voltage. The internal gate driver then reads the feedback and drives the four switches to maintain the output voltage. At light loads, the converter can operate in discontinuous conduction mode, where the switch node enters pulse-skipping mode. By skipping a few cycles, the system stays regulated and the efficiency increases for light 
loads. The converter reverts from pulse-skipping mode to full switching continuous conduction mode as soon as the DC current going through the inductor becomes larger than the amplitude of the inductor current ripple. The LT8390 also has an under-voltage shutdown, soft-start, fixed switching frequency, and output current limiting. Figure 4-8 shows the block diagram of the entire LT8390 controller.

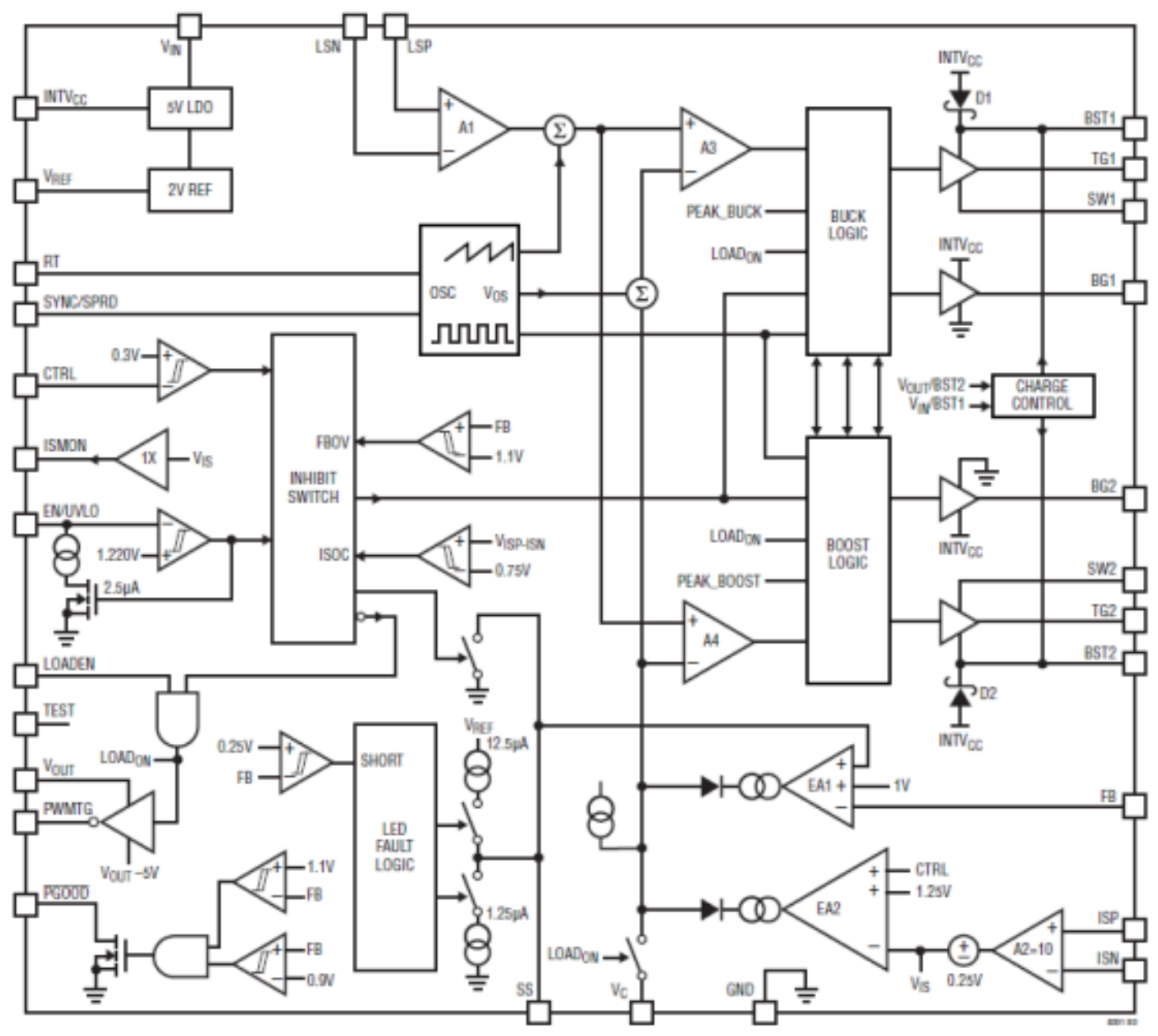

Figure 4-8: Block Diagram of LT8390 [32]

The LT8390 cannot operate as a power converter without external components. This chapter follows the design of the external components to create the complete four- 
switch buck-boost topology. The first components designed are the power components. Sizing each power component (inductor, MOSFETs, and input and output capacitors) is critical, since they exhibit certain voltages and currents during operation, and they must handle the worst-case scenarios without failure. The value of inductance and capacitance also needs sizing so that it works with the operation of the LT8390. Components are generally sized towards the nominal input voltage of $24 \mathrm{~V}$ to make the most use of each power component. For inputs that fall below 20V, either the output power must get derated, or additional sizing should occur. The end of this chapter outlines this per power component.

The selection of switching frequency, $\mathrm{f}_{\mathrm{sw}}$, must occur before calculating the size of the inductor, since the inductor depends on the switching frequency. For the proposed MISO, the switching frequency is set to $200 \mathrm{kHz}$. In the LT8390, a series resistance to the $\mathrm{R}_{\mathrm{T}}$ pin sets the switching frequency. A resistor value of $226 \mathrm{k} \Omega$ sets this $200 \mathrm{kHz}$ frequency. The LT8390 can operate with spread spectrum frequency modulation. This improves EMI; however, this MISO does not have specifications for EMI, so the SYNC/SPRD pin gets grounded to turn off this feature and to keep a fixed switching frequency.

The MISO critical inductance design process involves finding the critical inductance of both the buck and boost mode and choosing the larger value of the two. Critical inductance, for either mode uses volt-second balance and continuous conduction mode conditions for calculation. The derivation of equations 4-1 and 4-2 come from these two concepts. 


$$
\begin{gathered}
L_{\text {boost }}>\frac{V_{\text {in (min })}^{2}\left(V_{o}-V_{\text {in (min })}\right)}{2 V_{o} f_{s w} P_{o(\max )}\left(\% I_{L(\text { ripple })}\right)} \\
L_{\text {buck }}>\frac{V_{o}^{2}\left(V_{i n(\max )}-V_{o}\right)}{2 V_{\text {in }(\max )} f_{s W} P_{o(\max )}\left(\% I_{L(\text { ripple })}\right)}
\end{gathered}
$$

The critical inductance is the larger value of the two equations in 4-1 and 4-2. $\% \mathrm{I}_{\mathrm{L}(\text { ripple) }}$ refers to the ratio of the change in current through the inductor, $\Delta \mathrm{I}_{\mathrm{L}}$, to the average current through the inductor, $\mathrm{I}_{\mathrm{L}}$. Since the average current through an inductor is proportional to the average output current, $\% \mathrm{I}_{\mathrm{L}(\mathrm{ripple})}$ represents the load required for the converter to go from discontinuous conduction mode, where the inductor current hits $0 \mathrm{~A}$, to continuous conduction mode, where the inductor current stays greater than $0 \mathrm{~A}$. Specifications do not exist for this value, so a modest value of 0.3 , or $30 \%$, is chosen for $\% \mathrm{I}_{\mathrm{L}(\mathrm{ripple}) \text {. }}$ A smaller percentage would result in a larger and a more expensive inductor. For a $\mathrm{V}_{\mathrm{in}(\max )}$ of $60 \mathrm{~V}, \mathrm{~V}_{\mathrm{in}(\min )}$ of $20 \mathrm{~V}, \mathrm{~V}_{\mathrm{o}}$ of $48 \mathrm{~V}$ and a $\mathrm{P}_{\mathrm{o}(\max )}$ of $200 \mathrm{~W}$, equations $4-3$ and 4-5 show the following captions.

$$
\begin{gathered}
L_{\text {boost }}>\frac{20 \mathrm{~V}^{2}(48 \mathrm{~V}-20 \mathrm{~V})}{2 * 48 \mathrm{~V} * 200 \mathrm{kHz} * 200 \mathrm{~W} * 0.3} \\
L_{\text {boost }}>9.72 \mu \mathrm{H} \\
L_{\text {buck }}>\frac{48 \mathrm{~V}^{2}(60 \mathrm{~V}-48 \mathrm{~V})}{2 * 60 \mathrm{~V} * 200 \mathrm{kHz} * 200 \mathrm{~W} * 0.3} \\
L_{\text {buck }}>19.2 \mu \mathrm{H}
\end{gathered}
$$

Per equations 4-4 and 4-6, the critical inductance for the converter equals $19.2 \mu \mathrm{H}$. However, the actual inductance used for this thesis must exceed this to stay above 
margins. For these reason, the actual inductance used is $22 \mu \mathrm{H}$. The next design process must size the current rating through the inductor before choosing an actual inductor.

Inductors have current ratings, so maximum inductor current calculation must occur for the design of this MISO. Equation 4-7 shows the maximum, or peak, current through the inductor

$$
I_{L(\max )}=I_{L(\operatorname{avg})}+\frac{\Delta I_{L}}{2}
$$

where $\Delta \mathrm{I}_{\mathrm{L}}$ resembles the peak to peak inductor current ripple. The $\mathrm{I}_{\mathrm{L}(\text { avg) }}$ and $\Delta \mathrm{I}_{\mathrm{L}}$ changes depending on the buck and boost region. Equations 4-8 to 4-15 show the calculations of $\mathrm{I}_{\mathrm{L}(\text { avg) }}$ and $\Delta \mathrm{I}_{\mathrm{L}}$, along with their calculated values per input and output parameters stated earlier in this chapter.

$$
\begin{gathered}
\Delta I_{L(\text { boost })}=\frac{V_{\text {in (min) }}\left(V_{o}-V_{\text {in (min })}\right)}{f_{\text {sw }} L V_{o}} \\
\Delta I_{L(\text { boost })}=\frac{20 \mathrm{~V}(48 \mathrm{~V}-20 \mathrm{~V})}{200 \mathrm{kHz} * 22 \mu \mathrm{H} * 48 \mathrm{~V}}=2.65 \mathrm{~A} \\
\Delta I_{L(\text { buck })}=\frac{V_{o}\left(V_{\text {in }(\max )}-V_{o}\right)}{f_{\text {sw }} L V_{\text {in }(\max )}} \\
\Delta \mathrm{I}_{\mathrm{L}(\text { buck })}=\frac{48 \mathrm{~V}(60 \mathrm{~V}-48 \mathrm{~V})}{200 \mathrm{kHz} * 22 \mu \mathrm{H} * 60 \mathrm{~V}}=2.18 \mathrm{~A} \\
I_{L(\text { boost }, \text { avg })}=I_{\text {in }(\text { avg })}=\frac{P_{o}}{V_{\text {in }(\text { min })}} \\
I_{L(\text { boost }, \text { avg })}=\frac{200 \mathrm{~W}}{20 \mathrm{~V}}=10 \mathrm{~A}
\end{gathered}
$$




$$
\begin{gathered}
I_{L(\text { buck }, a v g)}=I_{o(a v g)}=\frac{P_{o}}{V_{o}} \\
I_{L(b u c k, a v g)}=\frac{200 \mathrm{~W}}{48 \mathrm{~V}}=4.17 \mathrm{~A}
\end{gathered}
$$

Equations 4-16 to 4-19 shows the calculation of maximum inductor current for both the buck and boost regions.

$$
\begin{aligned}
& I_{L(\text { boost }, \text { max })}=I_{L(\text { boost }, \text { avg })}+\frac{\Delta I_{L(\text { boost })}}{2} \\
& I_{L(\text { boost }, \text { max })}=10 A+\frac{2.65 A}{2}=11.3 A \\
& I_{L(\text { buck, } \max )}=I_{L(\text { buck,avg })}+\frac{\Delta I_{L(\text { buck })}}{2} \\
& I_{L(\text { buck, } \text { max })}=4.17 \mathrm{~A}+\frac{2.18 \mathrm{~A}}{2}=5.26 \mathrm{~A}
\end{aligned}
$$

Therefore, the maximum current expected to go through the inductor equals 11.3A. This means that the inductor must have not only a current rating of at least $12 \mathrm{~A}$, but it must also have a saturating current rating of at least 12A. If the saturating current rating falls below $12 \mathrm{~A}$, then the inductor could saturate, which would lose inductance and efficiency. For an inductance of $22 \mu \mathrm{H}$ and a saturating current rating of $12 \mathrm{~A}$, this MISO selects the SER2918-223KL, a Coilcraft inductor that meets these ratings.

Since the LT8390 operates as a current mode controller, the controller uses a sense resistor series with the inductor to sense the inductor current. Pins LSP and LSN have a threshold voltage of $50 \mathrm{mV}$, so a specific resistance must exist to accurately sense 
the inductor current. Equations 4-20 and 4-21 calculate the size of this sense resistor for both the boost and buck region.

$$
\begin{gathered}
R_{\text {sense (boost) }}=\frac{2 * 50 \mathrm{mV} * V_{\text {in }(\min )}}{2 I_{o(\max )} V_{o}+\Delta I_{L(\text { boost })} V_{\text {in }(\min )}} \\
R_{\text {sense (boost) }}=\frac{2 * 50 \mathrm{mV} * 20 \mathrm{~V}}{2 * 4.167 \mathrm{~A} * 48 \mathrm{~V}+2.652 \mathrm{~A} * 20 \mathrm{~V}}=4.42 \mathrm{~m} \Omega \\
R_{\text {sense }(\text { buck })}=\frac{2 * 50 \mathrm{mV}}{2 I_{o(\max )}+\Delta I_{L(\text { buck })}} \\
R_{\text {sense }(\text { buck })}=\frac{2 * 50 \mathrm{mV}}{2 * 4.167 \mathrm{~A}+2.182 \mathrm{~A}}=33.2 \mathrm{~m} \Omega
\end{gathered}
$$

The MISO chooses the lower $\mathrm{R}_{\text {sense }}$ value of the two modes, along with an additional margin. Therefore, this design chooses a $4 \mathrm{~m} \Omega$ inductor $\mathrm{R}_{\text {sense. }}$

This chapter depicts the sizing of the switches as the next power component. This thesis report sizes the switches so that they can always handle the worst voltage and current conditions. For simplicity and ease of design, this MISO uses the same MOSFET for all four switches and designed for the worst-case scenario. Equations 4-24 to 4-26 show the largest voltage across any one switch for any mode.

$$
\begin{gathered}
\text { Buck: } V_{s w(\max )}=V_{i n(\max )} \\
\text { Boost: } V_{s w(\max )}=V_{o(\max )} \\
\text { Buck-Boost: } V_{s w(\max )}=V_{i n(\max )}-V_{o(\max )}
\end{gathered}
$$


With a $\mathrm{V}_{\mathrm{in}(\max )}$ of $60 \mathrm{~V}$ and $\mathrm{V}_{\mathrm{o}(\max )}$ of $48 \mathrm{~V}$, the equations show $60 \mathrm{~V}$ as the largest voltage across any switch at any time. Each switch also must have the ability to carry the maximum current through the drain and source terminals. Equation 4-27 and 4-28 show the largest continuous current through each switch at any given time.

$$
\begin{aligned}
& \text { Buck: } I_{s w(\max )}=I_{o(\max )}=\frac{P_{o(\max )}}{V_{o(\max )}}=4.17 \mathrm{~A} \\
& \text { Boost: } I_{S w(\max )}=I_{i n(\max )}=\frac{P_{o(\max )}}{V_{i n(\min )}}=10 \mathrm{~A}
\end{aligned}
$$

This design disregards the current through a switch in buck-boost mode due to its irrelevance. Since all four switches always switch for a single period, they exhibit a smaller continuous current compared to either the buck or boost converter, which always has a single switch on. Therefore, the largest current through each switch equals 10A. For a $\mathrm{V}_{\mathrm{sw}(\max )}$ of $60 \mathrm{~V}$ and a $\mathrm{I}_{\mathrm{sw}(\max )}$ of $10 \mathrm{~A}$, this MISO chooses the FDMS86520L.

Finally, this chapter shows the design of the input and output capacitors. Capacitance must store enough energy to supply the ripple current to the system and filter out the inductor current for a DC output current. These capacitors need to handle the maximum voltage at the input and output, as well as handle the RMS current that goes through the capacitor. Due to the RMS current that the capacitors exhibit, this MISO uses aluminum electrolytic capacitors for its bulk characteristics, along with several small ceramic capacitors to lower the ESR. In the buck region, the input current operates discontinuously due to the switches connected to the input, which means that the buck region sets the input capacitance. The boost region has a discontinuous output current 
which means that the boost region sets the output capacitance. Equations 4-29 and 4-30 show the equations for critical capacitance.

$$
\begin{gathered}
C_{\text {in }}=\frac{P_{o(\max )}\left(V_{\text {in (max })}-V_{o}\right)}{\% V_{\text {in (ripple })} f_{s w} V_{i n}^{3}} \\
C_{o}=\frac{P_{o(\max )}\left(V_{o}-V_{i n(\min )}\right)}{\% V_{o(\text { ripple })} f_{s w} V_{o}^{3}}
\end{gathered}
$$

As seen in equations 4-29 and 4-30, capacitance relates to $\% \mathrm{~V}_{\text {(ripple). The critical }}$ voltage ripple is the one at the output, which Chapter 3 specifies at $3 \%$. The input voltage ripple follows this percentage as well. With this, equations 4-31 and 4-32 show the calculation for the critical capacitance.

$$
\begin{gathered}
C_{\text {in }}=\frac{200 \mathrm{~W}(60 \mathrm{~V}-48 \mathrm{~V})}{.03 * 200 \mathrm{kHz} * 60 \mathrm{~V}^{3}}=1.85 \mu \mathrm{F} \\
C_{o}=\frac{200 \mathrm{~W}(48 \mathrm{~V}-20 \mathrm{~V})}{.03 * 200 \mathrm{kHz} * 48 \mathrm{~V}^{3}}=8.44 \mu \mathrm{F}
\end{gathered}
$$

Actual input and output capacitor values must exceed their critical values calculated in 4-31 and 4-32, so this MISO selects $56 \mu \mathrm{F}$ capacitors as the aluminum electrolytic capacitors. $V_{\text {in(max) }}$ equates to the maximum voltage that appears at the input and output capacitance. Therefore, the capacitors' voltage rating equals $63 \mathrm{~V}$. The maximum RMS current the capacitors exhibits occurs in the buck region, due to the switches connected to the input, which sees discontinuous current at its max. Equation 433 shows the calculation of maximum RMS current.

$$
I_{r \operatorname{ms}(\max )}=I_{o(\max )} \frac{V_{o}}{V_{i n(\max )}} \sqrt{\frac{V_{i n(\max )}}{V_{o}}-1}
$$




$$
I_{r m s(\max )}=4.17 A \frac{48 \mathrm{~V}}{60 \mathrm{~V}} \sqrt{\frac{60 \mathrm{~V}}{48 \mathrm{~V}}-1}=1.67 \mathrm{~A}
$$

From equation 4-34, the aluminum capacitors selected for this MISO have an RMS current rating of at least 1.8A. Ceramic capacitors need to exist in addition to the aluminum capacitors to lower their ESR. To further minimize the total ESR, 4 units of $2.2 \mu \mathrm{F}$ ceramic capacitors connect in parallel with the aluminum capacitors at both the input and output.

Essential features of the LT8390 require the addition of resistors and capacitors, which also require sizing. Without these features, the MISO module cannot operate properly as a power converter. The derivation of these values come entirely from the LT8390 datasheet [32]. These components primarily enable certain control feature, so they do not carry enough current to require physical sizing. This thesis report covers the sizing of component values according to equations given in the datasheet.

As previously mentioned, a resistor divider connected to the FB pin of the controller programs the output voltage. The resistor divider connects $\mathrm{V}_{\text {out }}$ to the FB pin with an $\mathrm{R}_{\text {top }}$ resistor and connects the FB pin to ground with an $\mathrm{R}_{\text {bot }}$ resistor. The reference voltage within the FB pin equals $1.0 \mathrm{~V}$. Equation 4-35 show how to set the resistor values for a specific output voltage. To set the output voltage to $48 \mathrm{~V}$, this design chooses $R_{\text {top }}$ equal to a series combination of $511 \mathrm{k} \Omega$ and $499 \mathrm{k} \Omega$ and $\mathrm{R}_{\text {bot }}$ to equal $215 \mathrm{k} \Omega$.

$$
V_{\text {out }}=1 V \frac{R_{t o p}+R_{b o t}}{R_{b o t}}
$$


The LT8390 has an undervoltage feature, where the controller shuts off if the input dips below a minimum set point. A resistor divider from $V_{\text {in }}$ to the EN/UVLO pin on the LT8390 sets the undervoltage. Equation 4-36 shows how to set this.

$$
V_{\text {in }(U V L O)}=1.220 \mathrm{~V} * \frac{R 1+R 2}{R 2}+2.5 \mu A * R 1
$$

In equation 4-36, R1 refers to the resistor that connects $V_{\text {in }}$ to EN/UVLO pin and $\mathrm{R} 2$ refers to the resistor that connects EN/UVLO pin to ground. To set $\mathrm{V}_{\text {in(min) }}$ to $10 \mathrm{~V}$, this design sets R1 to $604 \mathrm{k} \Omega$ and $\mathrm{R} 2$ to $100 \mathrm{k} \Omega$.

Several pins in the LT8390 need local bypass with a ceramic capacitor for clean operation. These pins include the $\mathrm{V}_{\mathrm{in}}, \mathrm{V}_{\mathrm{o}}$, and $\mathrm{INTV}_{\mathrm{cc}}$ pins. The INTV $\mathrm{cc}$ pin is bypassed with a $4.7 \mu \mathrm{F}$ capacitor and $\mathrm{V}_{\text {in }}$ and $\mathrm{V}_{\mathrm{o}}$ pins with a $1 \mu \mathrm{F}$ capacitor. The $\mathrm{INTV}_{\mathrm{cc}}$ pin provides a $5 \mathrm{~V}$ DC voltage, so its bypass capacitor only needs to handle $5 \mathrm{~V}$. The $\mathrm{V}_{\text {in }}$ and $\mathrm{V}_{\mathrm{o}}$ pins needs at least $63 \mathrm{~V}$ across these bypass capacitors due to their connections to the input and output of the converter.

The LT8390 has an output current control limit this MISO manipulates. The addition of a sense resistor enables this feature. It connects the $\mathrm{V}_{\mathrm{o}}$ pin to the system output then places ISP and ISN pins across the sense resistor. With this, the controller can sense the total output current of the system. To set the controller to limit the current, the CTRL pin must connect to the $\mathrm{V}_{\text {ref }}$ pin, which sets the threshold voltage of ISP and ISN to $100 \mathrm{mV}$. Equation 4-37 shows the equation to set the maximum output current.

$$
I_{o(\max )}=\frac{100 m V}{R_{I-\text { sense }}}
$$


For an $\mathrm{I}_{\mathrm{o}(\max )}$ of $4.17 \mathrm{~A}$, the calculated $\mathrm{R}_{\mathrm{I}-\text { sense }}$ equals $24 \mathrm{~m} \Omega$. However, the actual $\mathrm{R}_{\mathrm{I}-\mathrm{sense}}$ should fall under this value to allow the MISO to operate at full load with proper output voltage regulation. Due to this, the actual $\mathrm{R}_{\mathrm{I}-\text { sense }}$ equals $18 \mathrm{~m} \Omega$. With the presence of the aluminum electrolytic capacitors at the output, a low pass filter must exist for both ISP and ISN pins. Without this, the controller cannot accurately sense the voltage across

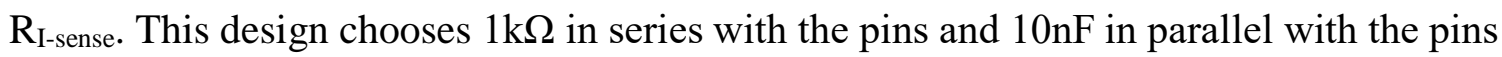
for the low pass filter.

An external capacitor enables the soft-start feature. This causes the output voltage to slowly rise from $0 \mathrm{~V}$ to the programmed output voltage. This design uses a $0.1 \mu \mathrm{F}$ capacitor for soft-start. It gets placed from the SS pin to ground. In addition, the SS pin sets certain fault protection modes: hiccup, latch-off, and keep-running. For simplicity, the LT8390 enables the keep-running mode during a fault by connecting a $100 \mathrm{k} \Omega$ resistor from $\mathrm{SS}$ pin to $\mathrm{V}_{\text {ref. }}$

The chip has an internal compensation system to adjust the control loop. Loop compensation maintains output voltage regulation during quick changes to the load. An uncompensated loop can cause instability, which leads to system failures. The controller uses external components to help with the internal compensation for a more stable system. This design adds a $14.3 \mathrm{k} \Omega$ resistor and $3.3 \mathrm{nF}$ capacitor to the $\mathrm{V}_{\mathrm{c}}$ pin for a more optimized loop response.

Each switch requires additional components for proper operation. The top two switches, switch A and D on Figure 4-1, need a bootstrap capacitor from the BST pin to the source of switches to bias each switch to turn it on properly. Two $0.1 \mu \mathrm{F}$ capacitors are used, one for each switch. In addition, external series gate resistors alleviate any noise 
that the gate of each switch can encounter. Noise causes the switches to turn on or off prematurely, which cause instability to the control loop. Therefore, this design places a $4.7 \Omega$ resistor in series with each gate to dampen any ringing noise. With this, all the components for the 200W MISO have been sized. Figure 4-9 shows the schematic of the MISO up to this point.

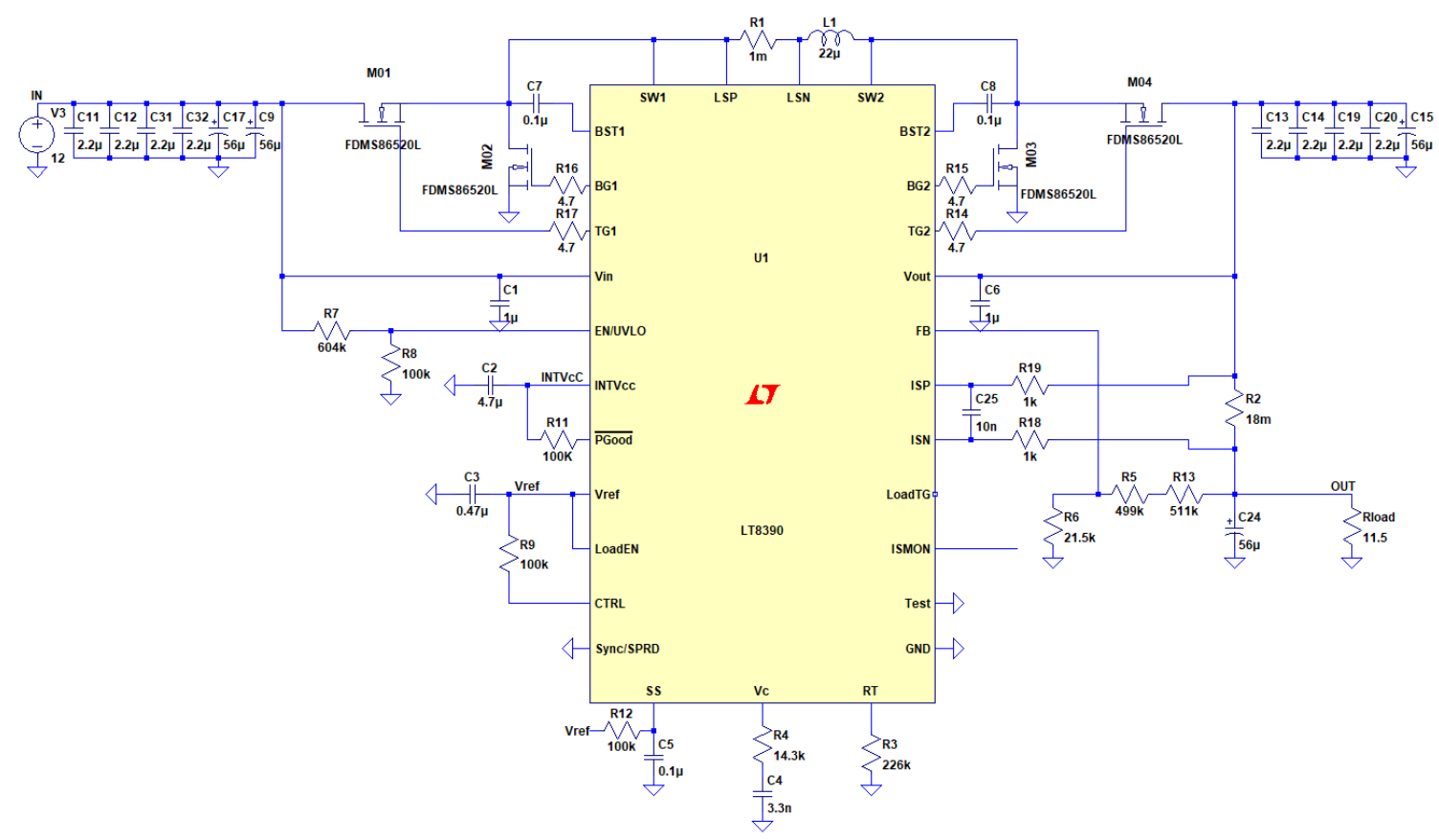

Figure 4-9: Schematic of MISO 200W

With the designed system, the MISO operates up to $200 \mathrm{~W}$. To create a $600 \mathrm{~W}$ system, three modules of the designed system connect in parallel. An additional control circuit gets added to allow multiple modules to share current amongst each other. Without it, a single module could pull more load than $200 \mathrm{~W}$, which would cause it to fail. Current sharing occurs by utilizing the current limiting circuit (ISP and ISN), and the ISMON pin. The ISMON pin outputs a voltage that relates to the voltage across the ISP and ISN pins, which means it relates to the output current going through the circuit. 
Figure 4-10 shows the block diagram that depicts how current sharing occurs for this MISO.

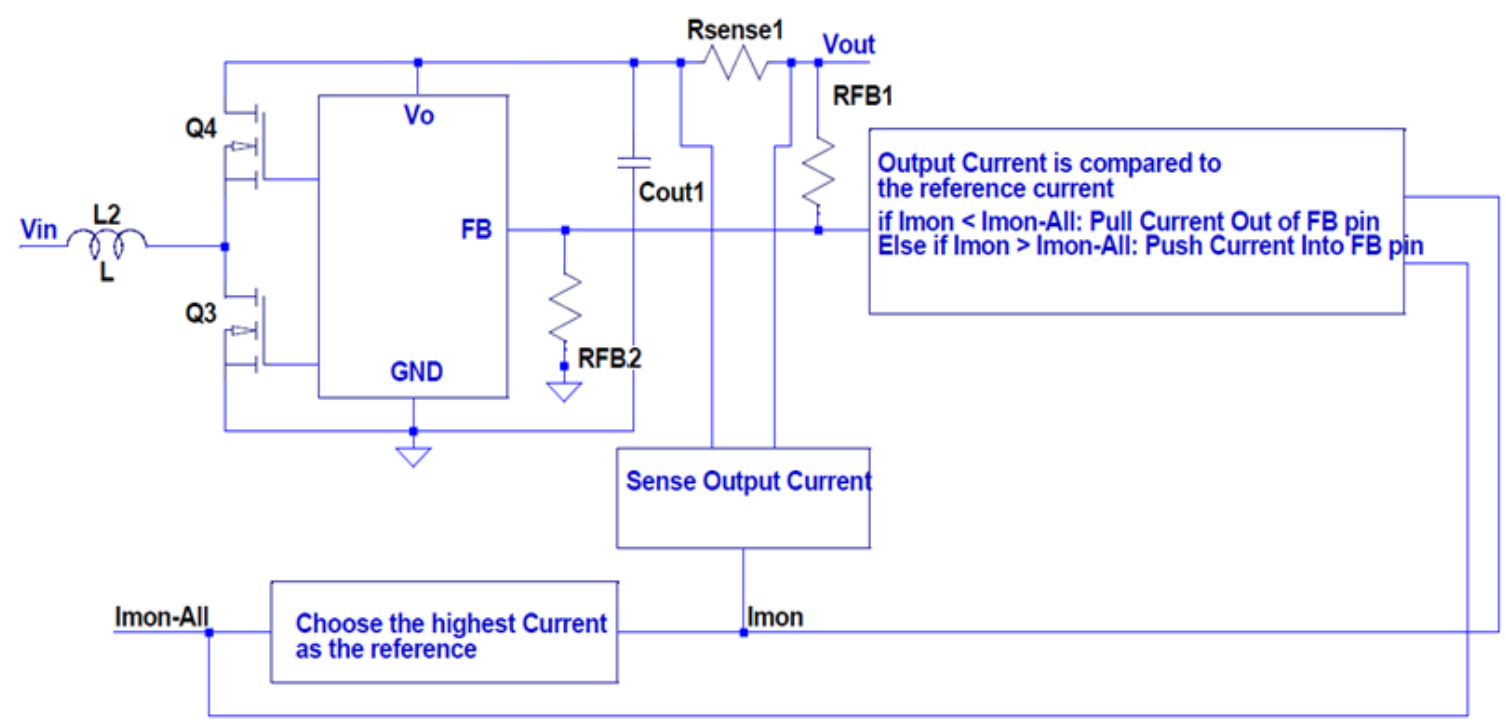

Figure 4-10: Block Diagram of Current Sharing

In Figure 4-10, Imon is the node at ISMON pin of the LT8390, and Imon-All is a node that all the current sharing control circuits for each module connect to. Each module has a corresponding Imon voltage that the LT8390 outputs, which relates to the load current. The control circuit then take all the Imon voltages for each module and selects the largest Imon voltage, which means that it chooses the module with the largest load current to act as the master. The master's Imon voltage then gets assigned to Imon-All, which feeds into all modules. Each module's control circuit then compare Imon-All to its Imon. If Imon-All exceeds Imon, then the load is smaller and needs to be increased.

Alternatively, if Imon exceeds Imon-all, then the load is greater and needs to be decreased. The change in load occurs by pushing or pulling current into or out of the FB pin. By pulling current out of the FB pin, the output voltage slightly decreases so that the voltage across the output sense resistor increases, thereby increasing the load. By pushing 
current into the FB pin, the output voltage increases which decreases the output current. The overall output voltage can consider this change as negligible, since it only needs to change in the order of millivolts. By doing current sharing this way, the load changes nearly instantaneously and seamlessly. There's also no theoretical limit to the number of modules that can connect in parallel with this method so the system's output power can easily upgrade as much as a user would want. Figure 4-11 shows the circuit implementation of the block diagram shown in Figure 4-10.

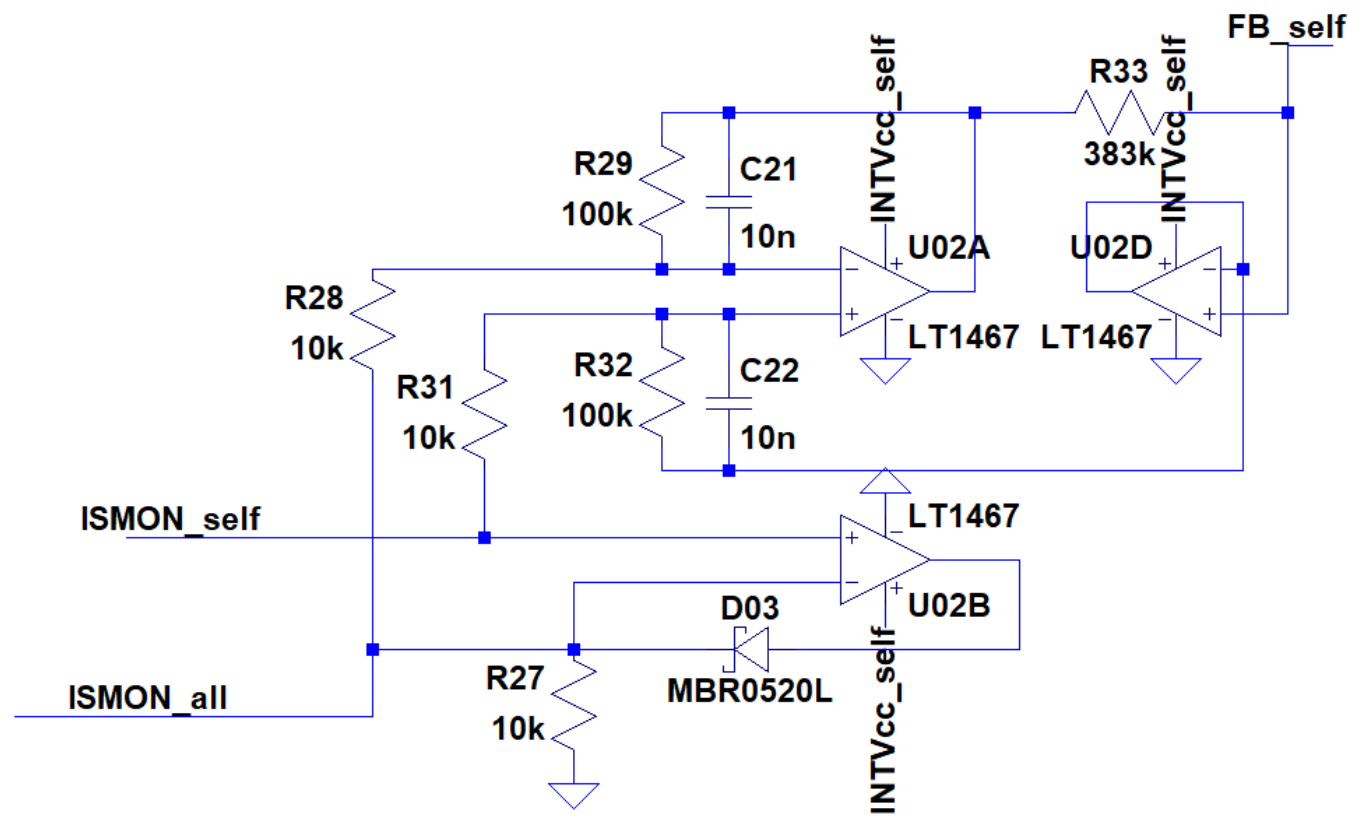

Figure 4-11: Current Sharing Control Circuit Implementation

Figure 4-12 shows the final schematic, which connects the circuit shown in Figure 4-9 to the one shown in Figure 4-11. 


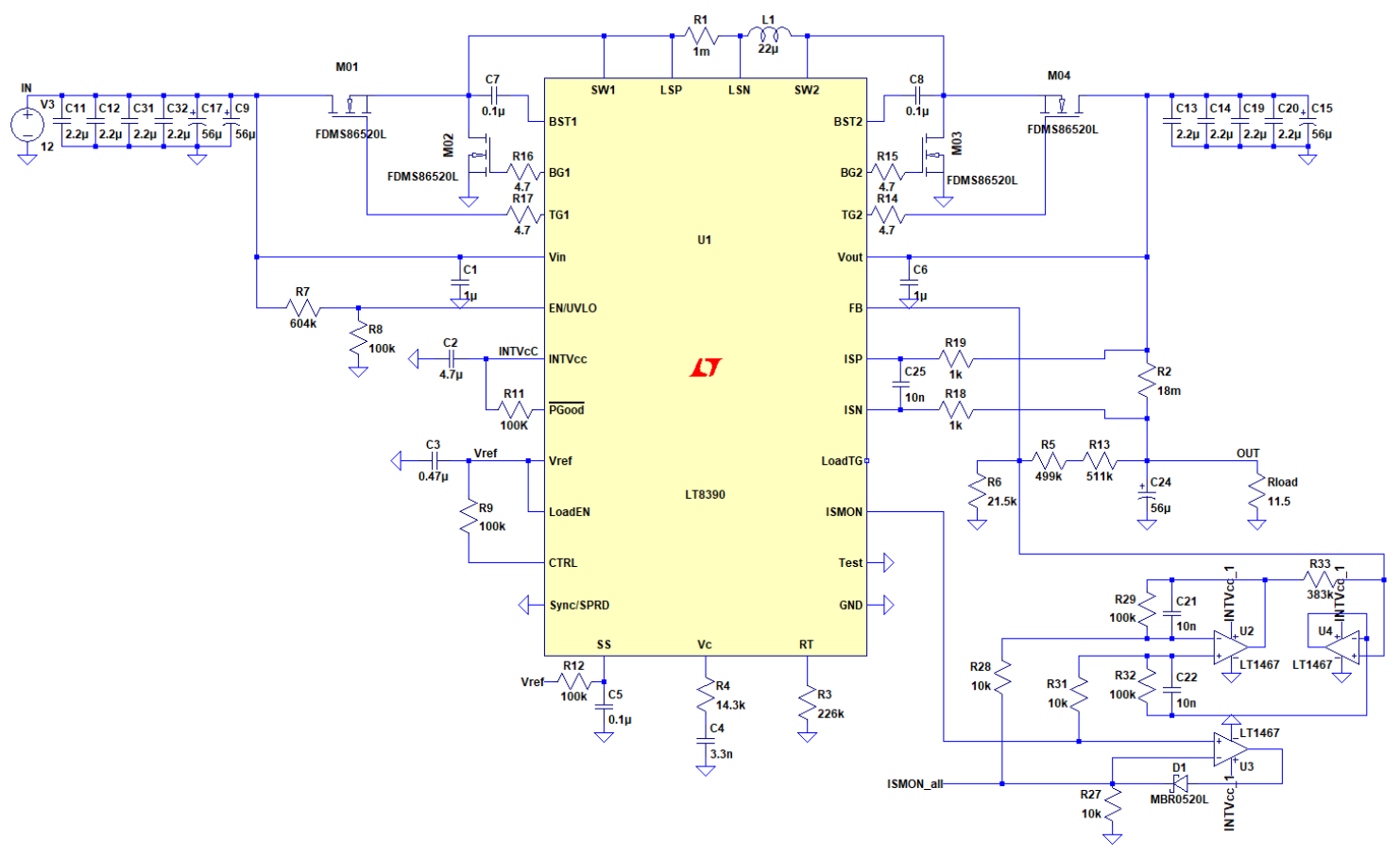

Figure 4-12: Complete Schematic of MISO 200W Module

LTSpice is used to simulate the circuit shown in Figure 4-12 to ensure proper operation from a theoretical standpoint. The simulation runs the circuit at full load until it achieves steady-state. Figure 4-13 shows the simulation results of the 200W MISO. 


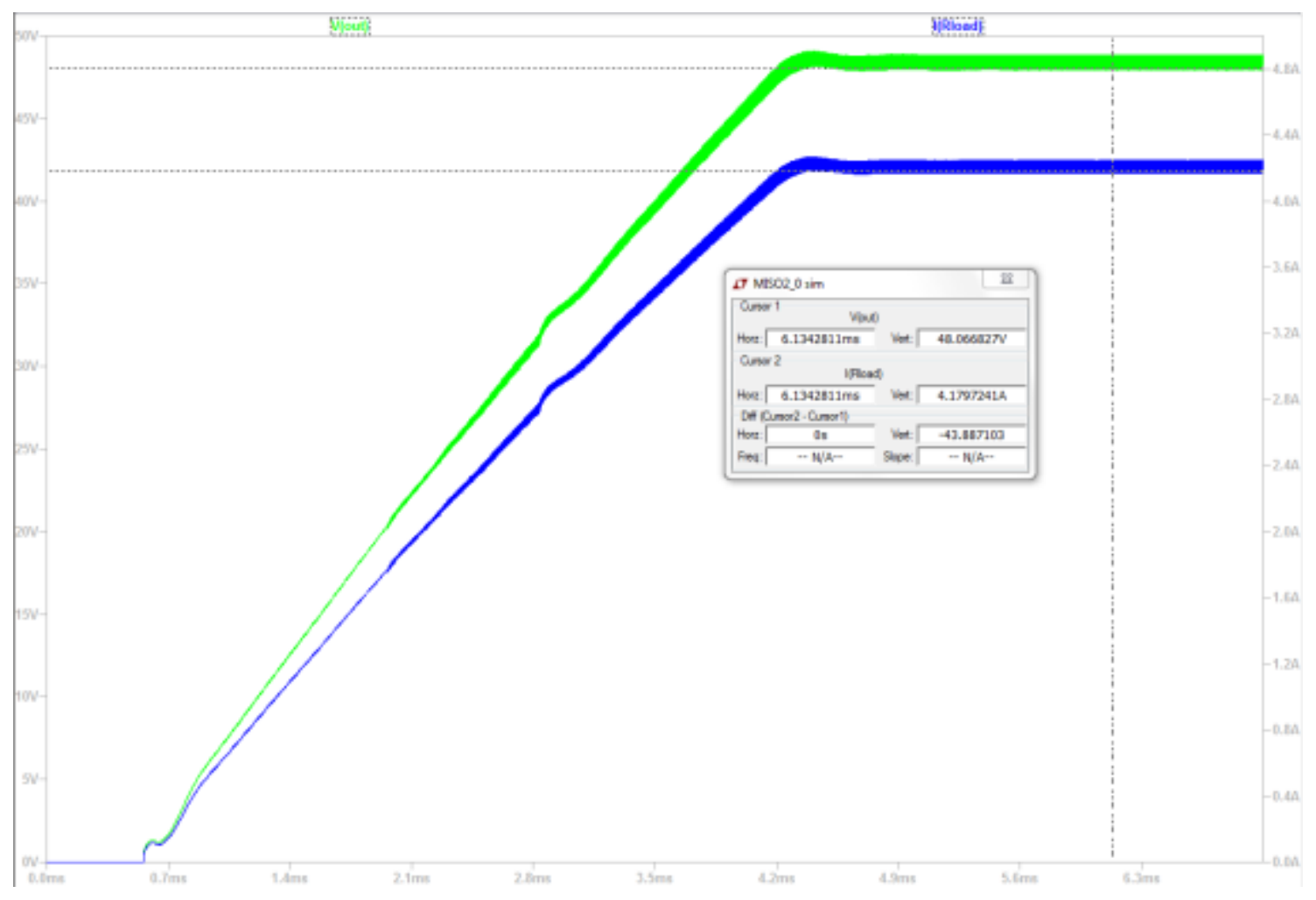

Figure 4-13: MISO 200W Simulation

Figure 4-13 shows a successful simulation of the MISO 200W, where the output voltage regulates at $48 \mathrm{~V}$ at full load around 4.17A. Therefore, the output power settles around $200 \mathrm{~W}$. In addition, the $600 \mathrm{~W}$ circuit is put together and simulated at full load. For the $600 \mathrm{~W}$ circuit, the inputs and outputs are tied together as well as the ISMON_all node. Each load per channel gets monitored to ensure equal current sharing. Figure 4-14 shows the simulation circuit and Figure 4-15 shows its results. 


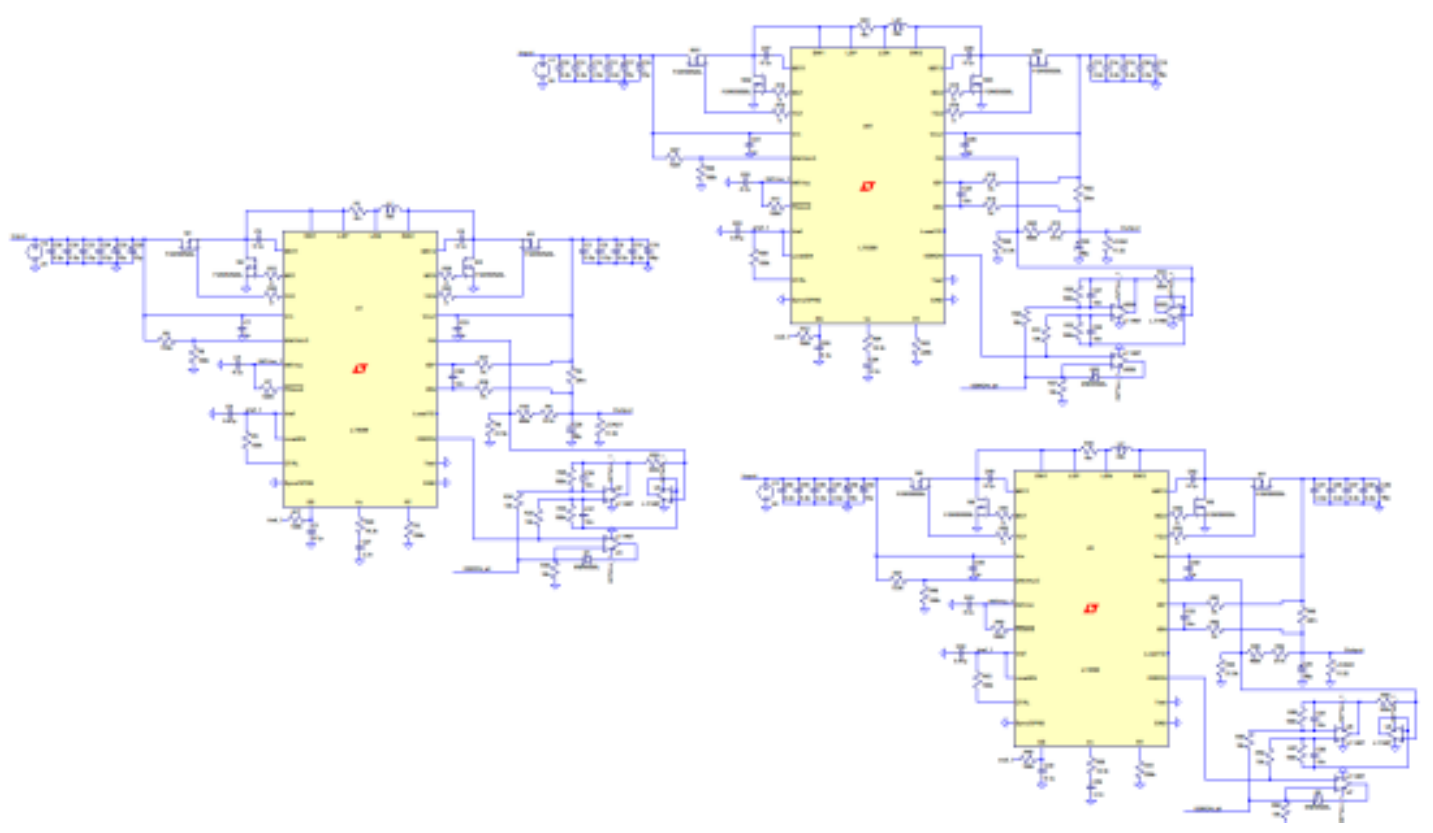

Figure 4-14: MISO 600W Schematic

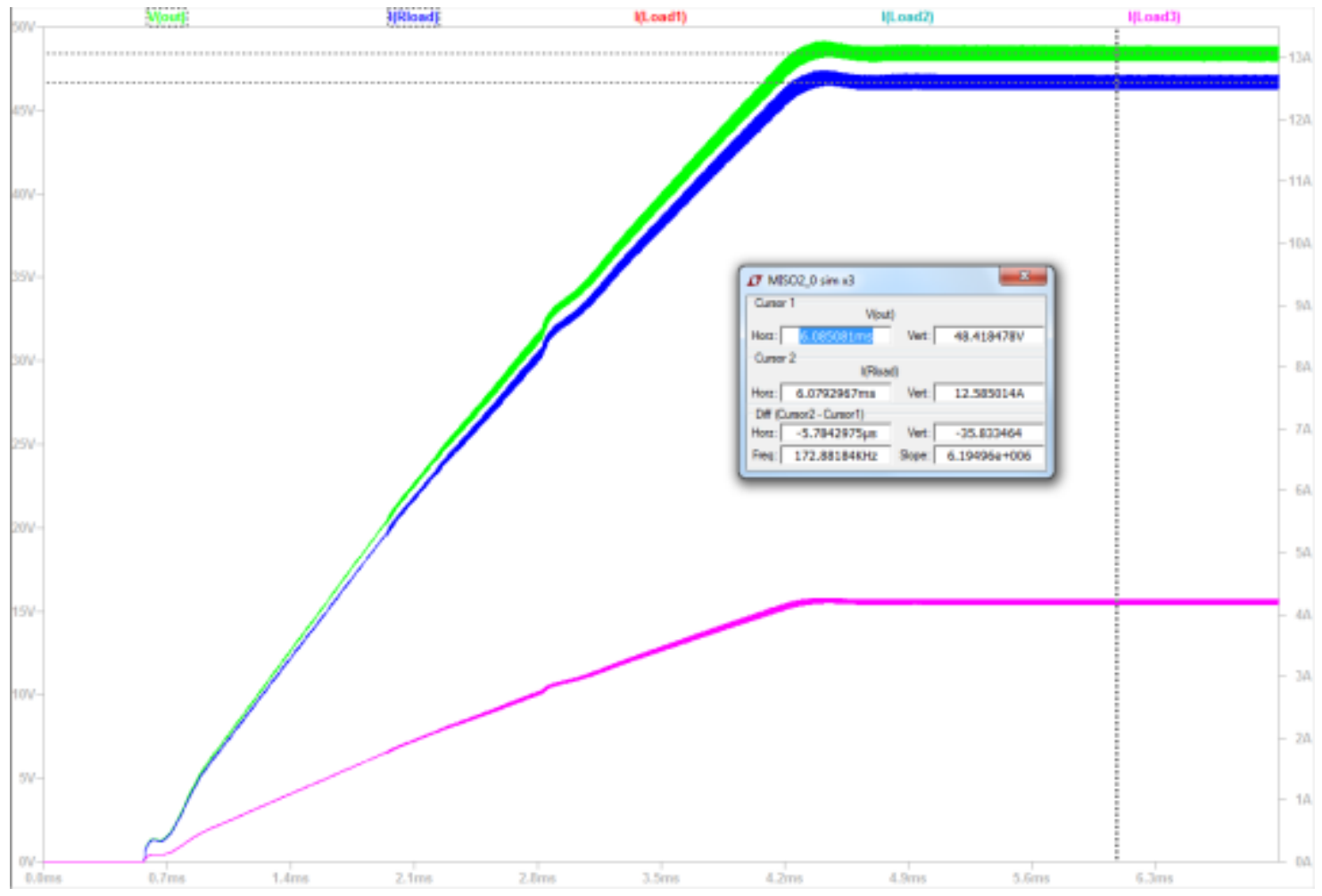

Figure 4-15: MISO 600W Simulation 
Figure 4-15 shows that the $600 \mathrm{~W}$ output voltage regulated at $48 \mathrm{~V}$ during steadystate. The simulation shows that current sharing occurs properly, with each channel showing identical load waveforms. Each module pulls about 4.17A at full load, resulting in a total $12.5 \mathrm{~A}$ load and $600 \mathrm{~W}$ overall output power.

A caveat for this designed MISO 200W is that it cannot properly operate at $200 \mathrm{~W}$ for input voltages lower than $20 \mathrm{~V}$. For operations at lower input voltages such as the specified minimum voltage of 10V, a higher input current appears for the same output power of $200 \mathrm{~W}$. This means that certain components, namely the inductor, switches, and inductor sense resistor, must be resized to meet the higher input current. The user may choose to instead derate the out power linearly with input voltage lower than $20 \mathrm{~V}$. For example, an input voltage of $10 \mathrm{~V}$ would result in an output power of $100 \mathrm{~W}$.

For the inductor, the same $22 \mu \mathrm{H}$ is still valid for lower than $24 \mathrm{~V}$ input operation, since the buck region set the critical inductance, and the minimum input voltage only affects the boost region. The current rating will change, however, per equation 4-16. Equation 4-38 shows the new calculated current rating of the inductor for a maximum input current of $20 \mathrm{~A}$.

$$
I_{L(\text { boost }, \max )}=20 A+\frac{2.65 A}{2}=21.3 A
$$

The SER2918-223KL cannot handle this amount of current and, therefore, either a new inductor must be selected, or the output power must undergo the derating process. One approach involves lowering the inductance value, since the critical inductance in the boost region lies beneath $22 \mu \mathrm{H}$ per equation $4-4$. By doing so, the number of inductors available for selection grows. 
This modified converter needs a newly calculated inductor current sense resistor, since pins LSP and LSN have a threshold of 50mV. Per equation 4-20, the boost region determines the new sense resistor.

$$
R_{\text {sense }(\text { boost })}=\frac{2 * 50 \mathrm{mV} * 10 \mathrm{~V}}{24.17 \mathrm{~A} * 48 \mathrm{~V}+2.65 \mathrm{~A} * 10 \mathrm{~V}}=2.34 \mathrm{~m} \Omega
$$

From equation 4-39, the new sense resistor for a minimum voltage of $10 \mathrm{~V}$ equals $2 \mathrm{~m} \Omega$. Lastly, the switch needs a redesign for lower input voltages. At lower input voltages, the expected current equals 20A, per average input current found in equation 438. The FDMS86520L has a current rating of 22A, which only leaves a margin of $2 \mathrm{~A}$. The two approaches are either to connect two switches in parallel to help alleviate the increase in input current, or choose a different switch that can withstand currents greater than 22A.

With the fully designed MISO schematic, the design process moves into layout. Layout is critical in power converters due to the noisy inductor, which can add enough noise to certain traces to ruin the control loop. This thesis uses Altium Designer as the layout software for all the designed boards [33]. One major layout consideration includes separating the power components on one side of the board from the small signal components on another side of the board, so the power components do not interfere with the other components. Another major consideration involves the trace size of any power components. Since these traces carry currents up to 20A, they need considerable width. Insufficient trace width results in the trace's temperature to rise, which can result in a failure. Figure 4-16 shows the layout of the 200W module, along with the 3D view of the board shown in Figure 4-17. 


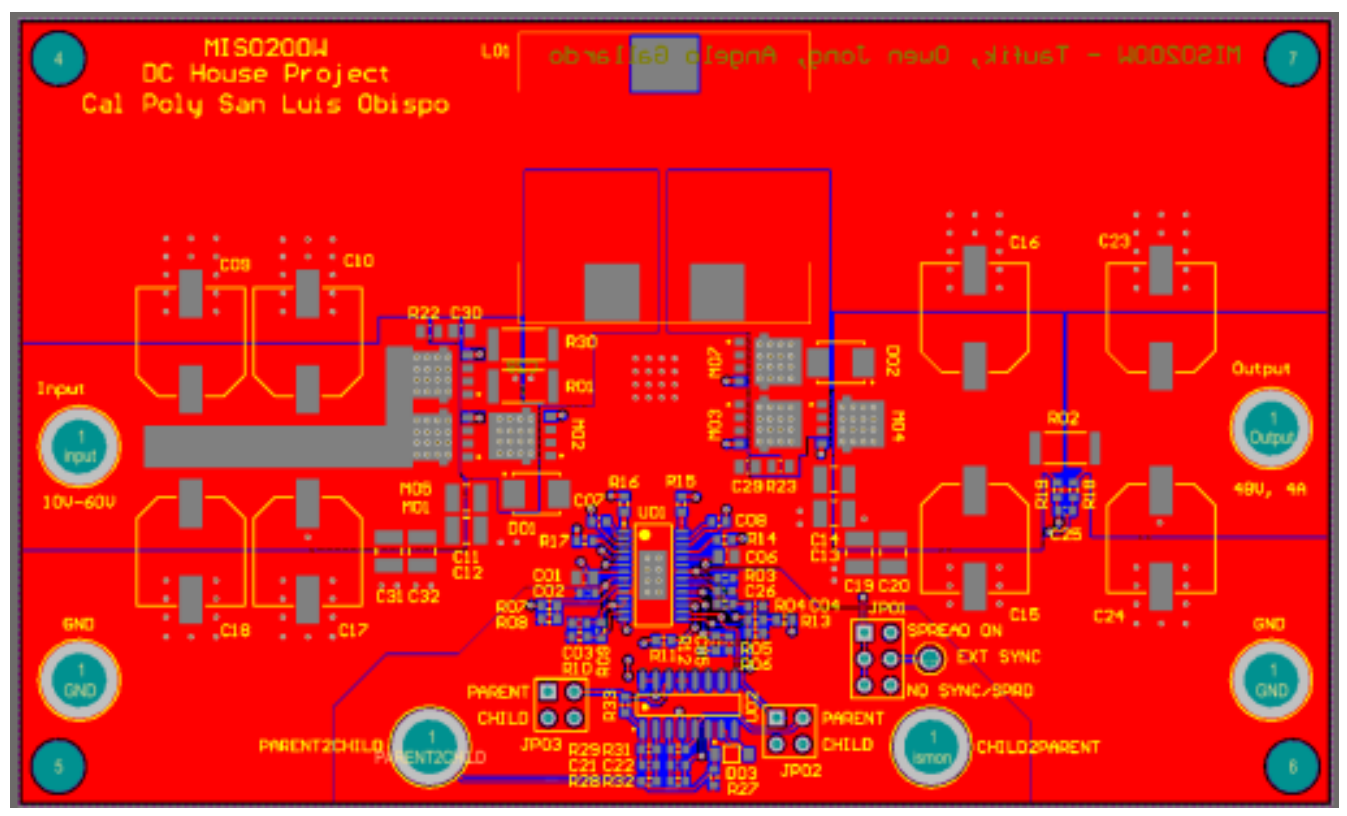

Figure 4-16: MISO 200W Layout

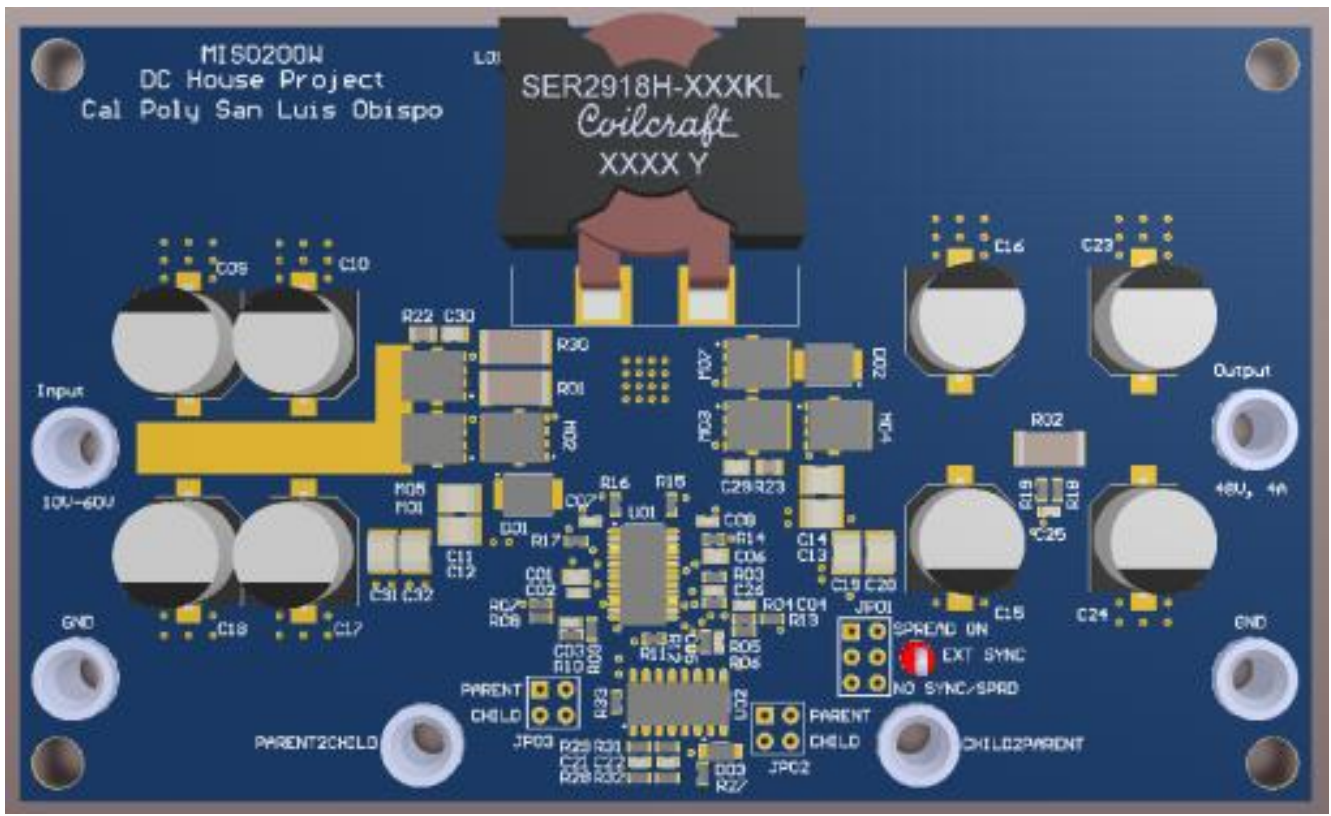

Figure 4-17: MISO 200W 3D View

The 200W layout includes banana plugs at both the input, output, and ISMON output nodes, for simplicity. To connect multiple $200 \mathrm{~W}$ boards together for parallel 
applications, use a banana-banana wire to connect the Input, Output, and GND banana jacks as well as the PARENT2CHILD banana jack. This jack is the same node as the ISMON_all node described in Figure 4-11. This layout also includes the option of disconnecting the current sharing control circuit from the rest of the power converter.

The $600 \mathrm{~W}$ layout compromises of the general layout of 3 of the $200 \mathrm{~W}$ modules in parallel with each other. Additionally, the $600 \mathrm{~W}$ implements an edge connector, as specified in Chapter 3. The 600W board contains the male fingers of the edge connector, which contains 184 positions, 92 on the top layer and the other 92 on the bottom layer. The rating for each position equals $1 \mathrm{~A}$, therefore 67 positions are dedicated to the Input, 20 positions to the Output, a single position to ISMON_all, and the rest to GND. Figure 4-18 shows the layout for the $600 \mathrm{~W}$ board. Figure $4-19$ shows the 3D view of the $600 \mathrm{~W}$ board. 


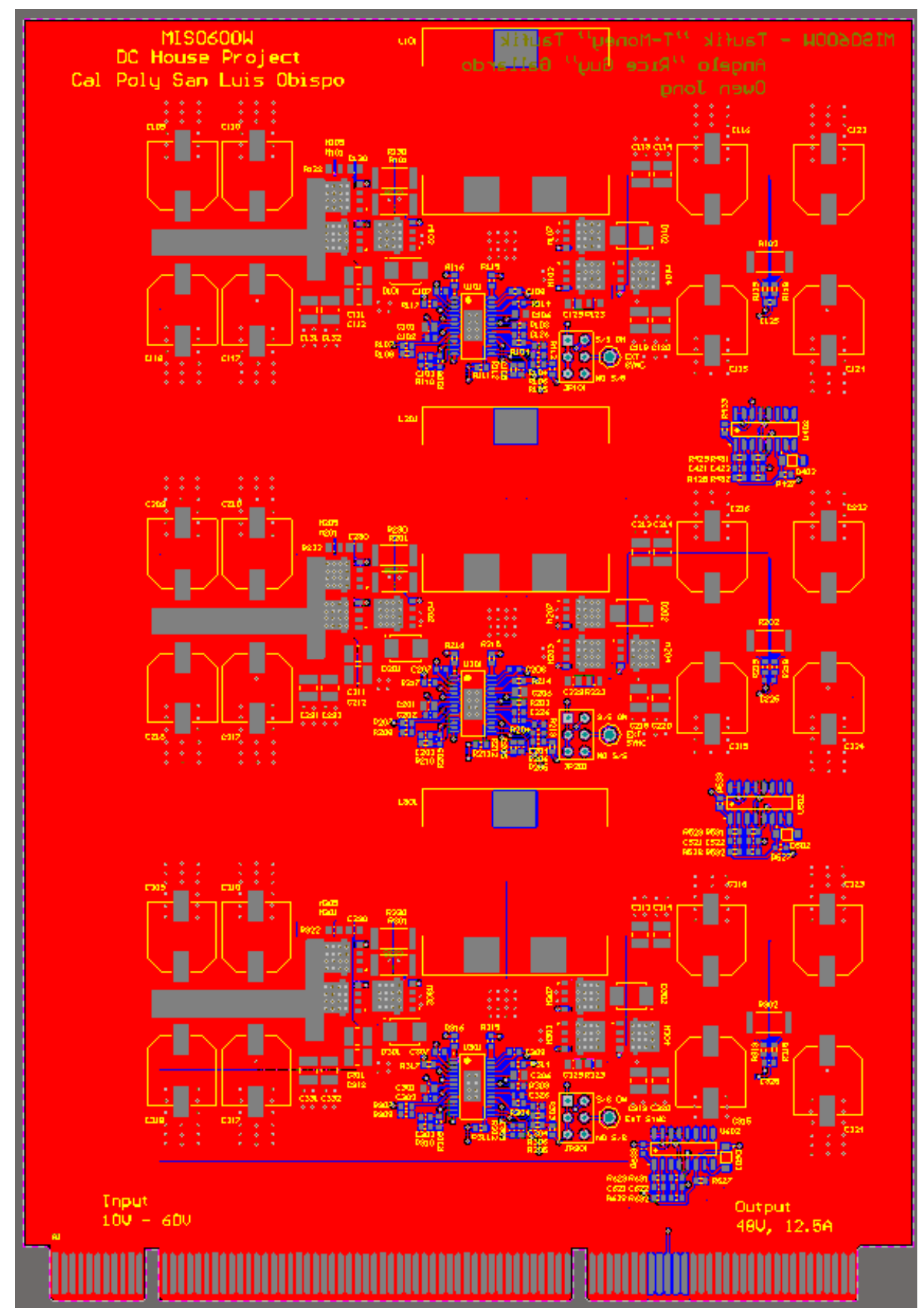

Figure 4-18: MISO 600W Layout 


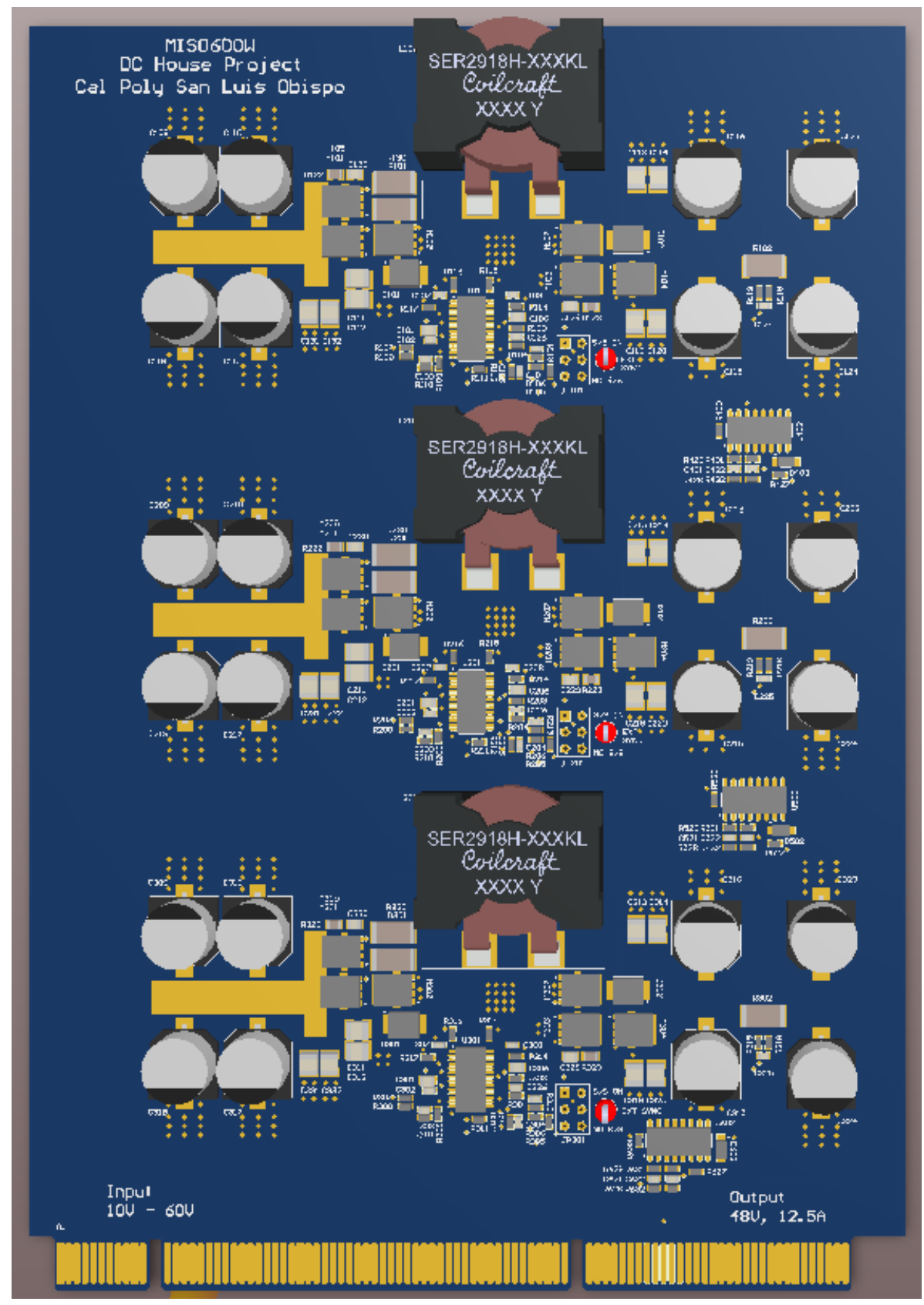

Figure 4-19: MISO 600W 3D View

An additional board is made to hold the female end of the edge connectors. As specified in Chapter 3, up to three MISO 600W boards connect in parallel in a single system. Therefore, three female edge connectors are placed in parallel on the additional "mother" board. The space between each edge connector equals 1 inch to ensure that two 
boards do not touch each other. Figure 4-20 shows the layout of the board and Figure 424 shows its $3 \mathrm{D}$ view.

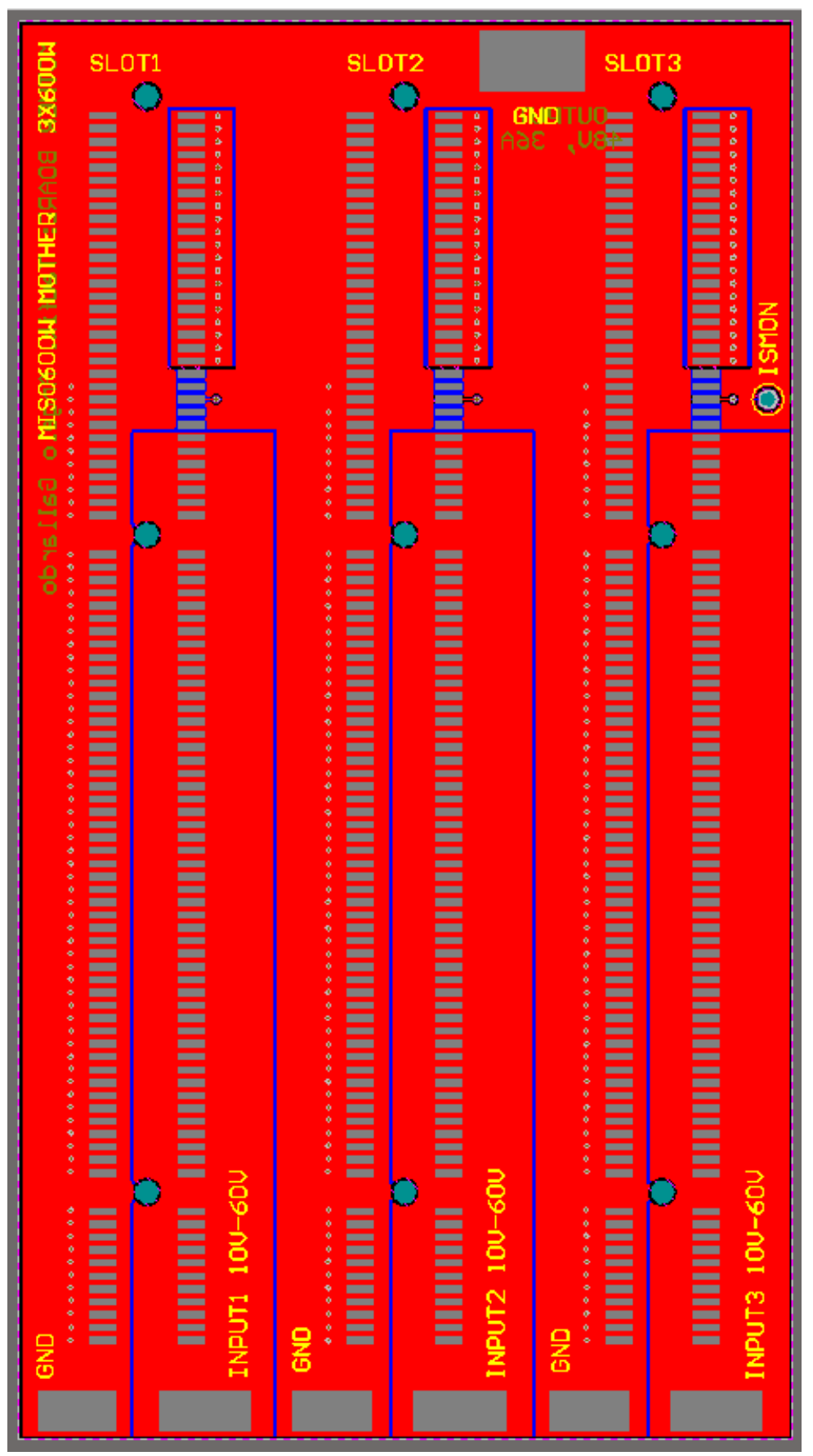

Figure 4-20: MISO Mother Layout 


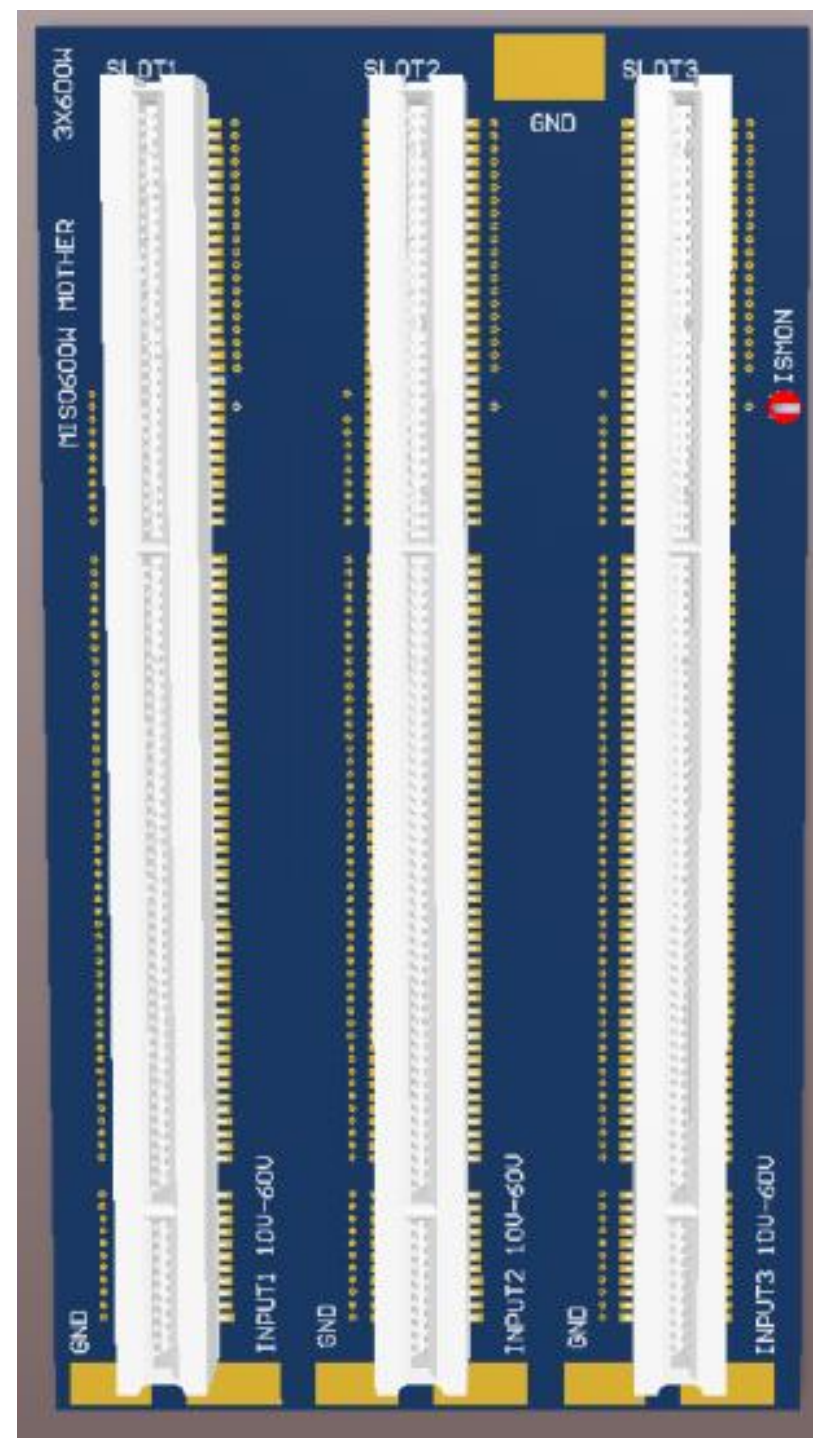

Figure 4-21: MISO Mother 3D View 


\section{Hardware Test and Results}

This chapter outlines the build and test of the MISO boards designed for this thesis. Each board, MISO200, MISO600, and 3 x MISO600 with the MISO mother (or known as MISO1800 for the rest of this thesis), was assembled and tested to see if they meet the specifications discussed in previous chapters. This chapter discusses the building process of the hardware, the test setup for each board, and the results of each test. The following chapter analyzes the test results found in this chapter.

Each board performed five different tests to ensure their operation meets the specifications: efficiency, line regulation, load regulation, output voltage ripple, and thermals. The efficiency test shows how efficient the power converter converts energy to $48 \mathrm{~V}$ and the power lost within the DC-DC conversion. The test uses the nominal $24 \mathrm{~V}$ input and the load pulls 5\% load to $100 \%$ load in steps of 5\%. Equation 5-1 shows the equation used for efficiency.

$$
\eta=\frac{P_{o}}{\sum \operatorname{Pin}} * 100 \%=\frac{V_{o} I_{o}}{\sum V_{i n} I_{\text {in }}} * 100 \%
$$

The line regulation test shows how well the converter regulates its output voltage due to changes at the input voltage. Data is gathered while pulling the converter at full load. Equation 5-2 shows this calculation.

$$
\text { Line Regulation }=\frac{V_{o, \text { high input }}-V_{o, \text { low input }}}{V_{\text {out }, \text { nominal input }}} * 100 \%
$$

The load regulation test shows how well the converter regulates its output voltage due to changes at the load, while operating at the nominal input voltage. This load regulation calculation follows equation 5-3. 


$$
\text { Load Regulation }=\frac{V_{o, \text { no load }-} V_{o, \text { full load }}}{V_{o, \text { full load }}} * 100 \%
$$

Output voltage ripple test shows the AC ripple voltage present at the output voltage during full load. The output voltage is ideally DC, but parasitics within the system causes the output capacitors to not fully remove the AC portion of the voltage and therefore a ripple appears at the output voltage. The converter operates at full load during the test to view the worst-case output voltage ripple from the converter. The oscilloscope probe, set to AC coupling, measures the peak to peak $\mathrm{AC}$ ripple voltage at the output. Equation 5-4 calculates the percent ripple voltage.

$$
\% V_{o, \text { ripple }}=\frac{V_{o, \text { ripple peak-peak }}}{\bar{V}_{o}} * 100 \%
$$

Lastly, this thesis gathers thermal images for each board. The thermal test consists of running the board at full load until all components have reached thermal equilibrium, or about 15 minutes. The Testo 870-1 thermal camera captures a picture that shows the temperature of each component on the board. This shows how hot the overall board gets at full load and if any components exhibit overheating.

The required equipment to test any of the designed boards consist of a power supply, an electronic load, an oscilloscope, and a set of multimeters. Table 5-1 reveals the set of equipment used throughout the testing of all MISO boards. Figure 5-1 shows the general block diagram of each test setup. 
Table 5-1: List of Equipment for Test Setups

\begin{tabular}{|c|c|c|}
\hline \multirow{2}{*}{ Equipment } & Company and Model Number & Ratings \\
\hline \multirow{2}{*}{ Electronic Load } & HP 6032A & 0V-60V, 0-50A 1000W \\
\cline { 2 - 3 } & Mean Well SE-600-24 & 24V (fixed), 25A, 600W \\
\cline { 2 - 3 } & BK Precision 8510 & $120 \mathrm{~A}, 600 \mathrm{~W}$ \\
\hline \multirow{2}{*}{ Oscilloscope } & Lecroy HD4096 & $1000 \mathrm{VDC}, 30 \mathrm{~A}, 3000 \mathrm{~W}$ \\
\hline \multirow{2}{*}{ Multimeter } & Extech multimeters & 30A current probe \\
\cline { 2 - 3 } & Fluke multimeters & $10 \mathrm{~A}$ fuse \\
\hline
\end{tabular}

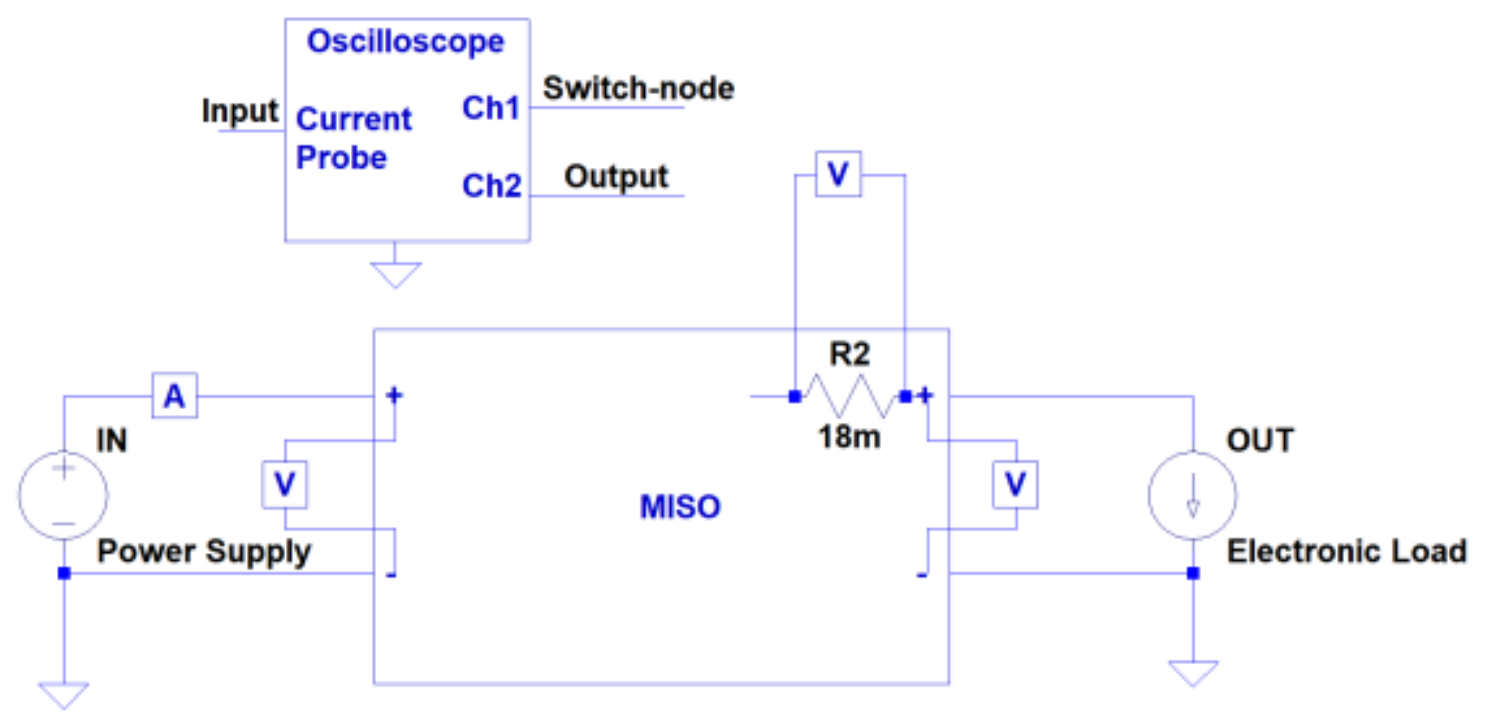

Figure 5-1: Block Diagram of Generic Test Setup

Referring to Figure 5-1, a power supply powers the MISO, while an electronic load pulls current out of the MISO. This thesis uses an oscilloscope to monitor the switch-node, output voltage, and input current of the MISO, when applicable. A multimeter measures input current up to $10 \mathrm{~A}$ due its fuse. The oscilloscope measures any 
current larger than 10A. Multimeters measure input voltage and output voltage right at the input and output of the MISO. Another multimeter monitors the voltage across R2, which corresponds to the load going through that channel. MISO600 and MISO1800 uses multimeters across R2 of each channel to monitor the load per channel.

The MISO200 designed in Chapter 4 uses Osh Park to manufacture the board. Figure 5-2 shows the unpopulated board. The components designed in Chapter 4 populated this MISO board. Refer to Appendix A to see the bill of materials for the MISO200. The semiconductor components, such as the LT8390, LT1467, and FDMS86520L MOSFETs, are soldered onto the board using a heat gun for a proper solder joint, especially for the components with a ground pad on its bottom side. For the rest of the components, a soldering iron is used to hand solder onto the board. Figure 5-3 shows the populated MISO200 board. 


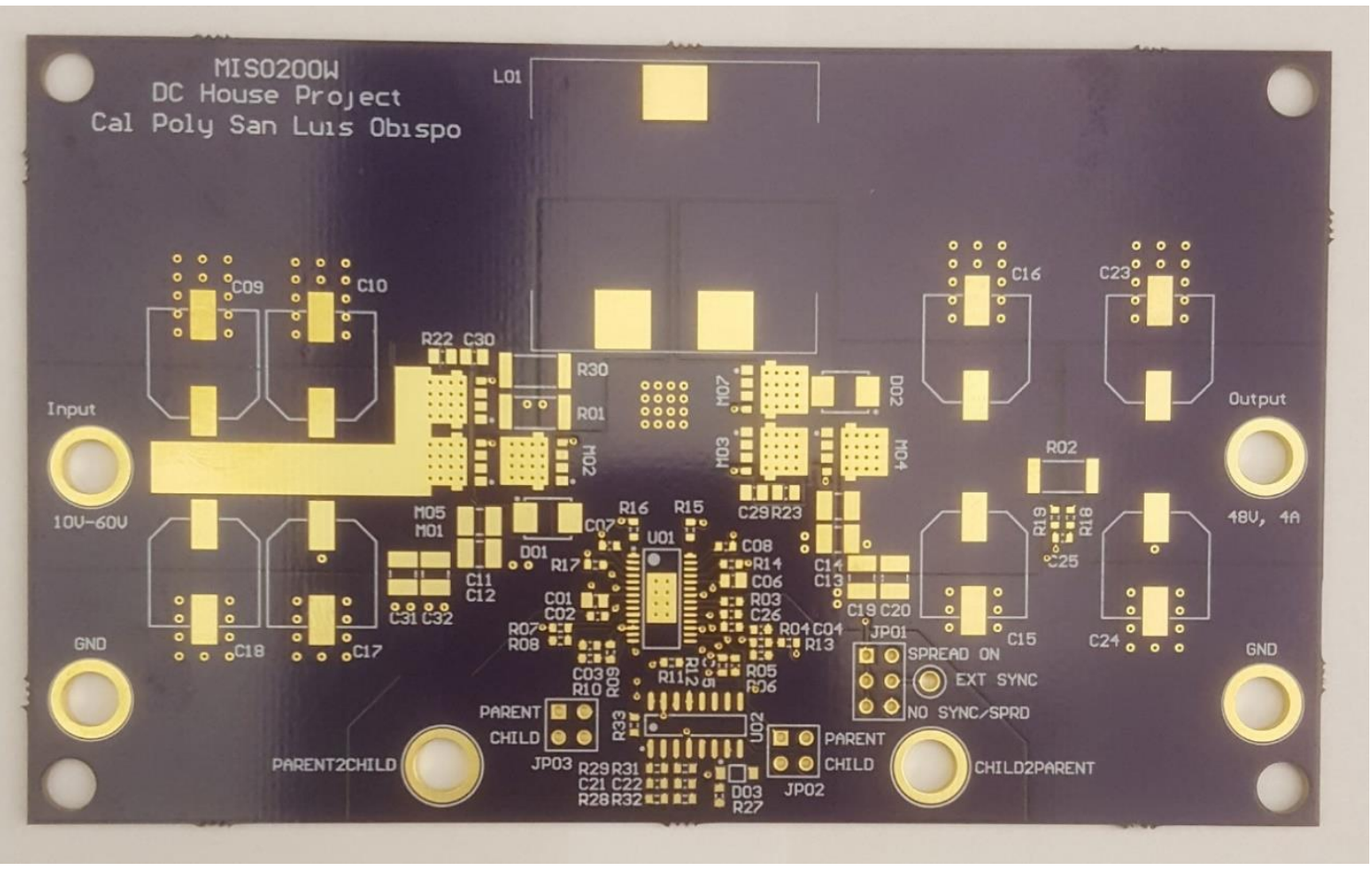

Figure 5-2: Blank MISO200 Board

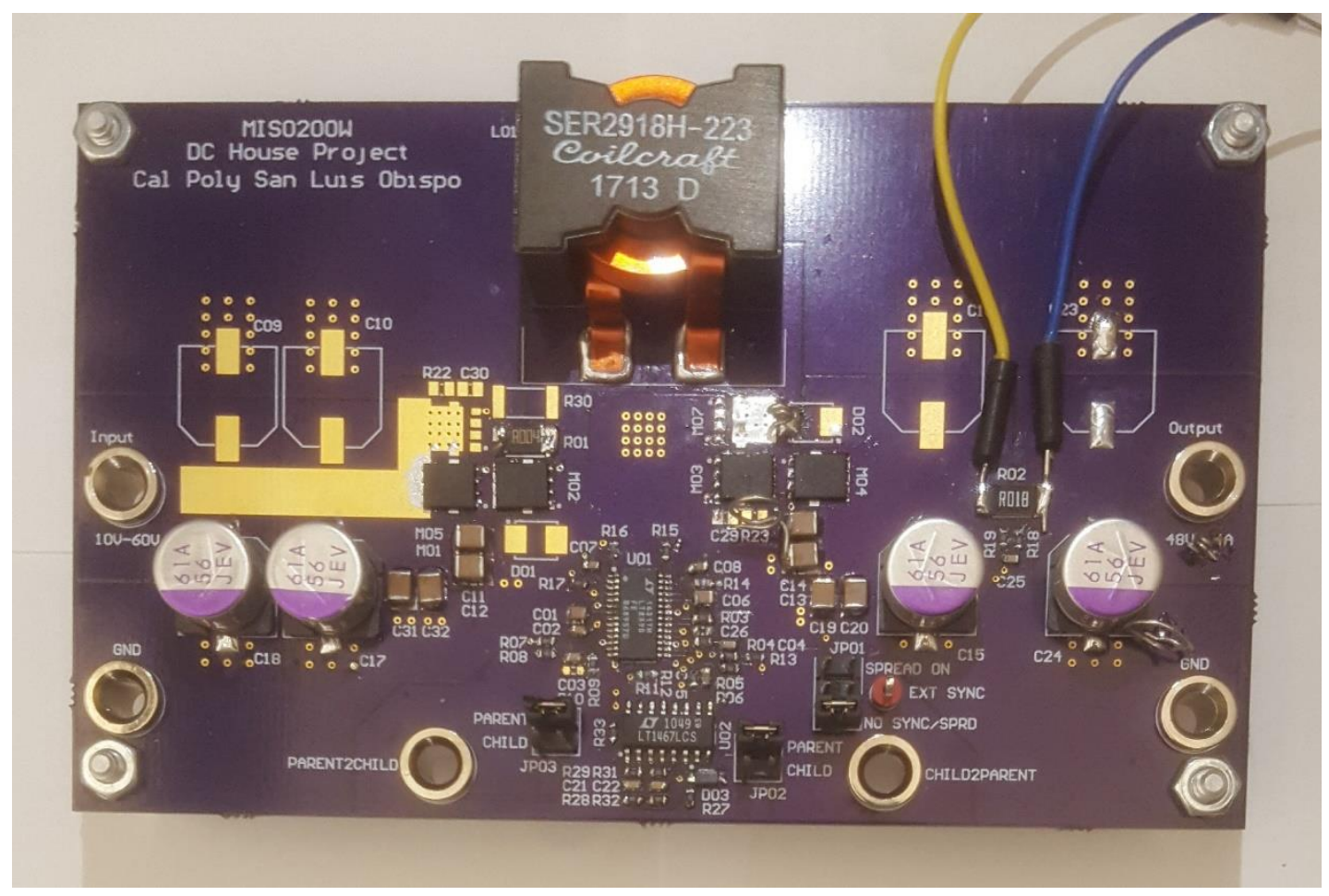

Figure 5-3: Populated MISO200 Board 
This test setup uses the HP6032A and the BK Precision 8510 as the power supply and electronic load. The electronic load pulls current from $0 \mathrm{~A}-4.17 \mathrm{~A}$ to achieve $200 \mathrm{~W}$ of output power. Figure 5-4 displays the capture of the test setup for a single MISO200 board.

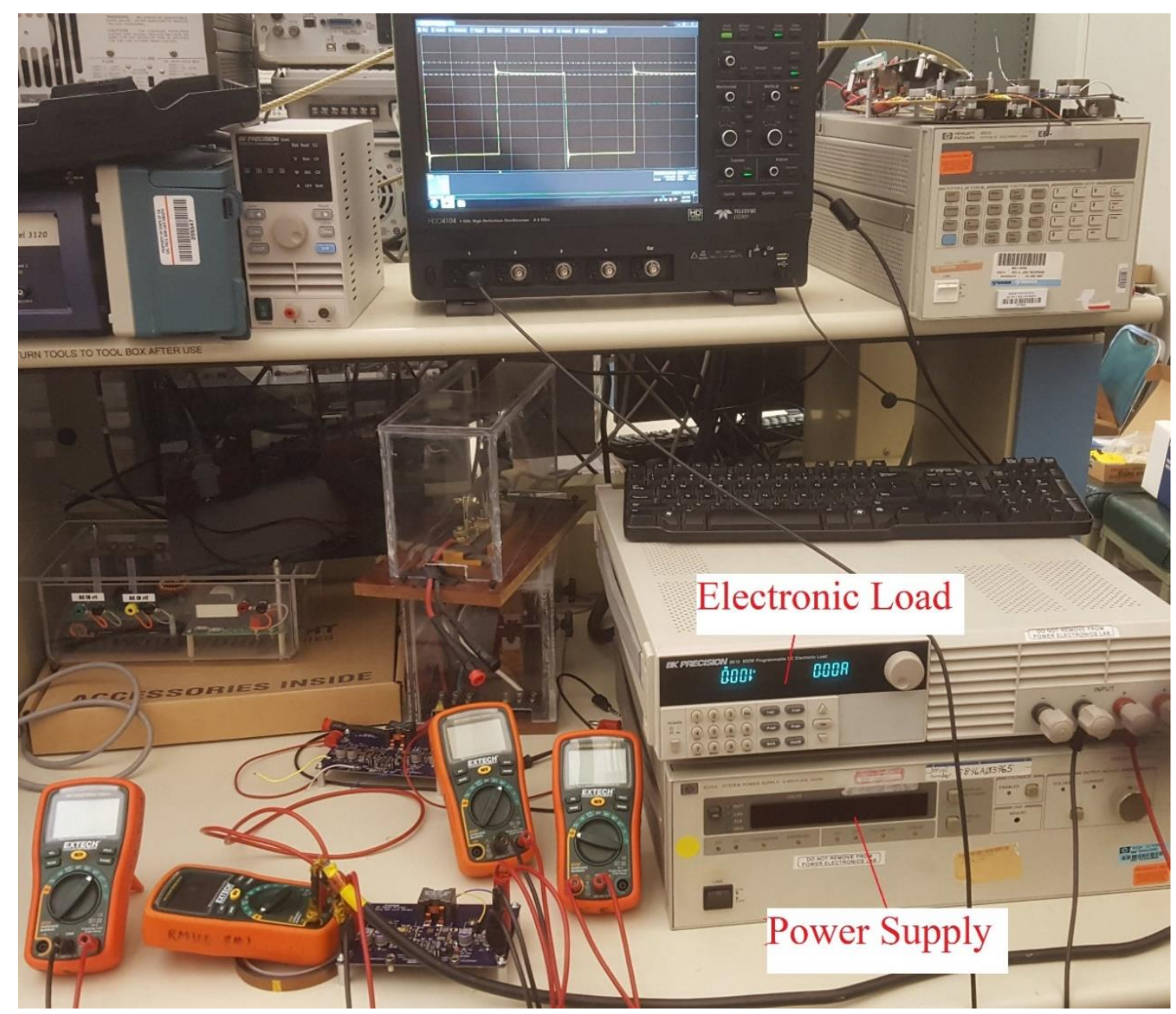

Figure 5-4: MISO200 Test Setup

The MISO200 performs the efficiency test by using multimeters to measure input current, input voltage, and output voltage, and using the electronic load to read out output current. Since the input current never exceeds $10 \mathrm{~A}$ for $24 \mathrm{~V}$ input, a multimeter is used to 
measure the input current. Figure 5-5 shows the efficiency plot, while Appendix C contains the raw data used to generate the plot.

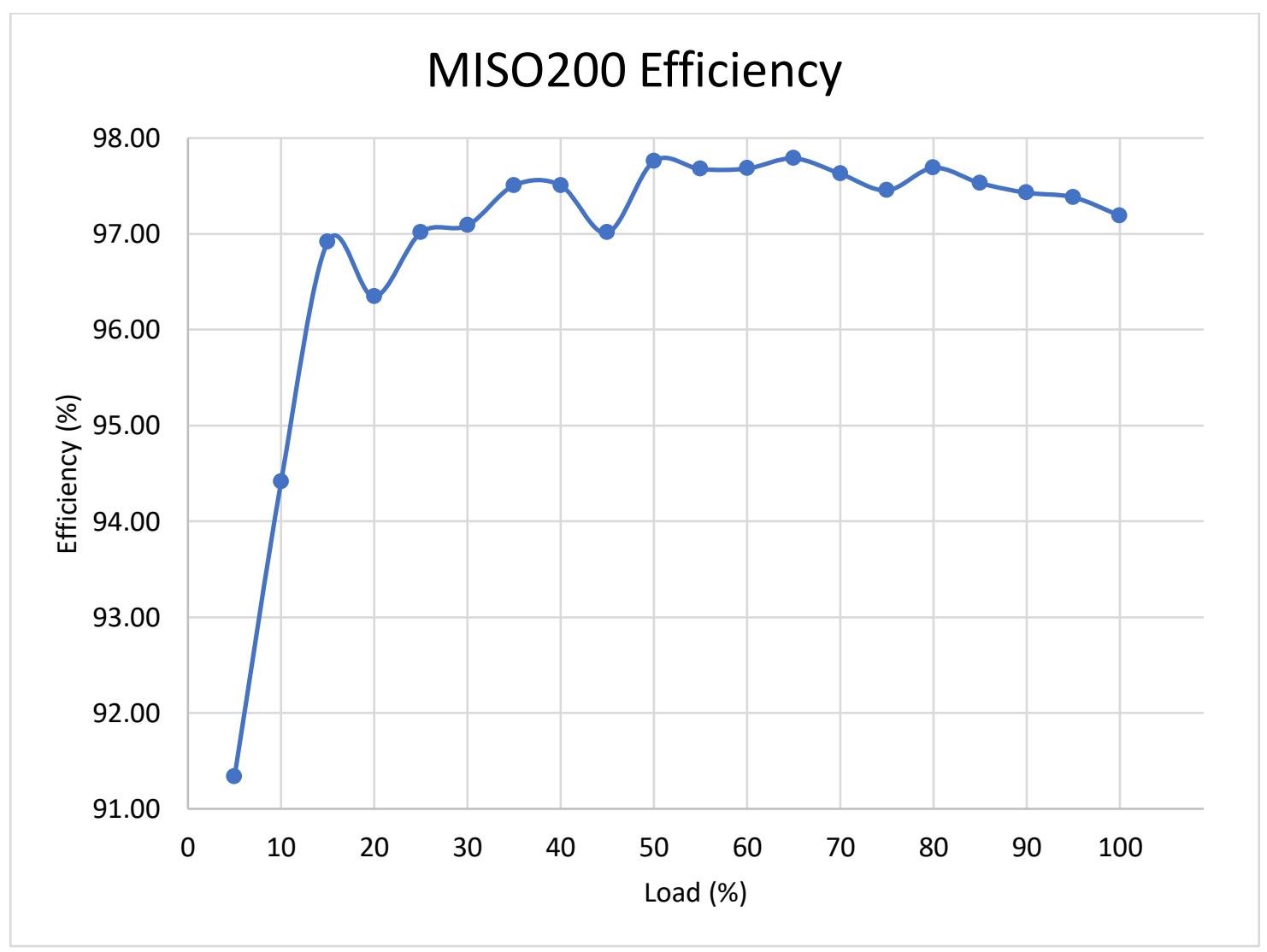

Figure 5-5: MISO200 Efficiency Plot

This setup performs line regulation by monitoring the output voltage with changes to the input voltage. Although Chapter 3 specified the line regulation from $12 \mathrm{~V}$ to $36 \mathrm{~V}$ at full load, data shows that the output voltage goes out of regulation at low input voltages due to high currents. Therefore, a higher $\mathrm{V}_{\mathrm{o}-\mathrm{low}}$ is chosen for full load operation. Chapter 6 further analyzes this change in line regulation. Table 5-2 tabulates the data by using equation 5-2 to calculate line regulation percentage. 
Table 5-2: MISO200 Line Regulation

\begin{tabular}{|c|c|c|c|c|}
\hline $\begin{array}{c}\mathrm{I}_{\mathrm{o}}(\mathrm{A}) / \\
\mathrm{P}_{\mathrm{o}}(\mathrm{W})\end{array}$ & $\begin{array}{c}\mathrm{V}_{\mathrm{o}-\text { high }}(\mathrm{V}) \\
\text { @ Vin = 36V }\end{array}$ & $\mathrm{V}_{\text {o-low }}(\mathrm{V})$ & $\begin{array}{c}\mathrm{V}_{\text {o-nominal }}(\mathrm{V}) \\
\text { @ Vin = 24V }\end{array}$ & Line Reg (\%) \\
\hline \multirow{2}{*}{$4.17 / 200$} & 48.2 & $\begin{array}{r}45.7 @ \\
20 \mathrm{Vin}\end{array}$ & 48.2 & 5.19 \\
\cline { 2 - 5 } & 48.2 & $\begin{array}{r}48.2 @ \\
21 \mathrm{Vin}\end{array}$ & 48.2 & 0 \\
\hline $2.08 / 100$ & 48.4 & $\begin{array}{r}48.2 @ \\
12 \mathrm{Vin}\end{array}$ & 48.3 & 0.414078675 \\
\hline $2.29 / 110$ & 48.4 & $\begin{array}{r}48.3 @ \\
12 \mathrm{Vin}\end{array}$ & 48.3 & 0.207039337 \\
\hline
\end{tabular}

The MISO200 obtains load regulation by changing the load from no load to full load and monitoring the output voltage. Equation 5-5 shows the calculation of load regulation, which uses data from Appendix C.

$$
\text { Load Regulation }=\frac{48.6 \mathrm{~V}-48.2 \mathrm{~V}}{48.2 \mathrm{~V}} * 100 \%=0.830 \%
$$

The MISO200 measures output voltage ripple with the oscilloscope by probing both the switch-node and the output voltage at the spot located closest to the actual output of the MISO. The switch-node is probed to show the switching performance of the converter as well as to have a solid triggering point for a stable waveform. For the quietest waveform of the output voltage ripple, the oscilloscope uses a turret style configuration, with the ground clip removed, for the shortest path from signal to ground. Figure 5-6 displays this configuration. 


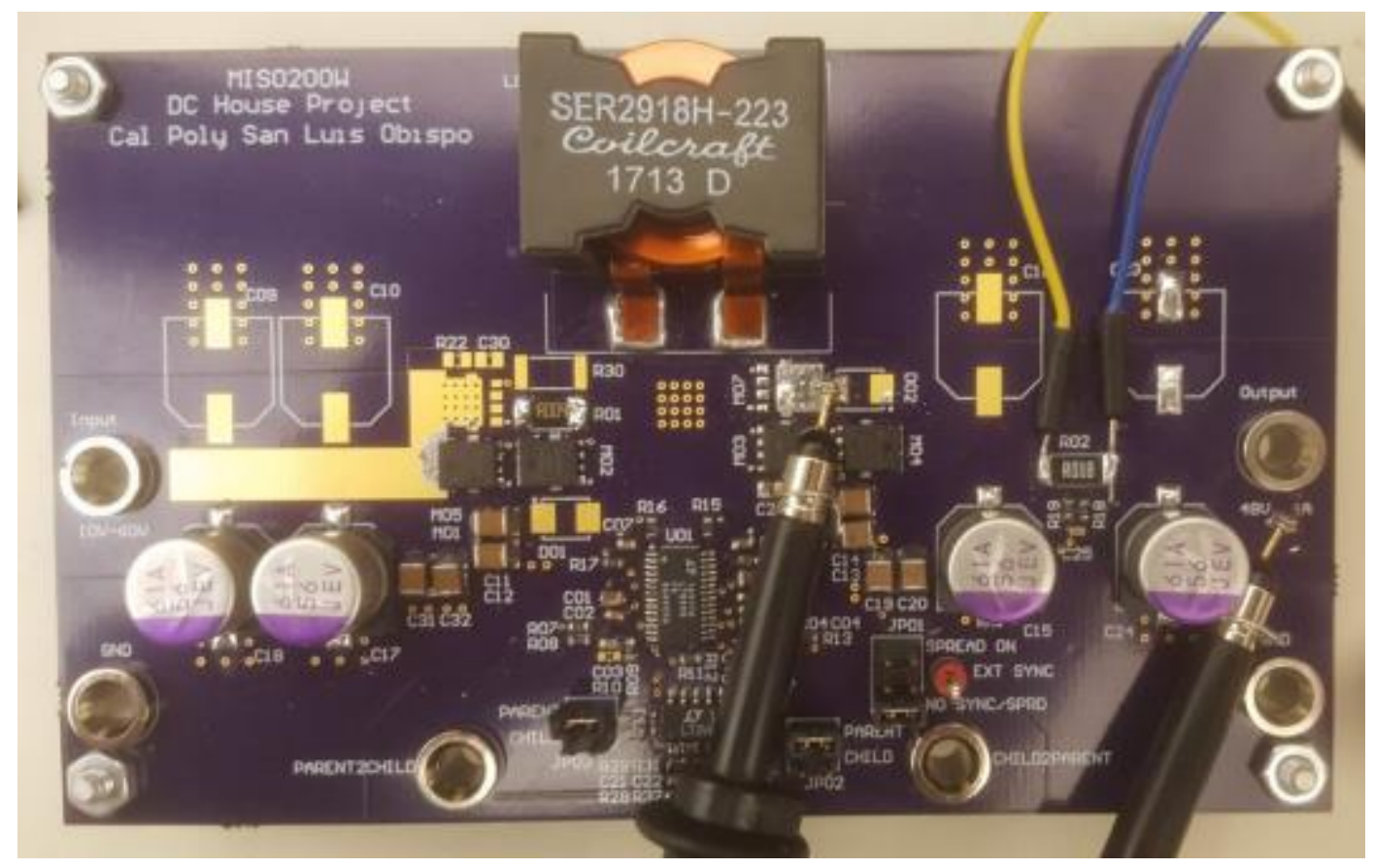

Figure 5-6: MISO200 Oscilloscope Probe Configuration

Figure 5-7 shows the output voltage ripple and switch-node waveforms. Table 5-3 summarizes the data obtained in the waveform capture. Equation 5-4 calculates $\% \mathrm{~V}_{\mathrm{o}}$, ripple for a $\mathrm{V}_{\mathrm{o}}$ of $48.2 \mathrm{~V}$ at full load.

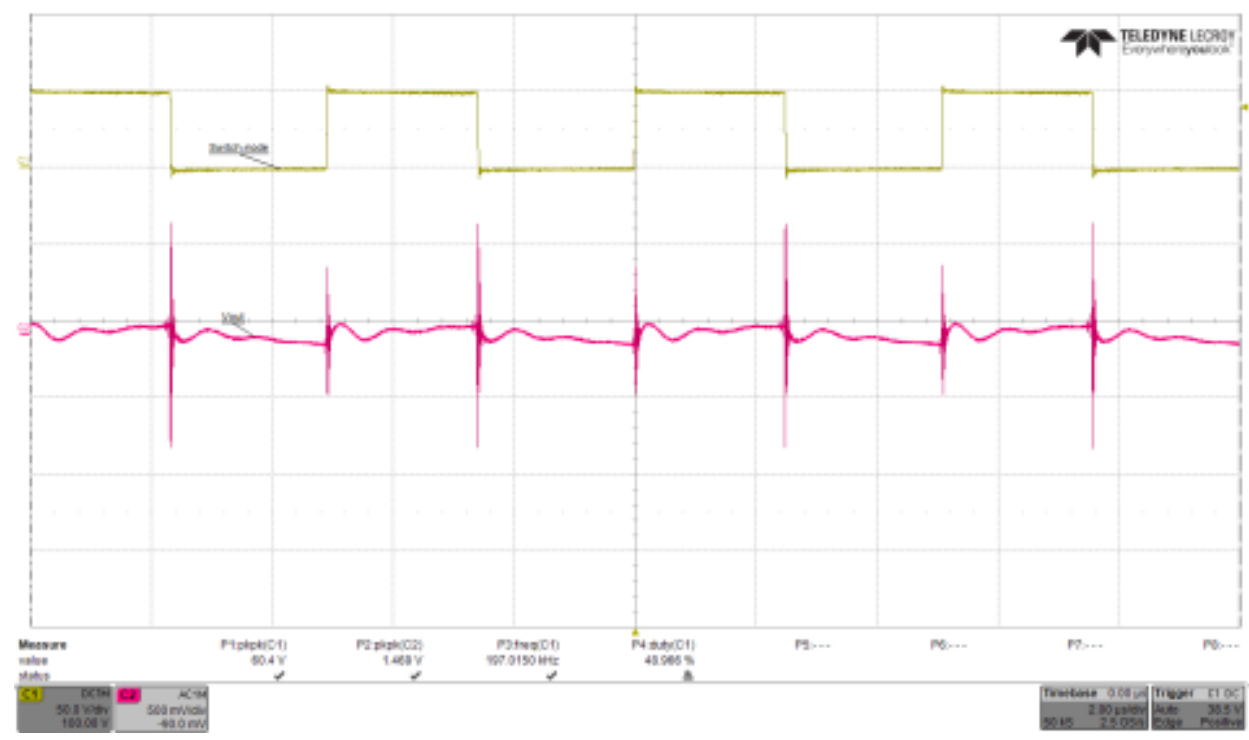

Figure 5-7: MISO200 Output Voltage Ripple and Switch-Node Waveform 
Table 5-3: MISO200 Output Voltage Ripple and Switch-Node Data

\begin{tabular}{|c|c|c|c|c|}
\hline $\begin{array}{c}\mathrm{V}_{\text {switch-node }} \\
\left(\mathrm{V}_{\text {pk-pk }}\right)\end{array}$ & $\begin{array}{c}\mathrm{f}_{\mathrm{sw}} \\
(\mathrm{kHz})\end{array}$ & $\begin{array}{c}\text { Duty Cycle } \\
(\%)\end{array}$ & $\begin{array}{c}\mathrm{V}_{\mathrm{o}, \text { ripple }} \\
\left(\mathrm{V}_{\mathrm{pk}-\mathrm{pk}}\right)\end{array}$ & $\begin{array}{c}\% \mathrm{~V}_{\mathrm{o}} \text {, ripple } \\
(\%)\end{array}$ \\
\hline 60.4 & 197.0 & 48.9 & 1.47 & 3.05 \\
\hline
\end{tabular}

Lastly, the MISO200 pulls full load until thermal equilibrium to obtain thermal pictures. Figure 5-8 shows the thermal picture captured for this board.
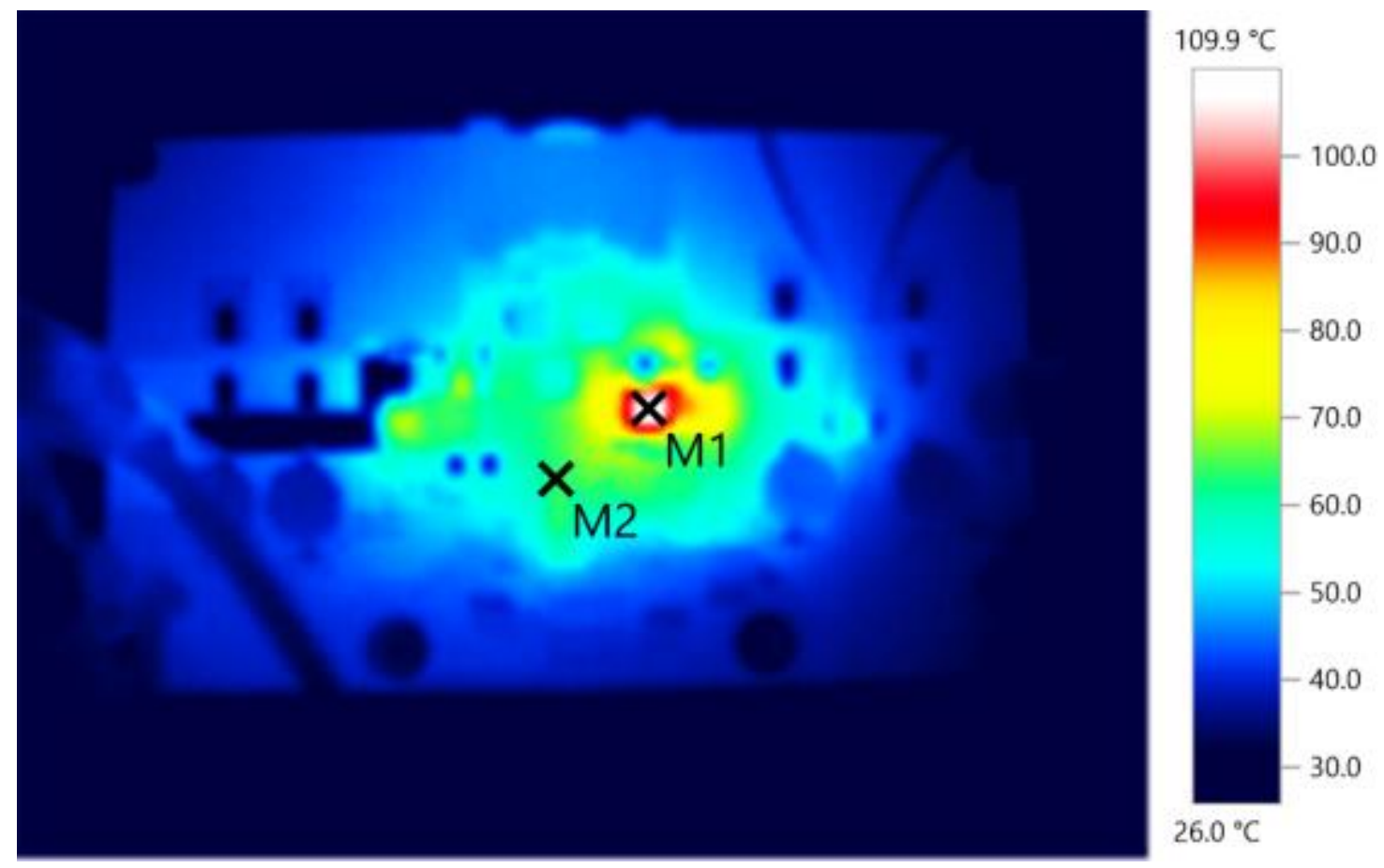

$26.0^{\circ} \mathrm{C}$

Figure 5-8: MISO200 Thermal Picture. M1: LS Boost FET, M2: LT8390

Figure 5-8 shows that the general power components temperature ranges from about $60^{\circ} \mathrm{C}$ to $80^{\circ} \mathrm{C}$. The peak temperature spot runs at $109.9^{\circ} \mathrm{C}$. This spot is located on the low-side boost FET, or the M03 FET on the schematic shown in Figure 4-12. 
Next, this chapter depicts MISO600 testing. As seen in Chapter 4, the MISO600 consists of 3 channels of MISO200 on a single board, along with golden fingers that make up the male side of the edge connectors which appears on the MISO mother board. The same building process of the MISO200, with a heat gun and hand solder, applies to the MISO600. This test setup must consider wire gauge since large amounts of input current get supplied to the MISO600. For a maximum input current of about 25-30A, a pair of 18 AWG wires twisted together to carry the necessary current. The positive connection uses one pair and the negative return path connection uses another pair. Figure 5-9 shows the populated MISO600 and Appendix B show the bill of materials. 


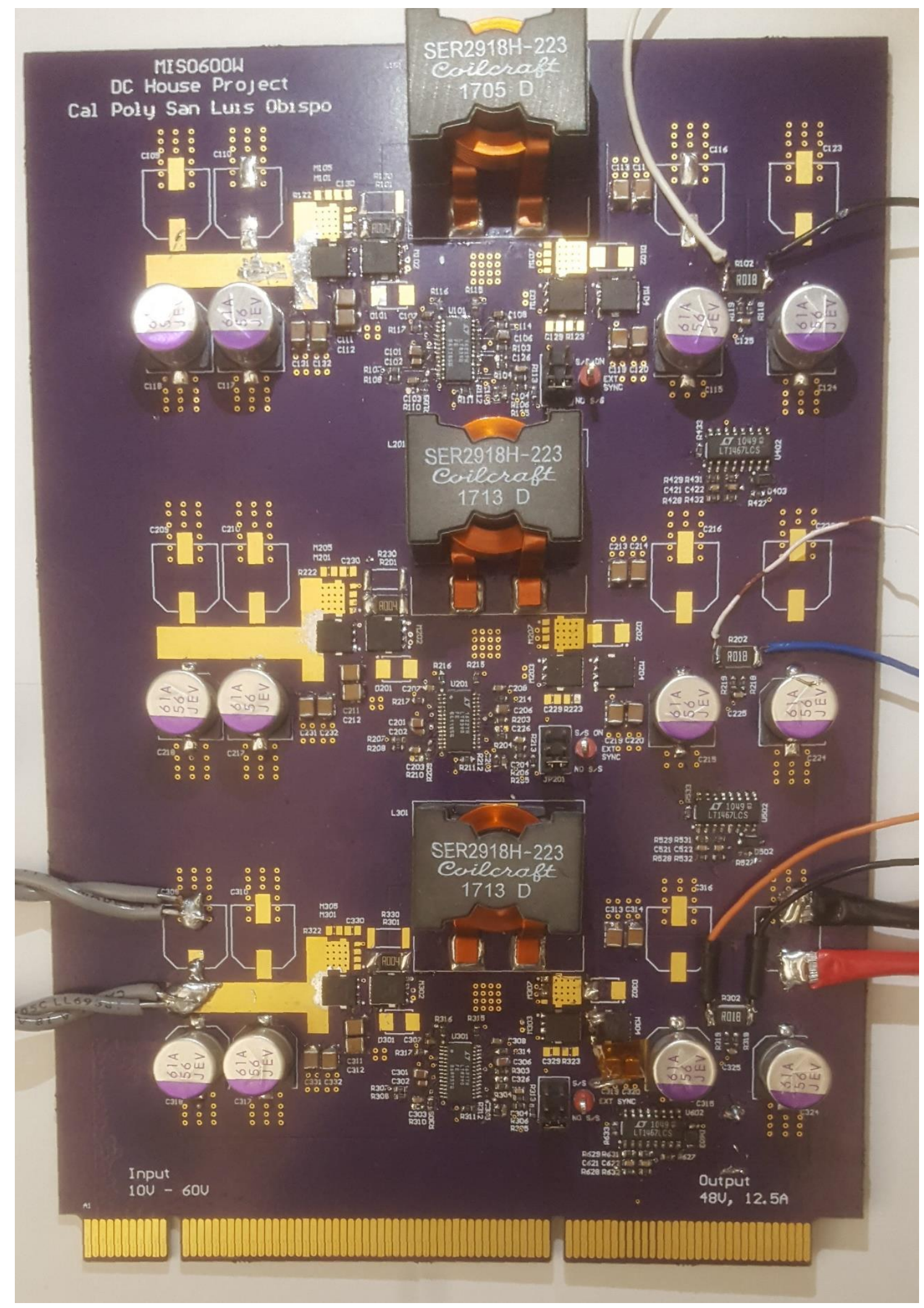

Figure 5-9: Populated MISO600 Board 
The MISO600 uses the same power supply and electronic load that the MISO200 used. One multimeter measures the input voltage and another one for the output voltage. Additional multimeters measure across R2 of each channel to monitor all load current. As seen in Figure 5-1, these multimeters monitor the load going through each channel by measuring the voltage across the channel's output sense resistor and using equation 5-6 to calculated load current. Figure 5-10 shows the snapshot of the test setup for the MISO 600.

$$
I_{o, p e r ~ c h a n n e l}=\frac{V_{R 2}}{18 m \Omega}
$$

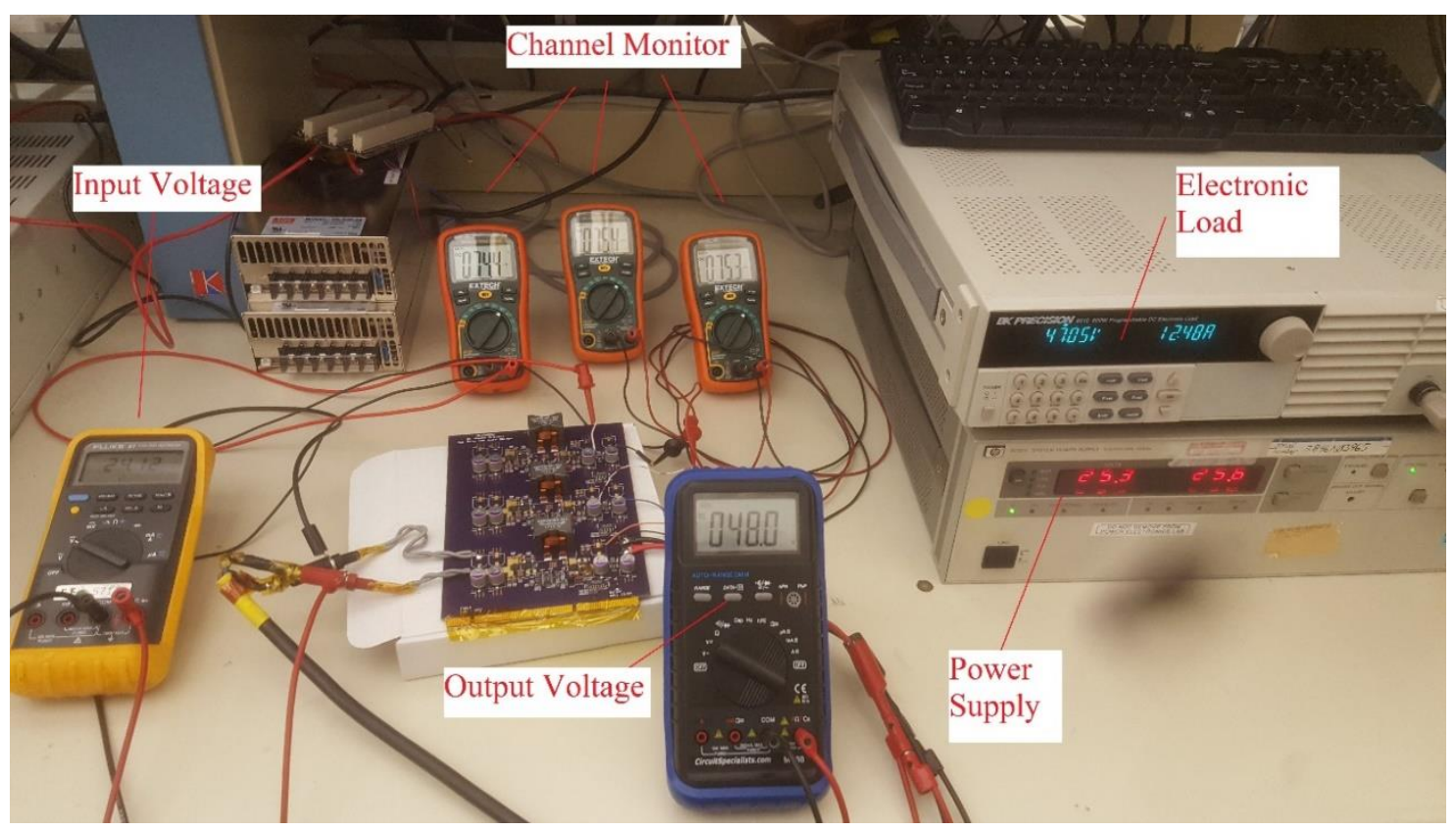

Figure 5-10: MISO600 Test Setup

The MISO600 obtains the efficiency plot by using multimeters to measure input and output voltage. The power supply's display measures input current since the multimeters cannot operate past 10A. Figure 5-11 shows the plot while Appendix D contains the raw data for the plot. 


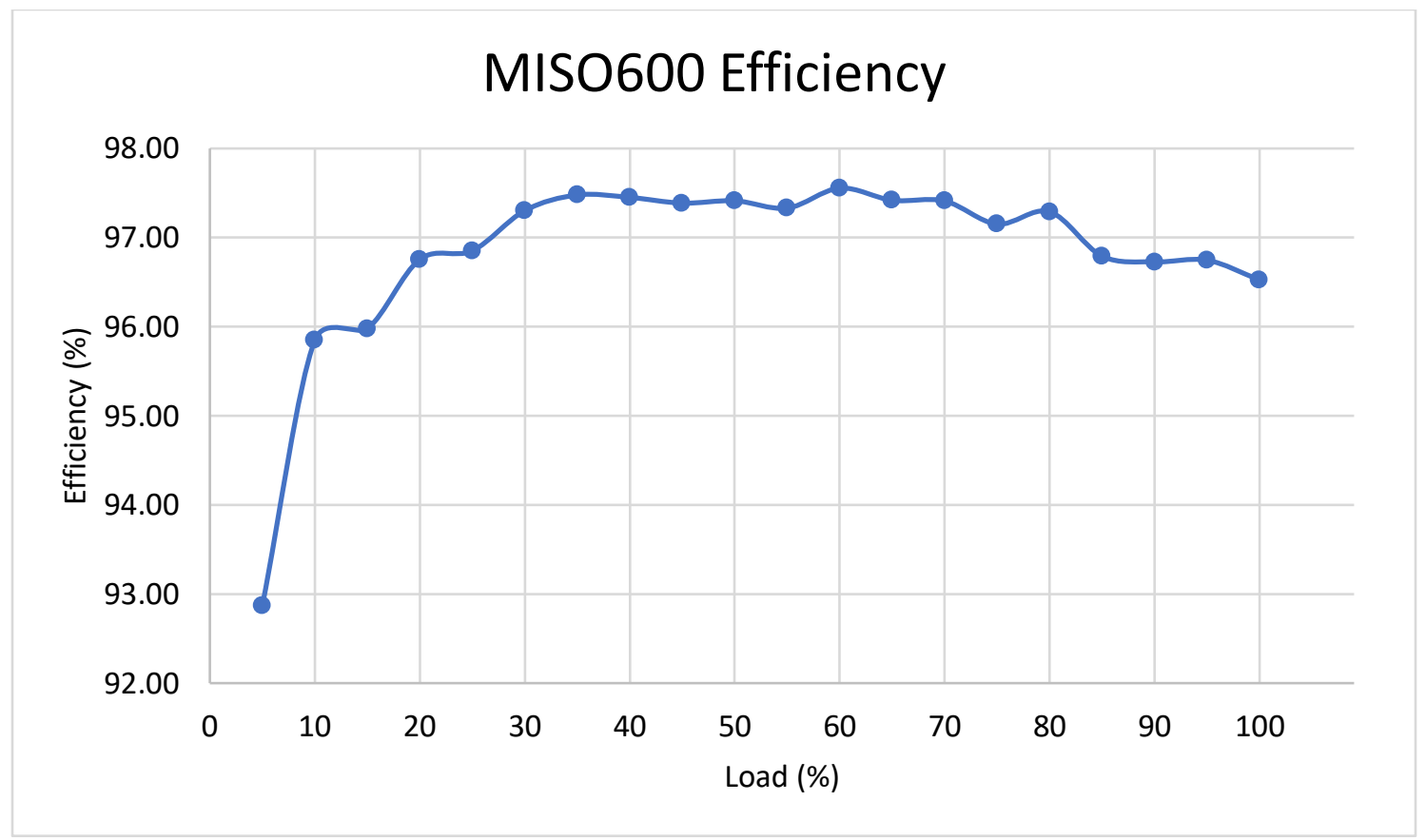

Figure 5-11: MISO600 Efficiency Plot

The MISO600 requires an additional test to measure load sharing per channel.

Ideally, all channels share an equal amount of current. Due to flaws and parasitics in the system, a general share in load becomes a more realistic result. Appendix D records the voltage across the output sense resistor. Equation 5-6 calculates load per channel and Table 5-4 tabulates the results of this data. Channel 1 refers to the track closest to the golden fingers, channel 2 refers to the middle track, and channel 3 refers to the track farthest from the golden fingers. 
Table 5-4: MISO600 Load Sharing Per Channel

\begin{tabular}{|c|c|c|c|c|}
\hline $\begin{array}{c}\text { Load Step } \\
(\%)\end{array}$ & $\begin{array}{c}\text { Theoretical Load } \\
\text { Per Channel (A) }\end{array}$ & $\begin{array}{c}\text { Actual Load } \\
\text { Channel 1 (A) }\end{array}$ & $\begin{array}{c}\text { Actual Load } \\
\text { Channel 2 (A) }\end{array}$ & $\begin{array}{c}\text { Actual Load } \\
\text { Channel 3 (A) }\end{array}$ \\
\hline 10 & 0.42 & 0.38 & 0.42 & 0.43 \\
\hline 50 & 2.08 & 2.06 & 2.09 & 2.08 \\
\hline 100 & 4.17 & 4.22 & 4.23 & 4.20 \\
\hline
\end{tabular}

Table 5-5 shows the line regulation obtained for the MISO600. Just like for the MISO200, low input voltages cause the system to go out of regulation due to the input current limiting features of the system, which require additional measurements to be taken at different loads and low input voltages.

Table 5-5: MISO600 Line Regulation

\begin{tabular}{|c|c|c|c|c|}
\hline $\begin{array}{l}\mathrm{I}_{\mathrm{o}}(\mathrm{A}) / \\
\mathrm{P}_{\mathrm{o}}(\mathrm{W})\end{array}$ & $\begin{array}{c}\mathrm{V}_{\text {o-high }}(\mathrm{V}) \\
@ \text { Vin }=36 \mathrm{~V}\end{array}$ & $\mathrm{~V}_{\text {o-low }}(\mathrm{V})$ & $\begin{array}{l}\mathrm{V}_{\text {o-nominal }}(\mathrm{V}) \\
@ \text { Vin }=24 \mathrm{~V}\end{array}$ & Line Reg $(\%)$ \\
\hline \multirow{2}{*}{$12.5 / 600$} & 48.1 & $\begin{array}{l}44.3 @ \\
20 \mathrm{Vin}\end{array}$ & 48.0 & 7.917 \\
\hline & 48.1 & $\begin{array}{c}48.0 @ \\
22 \mathrm{Vin}\end{array}$ & 48.0 & 0.207 \\
\hline $6.25 / 300$ & 48.3 & $\begin{array}{c}48.1 @ \\
12 \text { Vin }\end{array}$ & 48.2 & 0.414 \\
\hline $7.08 / 340$ & 48.2 & $\begin{array}{c}48.1 @ \\
12 \mathrm{Vin}\end{array}$ & 48.2 & 1.660 \\
\hline
\end{tabular}

Equation 5-7 calculates load regulation based on the efficiency raw data in Appendix D.

$$
\text { Load Regulation }=\frac{48.4 \mathrm{~V}-48.0 \mathrm{~V}}{48.0 \mathrm{~V}} * 100 \%=0.833 \%
$$


The same output voltage and switch-node probing style used for the MISO200 applies to the MISO600. This test probes channel 1's switch-node for triggering purposes. The output voltage probe is placed as close to the gold finger connection as possible for the truest output voltage reading. Figure 5-12 shows this waveform and Table 5-6 shows the summary of data.

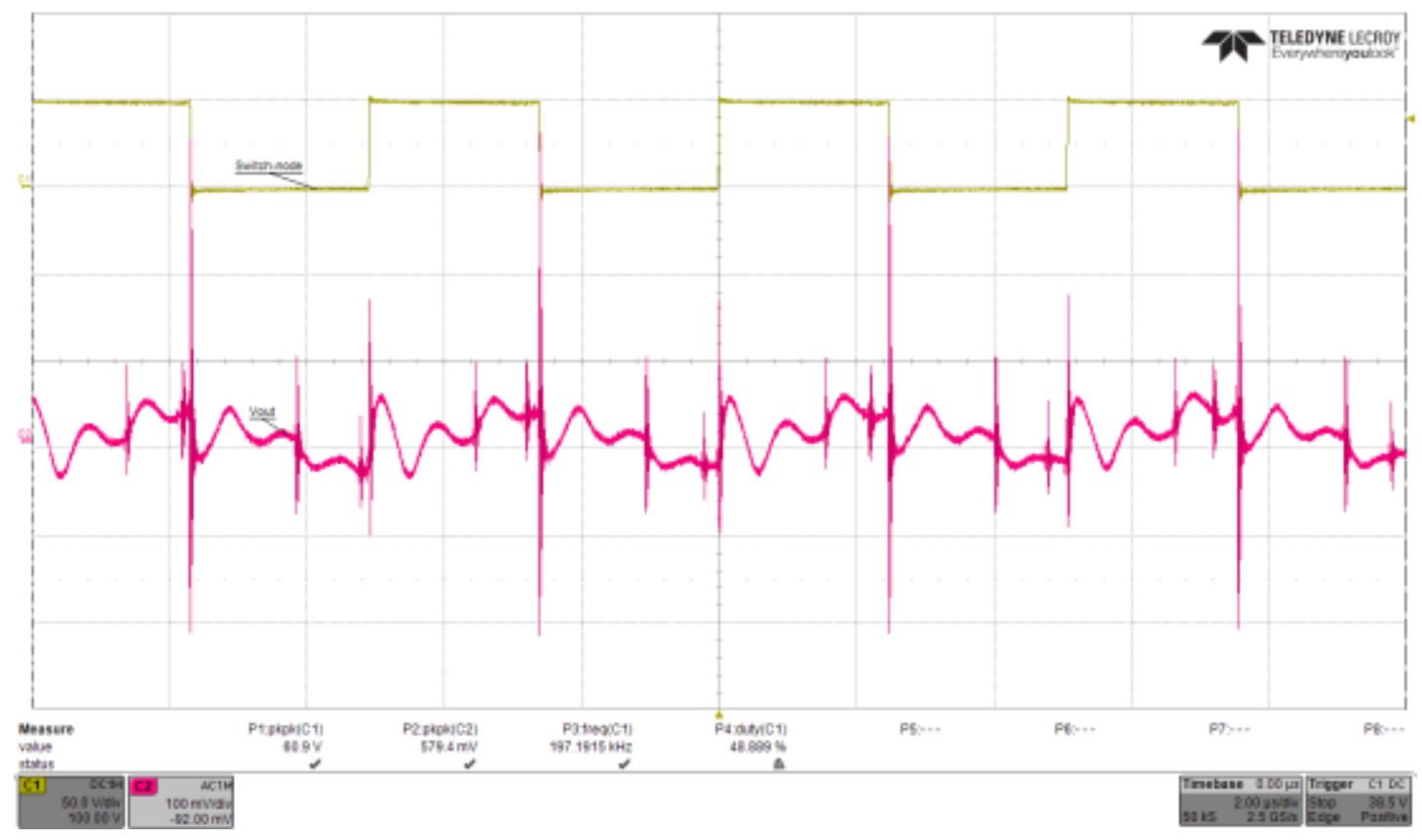

Figure 5-12: MISO600 Output Voltage Ripple and Switch-Node Waveform Table 5-6: MISO600 Output Voltage Ripple and Switch-Node Data

\begin{tabular}{|c|c|c|c|c|}
\hline $\begin{array}{c}\mathrm{V}_{\text {switch-node }} \\
\left(\mathrm{V}_{\text {pk-pk }}\right)\end{array}$ & $\begin{array}{c}\mathrm{f}_{\mathrm{sw}} \\
(\mathrm{kHz})\end{array}$ & $\begin{array}{c}\text { Duty Cycle } \\
(\%)\end{array}$ & $\begin{array}{c}\mathrm{V}_{\text {o, ripple }} \\
\left(\mathrm{V}_{\text {pk-pk }}\right)\end{array}$ & $\begin{array}{c}\% \mathrm{~V}_{\mathrm{o}} \text {, ripple } \\
(\%)\end{array}$ \\
\hline 60.9 & 197.2 & 48.9 & 0.580 & 1.21 \\
\hline
\end{tabular}

Lastly, the MISO600 performs the thermal test by applying full load until thermal equilibrium. Figure 5-13 shows the thermal capture. 


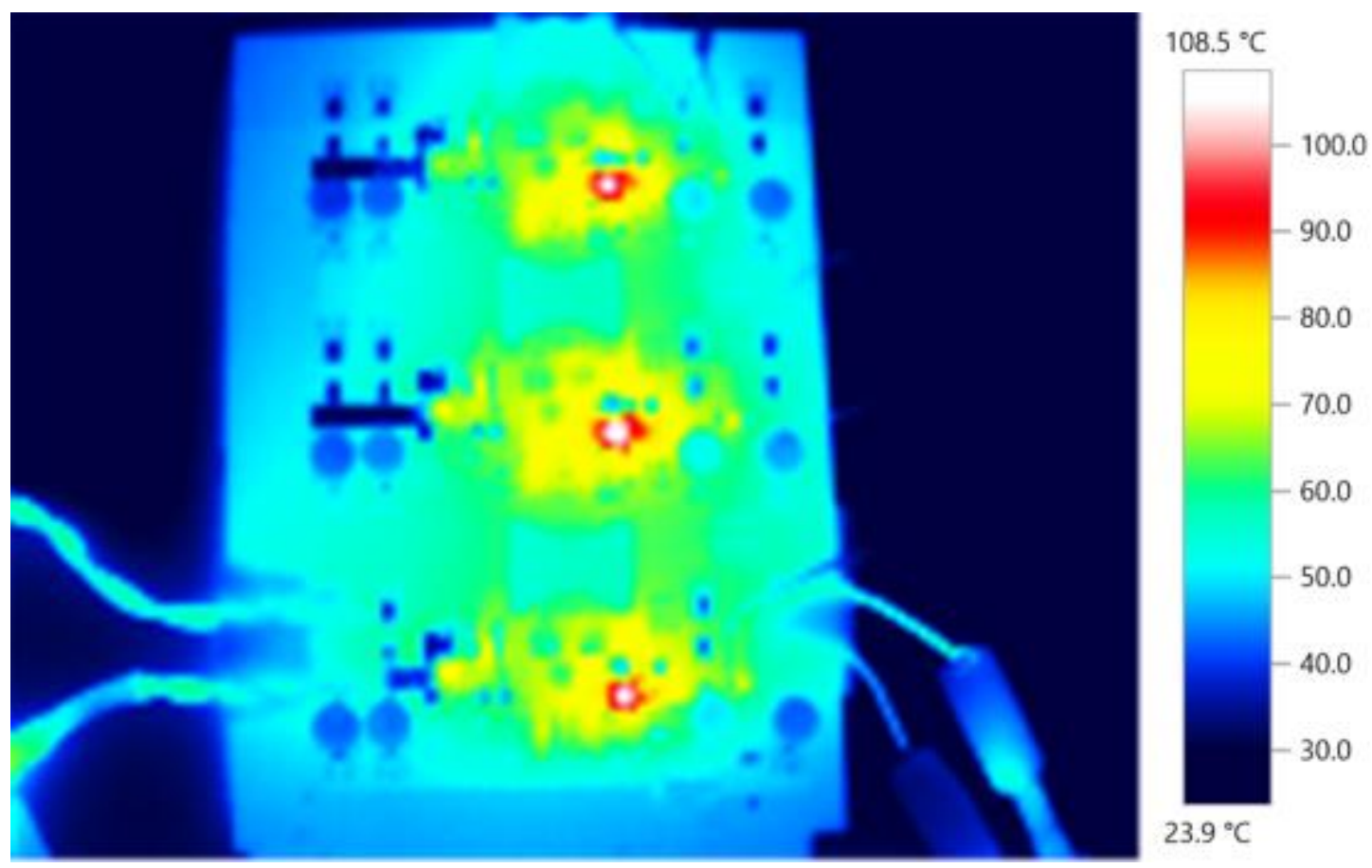

Figure 5-13: MISO600 Thermal Picture

Lastly, this chapter follows MISO1800 testing, or 3 x MISO600 on the MISO motherboard. By placing 3 MISO600 in parallel, the maximum output power becomes $1800 \mathrm{~W}$. The build process involves placing edge connectors on the MISO mother, and then connecting three MISO600. Figure 5-14 shows the populated MISO motherboard along with a picture of all three MISO600 boards connected to it in Figure 5-15. Refer to Appendix B for the bill of materials for the MISO600. The MISO mother uses the 5145246-1 PCI Express connector from TE Connectivity as the edge connectors. 


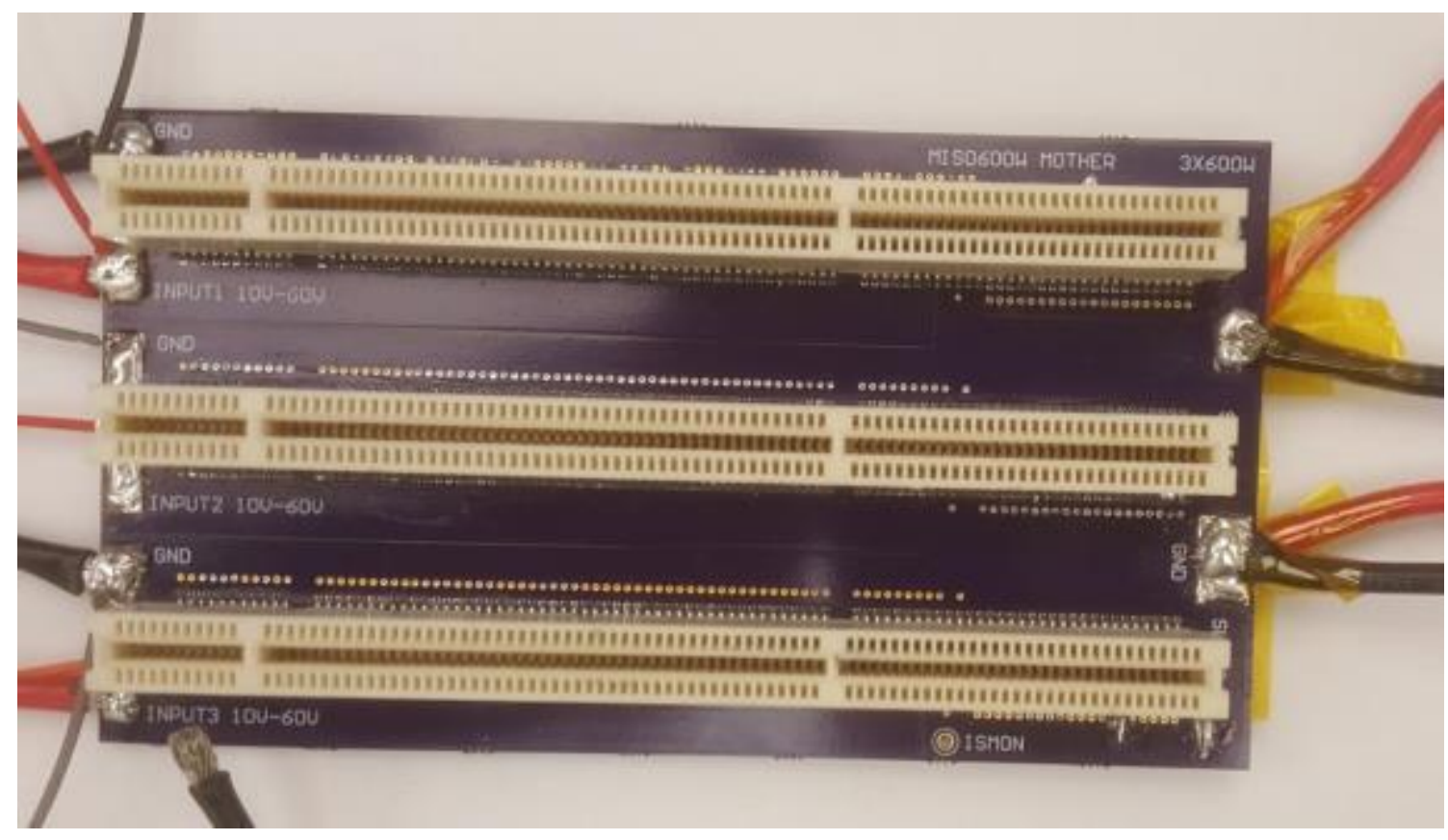

Figure 5-14: Populated MISO mother board 


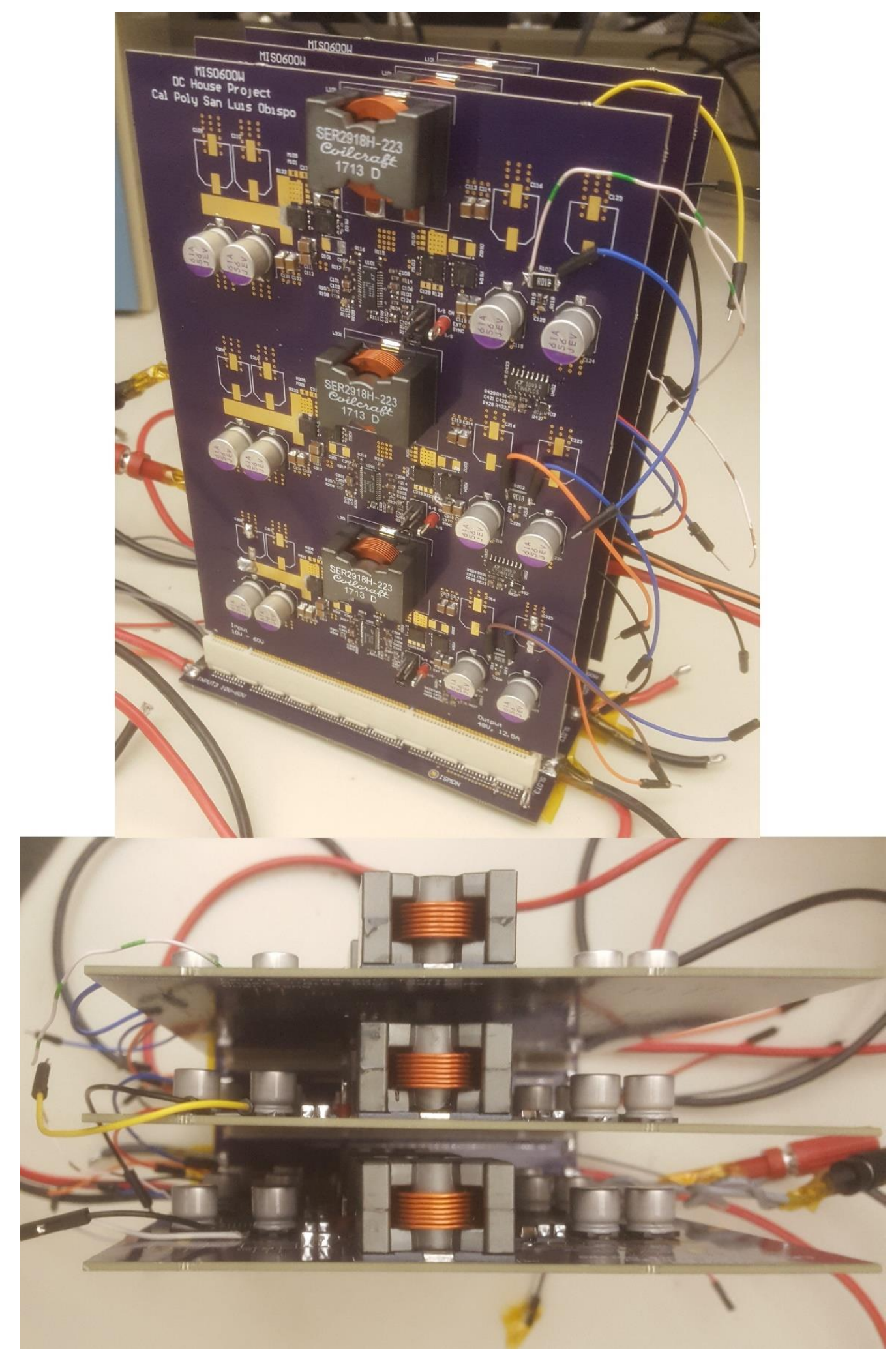

Figure 5-15: Fully Populated MISO1800 
Due to the current drawn from both the input and output of the MISO1800, 12 AWG wires are used to carry the necessary amount of current. Since the MISO1800 takes in multiple inputs, the input uses 3 different power supplies: two Mean Well SE-600-24 fixed voltage power supplies and the HP 6032A power supply. The MISO1800 cannot obtain line regulation due to these fixed voltage power supplies. The output requires the use of the Amrel PLA3K-1000-30 in parallel with the BK Precision 8510 to pull up to 1800W of output power. The test setup uses additional multimeters to probe all 9 channels and each input voltage. Figure 5-16 depicts the MISO1800 test setup.

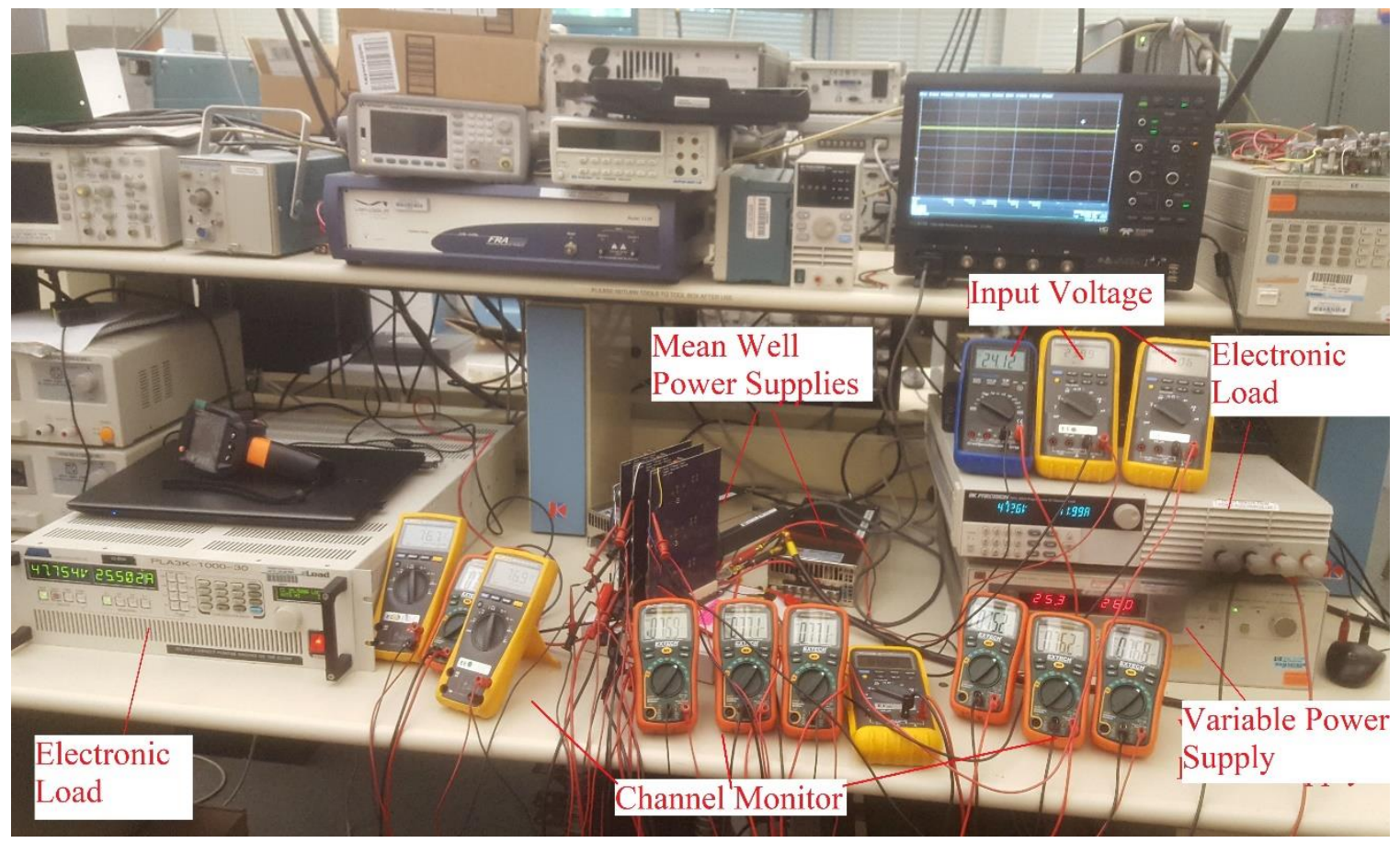

Figure 5-16: MISO1800 Test Setup 
The MISO1800 measures efficiency in this setup by monitoring each input current with a current probe and using the previous setup for input and output voltages. Figure 5-17 shows the efficiency plot for MISO1800 along with the raw data shown in Appendix $\mathrm{E} . \mathrm{V}_{\mathrm{in} 1}$ and $\mathrm{I}_{\mathrm{in} 1}$ corresponds to the input voltage and current for SLOT1 located on the MISO mother.

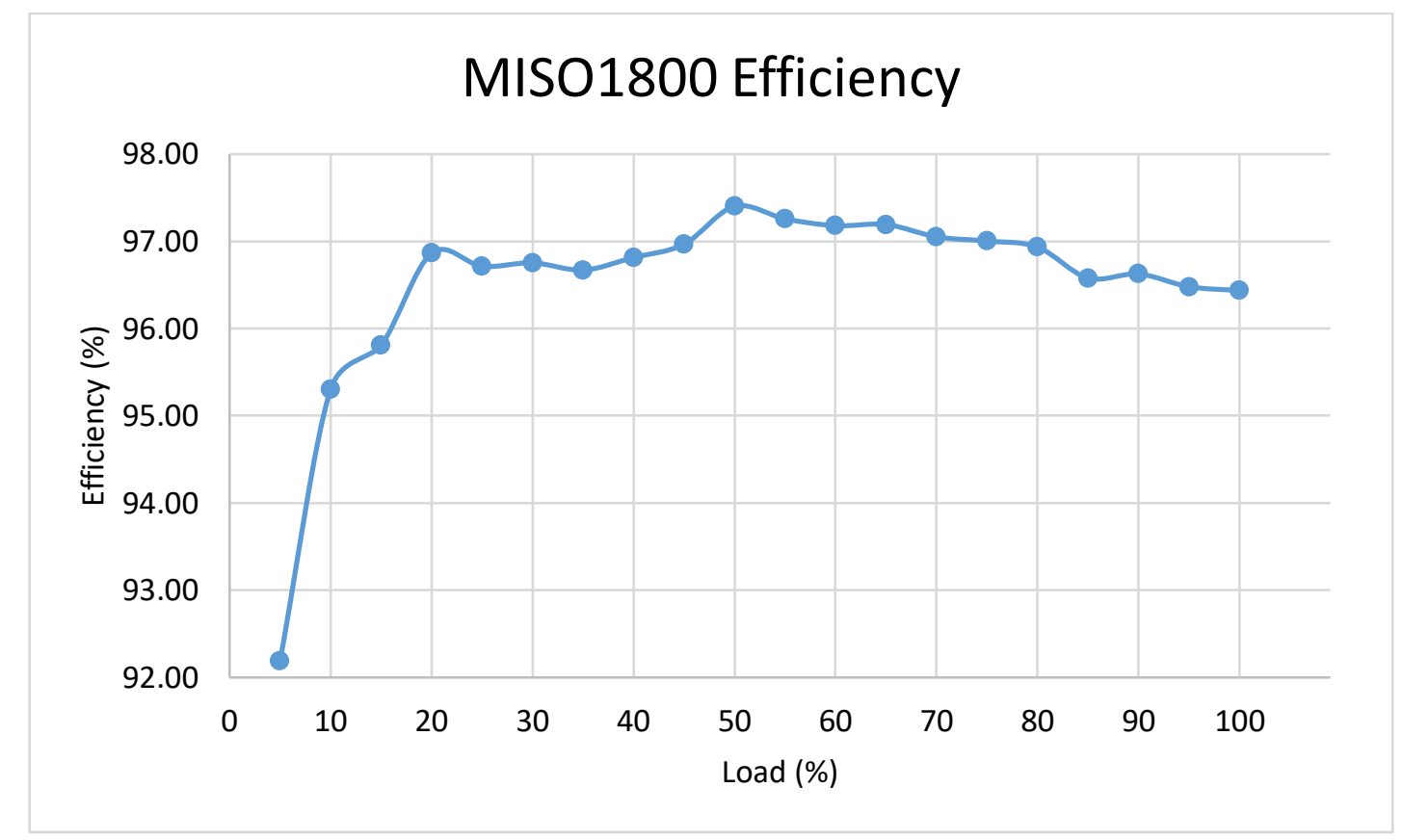

Figure 5-17: MISO1800 Efficiency Plot

Just like the MISO600, the load sharing must be monitored for the MISO1800 to ensure equal load per channel. Table 5-7 shows the calculated current pulled for every channel. Appendix F shows the voltages measured across each sense resistor. Channel 1 refers to the channel on SLOT1 closest to the golden fingers and Channel 9 refers to the channel on SLOT3 furthest from the golden fingers. 
Table 5-7: MISO1800 Load Sharing Per Channel

\begin{tabular}{|c|c|c|c|c|c|c|c|c|c|c|}
\hline $\begin{array}{c}\text { Load } \\
\text { Step } \\
(\%)\end{array}$ & $\begin{array}{c}\text { Theoreti } \\
\text { cal Load } \\
\text { Per } \\
\text { Channel } \\
(\mathrm{A})\end{array}$ & $\begin{array}{c}\text { Actual } \\
\text { Load } \\
\text { Ch1 } \\
(\mathrm{A})\end{array}$ & $\begin{array}{c}\text { Actual } \\
\text { Load } \\
\text { Ch2 } \\
\text { (A) }\end{array}$ & $\begin{array}{c}\text { Actual } \\
\text { Load } \\
\text { Ch3 } \\
\text { (A) }\end{array}$ & $\begin{array}{c}\text { Actual } \\
\text { Load } \\
\text { Ch4 } \\
(\mathrm{A})\end{array}$ & $\begin{array}{c}\text { Actual } \\
\text { Load } \\
\text { Ch5 } \\
(\mathrm{A})\end{array}$ & $\begin{array}{c}\text { Actual } \\
\text { Load } \\
\text { Ch6 } \\
(\mathrm{A})\end{array}$ & $\begin{array}{c}\text { Actual } \\
\text { Load } \\
\text { Ch7 } \\
\text { (A) }\end{array}$ & $\begin{array}{c}\text { Actual } \\
\text { Load } \\
\text { Ch8 } \\
(\mathrm{A})\end{array}$ & $\begin{array}{c}\text { Actual } \\
\text { Load } \\
\text { Ch9 } \\
(\mathrm{A})\end{array}$ \\
\hline 10 & 0.42 & 0.37 & 0.38 & 0.42 & 0.43 & 0.43 & 0.39 & 0.42 & 0.40 & 0.45 \\
\hline 50 & 2.08 & 2.03 & 2.06 & 2.09 & 2.09 & 2.10 & 2.08 & 2.08 & 2.08 & 2.12 \\
\hline 100 & 4.17 & 4.17 & 4.23 & 4.26 & 4.26 & 4.27 & 4.27 & 4.25 & 4.26 & 4.26 \\
\hline
\end{tabular}

Equation 5-8 calculates load regulation, using data from Appendix E.

$$
\text { Load Regulation }=\frac{48.4 \mathrm{~V}-48.2 \mathrm{~V}}{48.2 \mathrm{~V}} * 100 \%=0.414 \%
$$

The MISO1800 measures output voltage ripple by probing the output position on the MISO motherboard at a location closest to its output as well as an arbitrary switchnode. Figure 5-18 displays the waveform capture along with the data summarized in Table 5-8. 


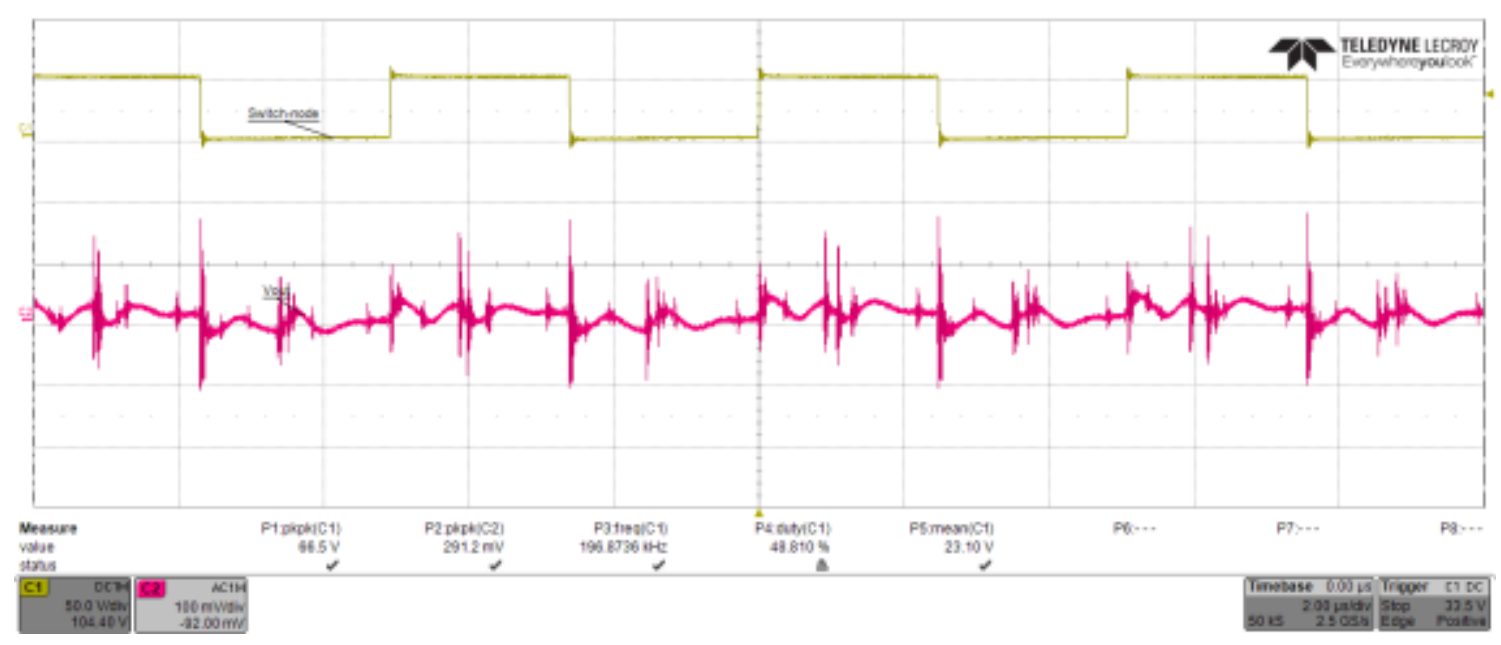

Figure 5-18: MISO1800 Output Voltage Ripple and Switch-Node Waveform

Table 5-8: MISO1800 Output Voltage Ripple and Switch-Node Data

\begin{tabular}{|c|c|c|c|c|}
\hline $\begin{array}{c}\mathrm{V}_{\text {switch-node }} \\
\left(\mathrm{V}_{\mathrm{pk}-\mathrm{pk}}\right)\end{array}$ & $\begin{array}{c}\mathrm{f}_{\mathrm{sw}} \\
(\mathrm{kHz})\end{array}$ & $\begin{array}{c}\text { Duty Cycle } \\
(\%)\end{array}$ & $\begin{array}{c}\mathrm{V}_{\mathrm{o}, \text { ripple }} \\
\left(\mathrm{V}_{\mathrm{pk}-\mathrm{pk}}\right)\end{array}$ & $\begin{array}{c}\% \mathrm{~V}_{\mathrm{o}} \text {, ripple } \\
(\%)\end{array}$ \\
\hline 66.5 & 197.8 & 48.8 & 0.291 & 0.606 \\
\hline
\end{tabular}

For the thermal test, the board operates at full load until thermal equilibrium. The thermal camera snapshots photos at multiple angles to see more thermal images of the MISO1800. Figure 5-19 to Figure 21 shows each snapshot. 

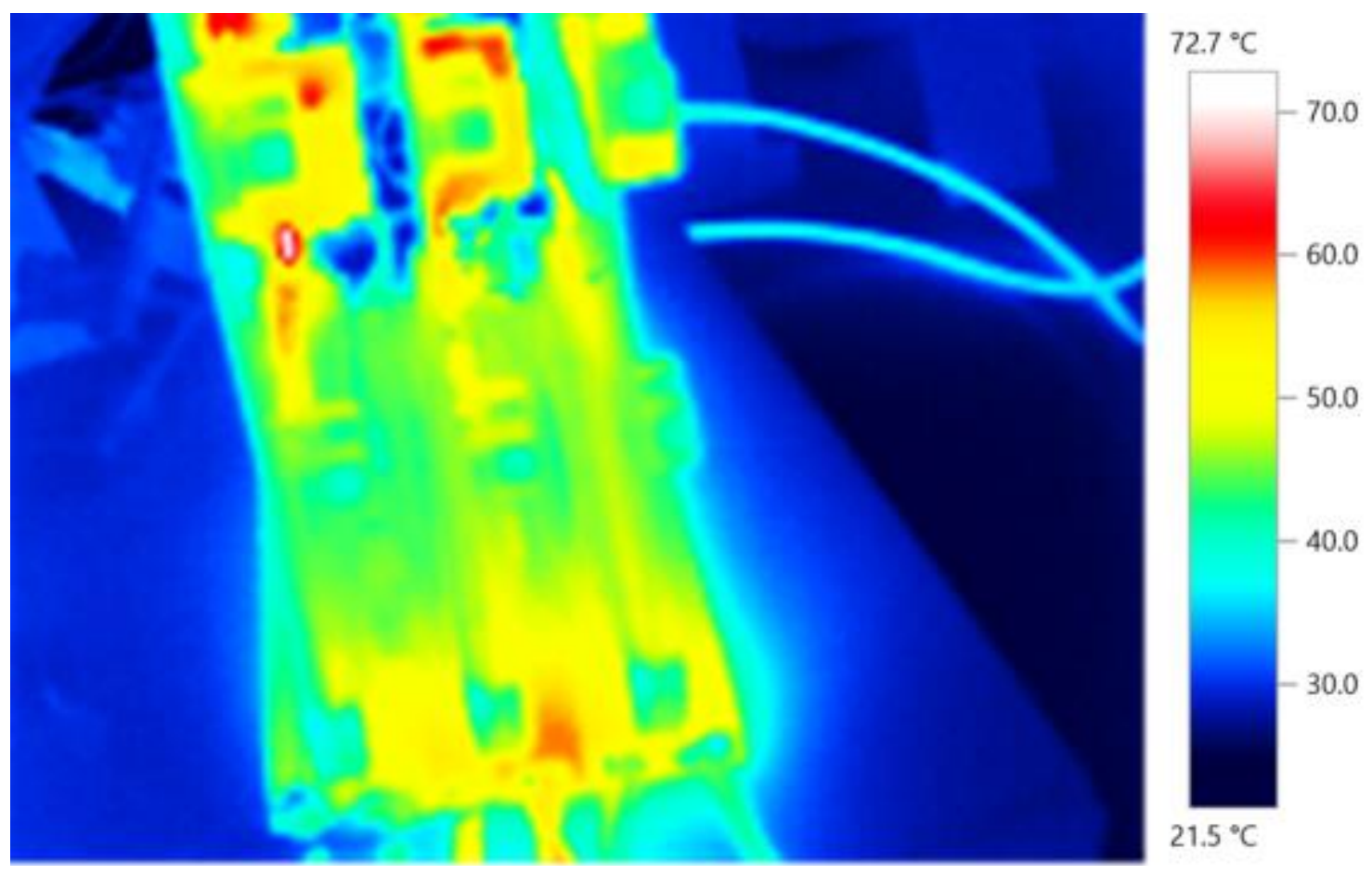

Figure 5-19: MISO1800 Thermal Picture Input Side

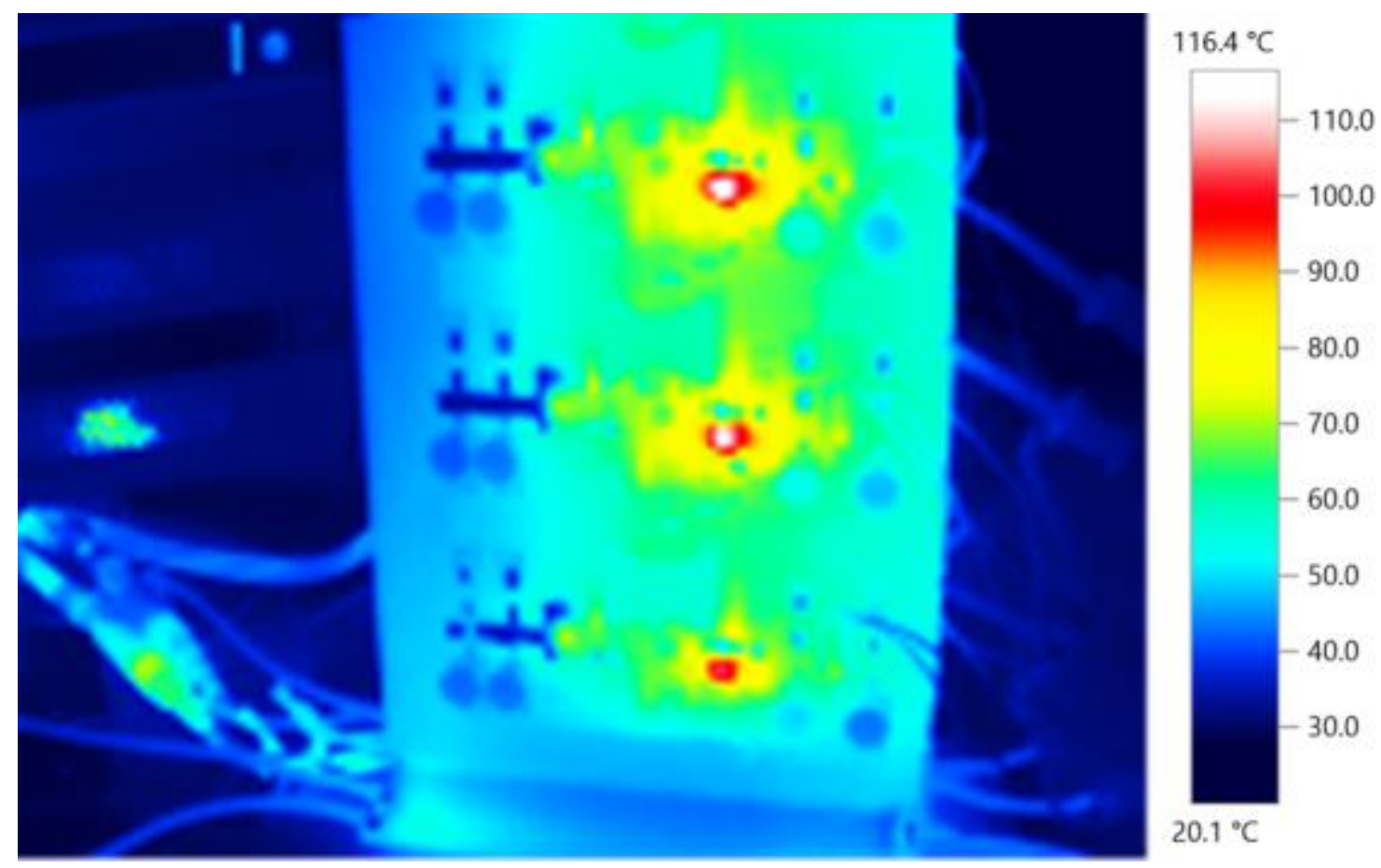

Figure 5-20: MISO1800 Thermal Picture Single Board 


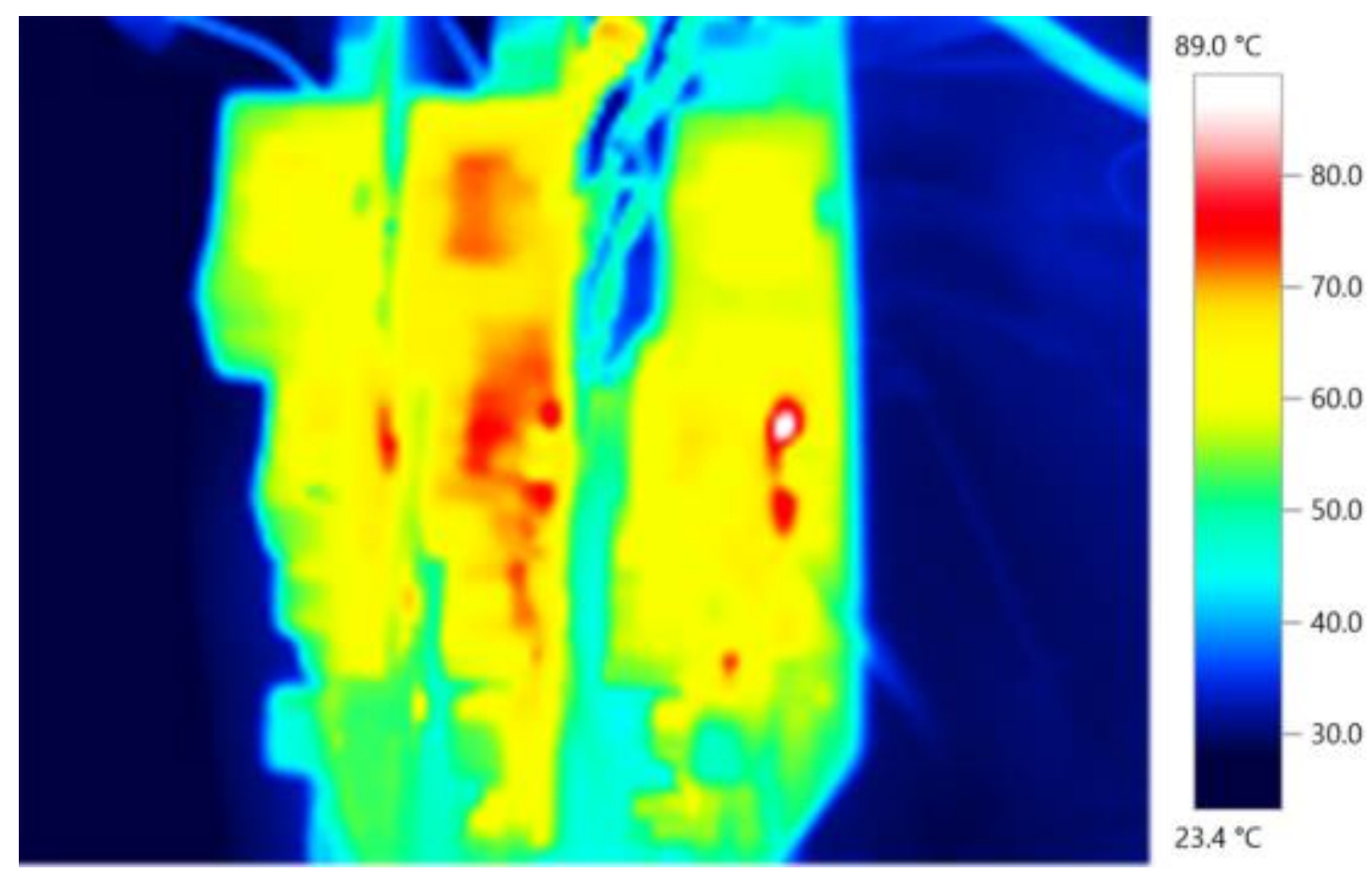

Figure 5-21: MISO1800 Thermal Picture Top View

Since the MISO1800 runs generally hot, about 80 degrees Celsius around the power components, the test setup adds an external DC fan to see how the system reacts to a cooling system. A cooling system is important, since high temperature can lead to a reduced lifetime. This test shows if the suitable cooling system can only consist of this fan. The fan uses an external DC power supply for power. Figures 5-22 to 5-24 show the thermal pictures with the fan. The picture angles replicate the ones used in Figures 5-19 to $5-21$. 


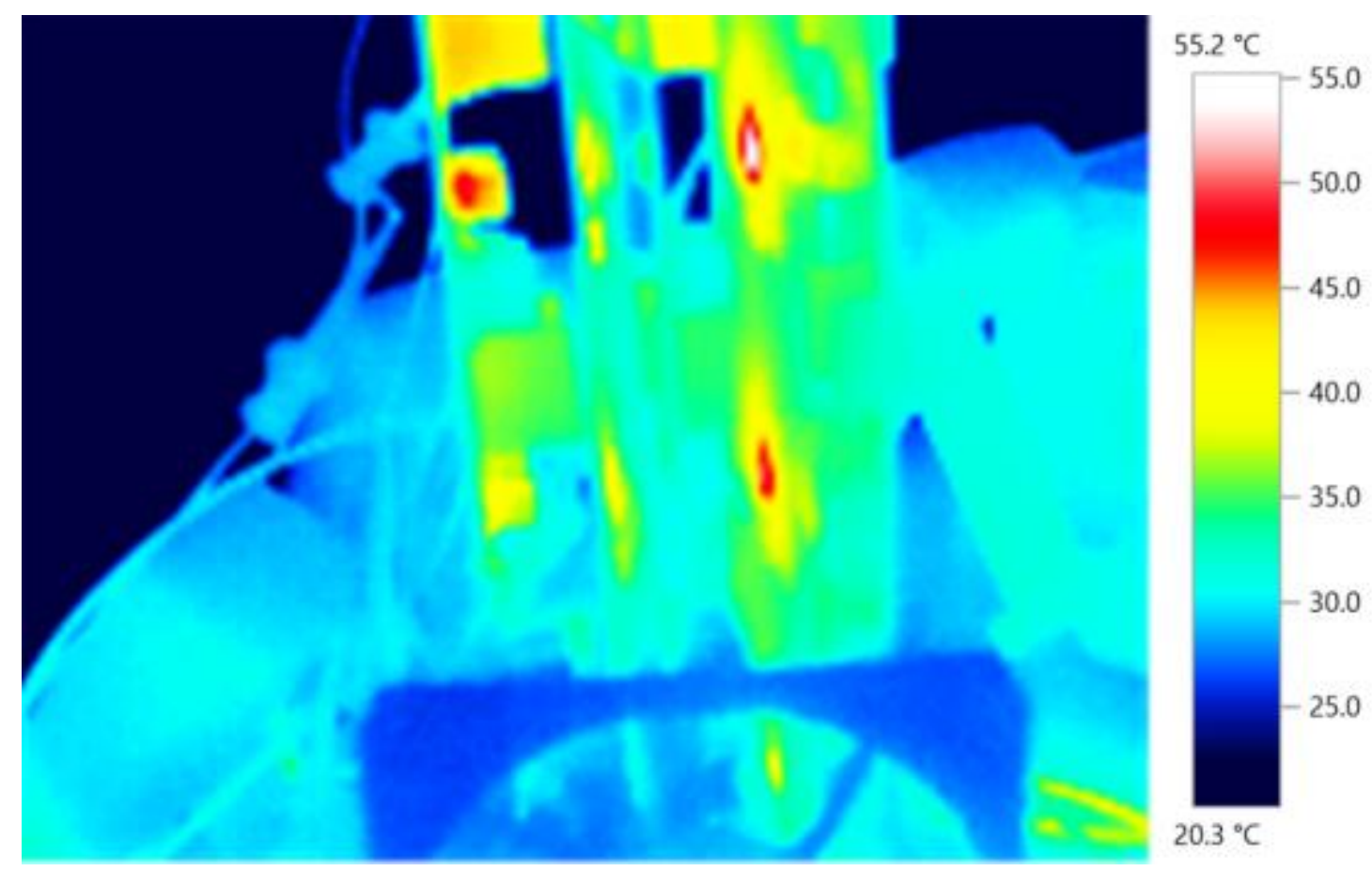

Figure 5-22: MISO1800 with Fan Input Side
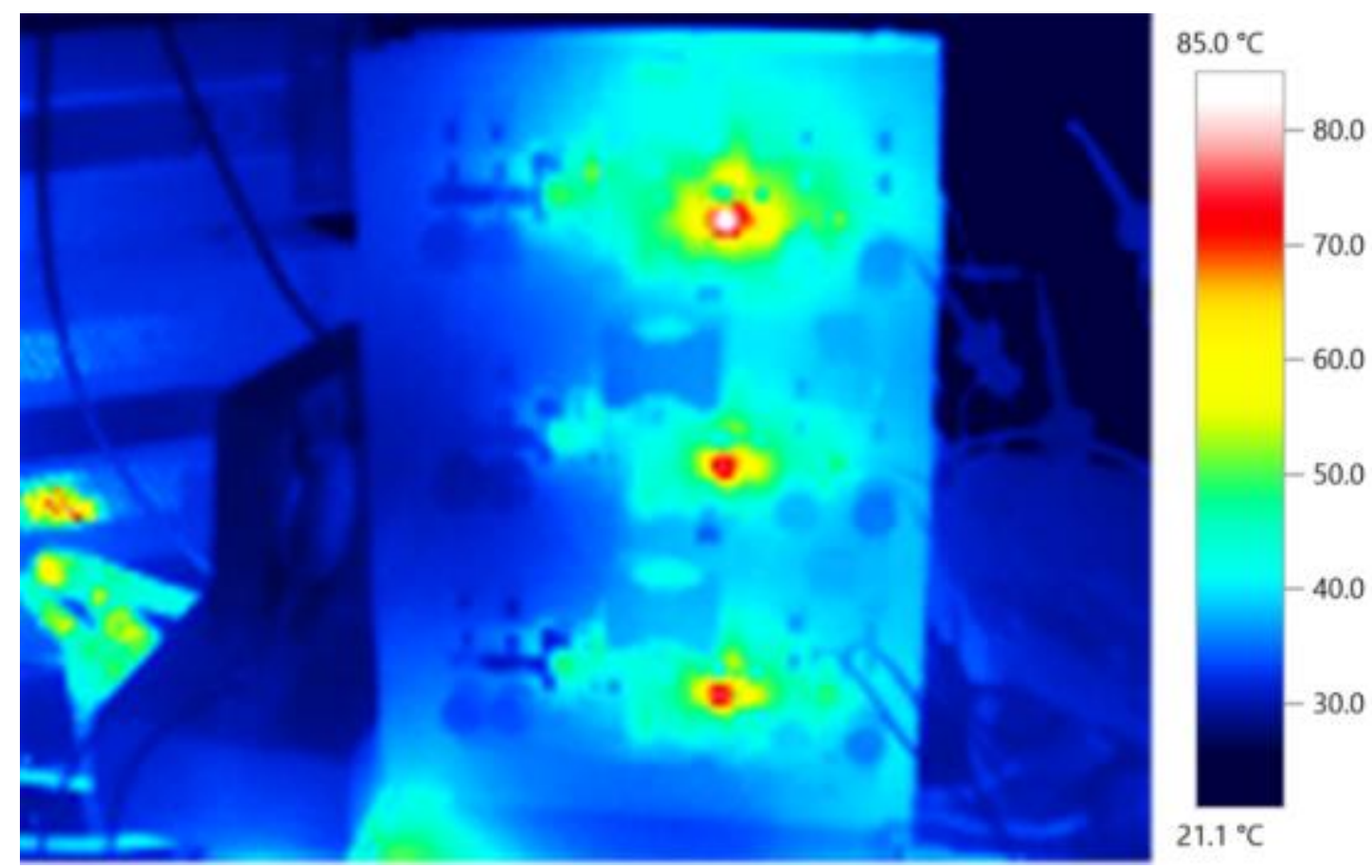

Figure 5-23: MISO1800 with Fan Single Board 


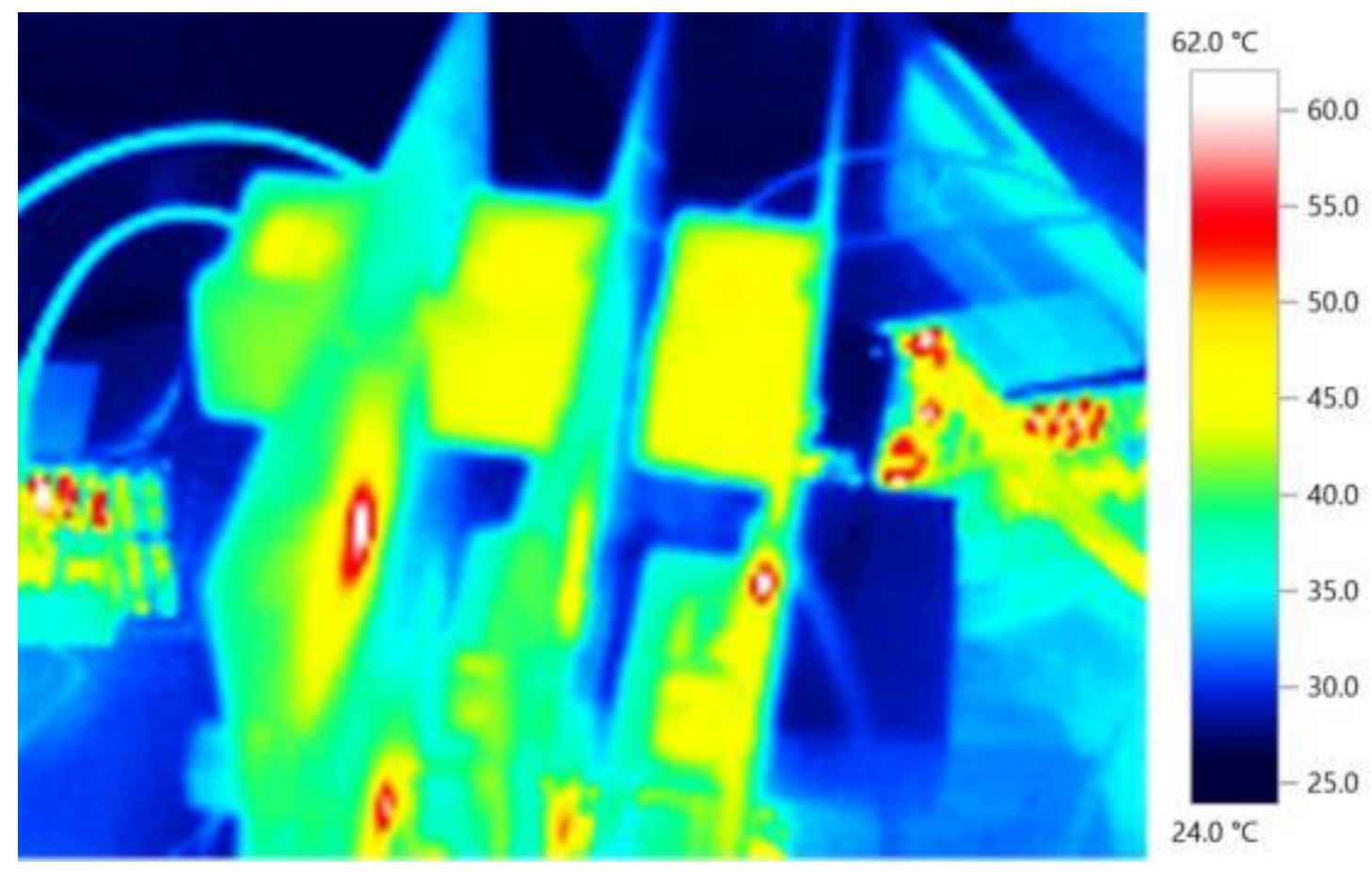

Figure 5-24: MISO1800 with Fan Top View 


\section{Conclusion}

This thesis sought to create a non-isolated Multiple Input Single Output (MISO) power converter that can operate efficiently up to $1800 \mathrm{~W}$ for the DC House project. A four-switch buck-boost converter with the LT8390 as the power controller was chosen for this power converter due primarily to its wide input range capability and flexibility. Implementing current sharing requires additional circuitry, which includes the LT1467. The previous chapters outlined the background, design, and test of the MISO created to meet the specifications stated in Chapter 3. Table 6-1 summarizes the findings of the MISO boards created for this thesis and compares it to the specifications made in Chapter 3.

Table 6-1: Summary of MISO Data

\begin{tabular}{|c|c|c|c|c|}
\hline Test & $\begin{array}{c}\text { Chapter 3 } \\
\text { Specifications }\end{array}$ & MISO200 & MISO600 & MISO1800 \\
\hline Efficiency & $\geq 90 \%$ & $97.2 \%$ at full load & $\begin{array}{c}96.5 \% \text { at full } \\
\text { load }\end{array}$ & $\begin{array}{c}96.4 \% \text { at full } \\
\text { load }\end{array}$ \\
\hline $\begin{array}{c}\text { Line } \\
\text { Regulation }\end{array}$ & $\begin{array}{c}3 \% \text { with 12V } \\
-36 \mathrm{~V} \text { input } \\
\text { at full load }\end{array}$ & $\begin{array}{c}5.19 \% \text { with } 20 \mathrm{~V}- \\
36 \mathrm{~V} \text { at full load, } \\
0.207 \% \text { with } 12 \mathrm{~V} \\
-36 \mathrm{~V} \text { input at } \\
55 \% \text { load }\end{array}$ & $\begin{array}{c}7.12 \% \text { with } \\
1.66 \% \text { at } 57 \% \\
\text { load }\end{array}$ & $\begin{array}{c}\text { N/A due to } \\
\text { fixed input } \\
\text { power supplies }\end{array}$ \\
\hline $\begin{array}{c}\text { Load } \\
\text { Regulation }\end{array}$ & $3 \%$ & $0.830 \%$ & $0.833 \%$ & $0.415 \%$ \\
\hline $\begin{array}{c}\text { Output } \\
\text { Voltage } \\
\text { Ripple }\end{array}$ & $3 \%$ & $3.05 \%$ & $1.21 \%$ & $0.606 \%$ \\
\hline & airflow & $\begin{array}{c}109.9^{\circ} \mathrm{C} \text { peak with } \\
\text { no airflow }\end{array}$ & $\begin{array}{c}108.5^{\circ} \mathrm{C} \text { peak } \\
\text { with no airflow }\end{array}$ & $\begin{array}{c}\text { with no airflow } \\
85.0^{\circ} \mathrm{C} \text { peak } \\
\text { with airflow }\end{array}$ \\
\hline Thermals
\end{tabular}


Table 6-1 shows results that meet the overall objective of this thesis. The efficiency of all three boards falls well within the $90 \%$ specification made in Chapter 3 . Despite combining multiple channels, a maintained efficiency of $97.2 \%$ full load MISO200 to $96.4 \%$ full load MISO1800 occurred. Load regulation also fell within spec throughout the three boards; no more than $0.833 \%$ at full load.

Output voltage ripple specifications fell within spec for the MISO600 and MISO1800 boards, but did not meet the specifications for the MISO200 board. This result did not meet expectations, because the MISO600 and MISO1800 uses the same general layout as the MISO200 board, but only larger. Therefore, the MISO200 board operates slightly noisier than the other boards. Figure 5-7 shows a small low frequency ripple voltage, but a large high frequency voltage spike, occurring at each switch-node transition. Board layout may influence the MISO200 to cause a higher ripple voltage compared to the other two boards. Since the other two boards have longer output voltage track lengths, which connect the output voltages of different modules together, they could dampen the ripple so that the high frequency spikes no longer dominate the overall output ripple voltage. A poor feedback trace for specifically the MISO200. This trace crosses over other traces, which means it could pick up noise that corresponds to noise at the output. Even, it barely falls out of spec, so it does not pose a problem to the overall system.

The concerned metrics include line regulation and thermals. Line regulation of $3 \%$ from $12 \mathrm{~V}$ to $36 \mathrm{~V}$ input failed because input current increases with a decrease in input voltage. The MISO200 was designed for an input voltage of $24 \mathrm{~V}$ and full load of $200 \mathrm{~W}$, so this MISO designed its maximum inductor around it. When the input voltage 
decreases, the current through the inductor exceeds its saturation current rating, which causes the inductor to enter saturation. When the inductor saturates, the converter loses regulation and the output voltage drops. To fix this problem, either a new revision sizes the inductor differently as outlined in Chapter 4, or the output power gets de-rated from $200 \mathrm{~W}$ to about 100W, or 50\% load. The same applies to the MISO600 and MISO1800 boards.

Another addressing concern includes thermals. Referring to the thermals captured in Figures 5-8, 5-13, and 5-20, M03 MOSFET always achieved a temperature above $100^{\circ} \mathrm{C}$ at full load. Although the board operates fine, the MOSFET degrades over time, eventually failing earlier than expected. Therefore, this chapter investigates it further. Referring again to the thermal pictures, $\mathrm{M} 01$ hits about $80^{\circ} \mathrm{C}$ peak temperature. This MOSFET stays on $100 \%$ of the time during the boost mode, which means that it dissipates all its heat through conduction losses. Therefore, the temperature peak on M03 does not relate to conduction, but due to another cause such as switching loss or board layout. Switching losses seems less likely since the duty cycle of the converter equates to nearly 50\%, which means that the low side FET should have the same amount of switching losses as the high side FET. The thermals do not show the high side FET heating up nearly as much, so the issue does not entirely involve switching losses. Future revisions should consider a change in board layout so that the heat can dissipate throughout the pad rather than the component itself. For now, the sufficient cooling system uses a DC fan to cool down the FET, as seen in the thermals shown in Figures 422 to $4-24$. 
Future revisions can improve on more issues other than the single hot MOSFET. For starters, the converter can be optimized for components usage and board space. Input and output capacitance should undergo additional optimization. This MISO uses $2 \mathrm{x}$ $56 \mu \mathrm{F}$ and $4 \times 2.2 \mu \mathrm{F}$ capacitors at both the input and output, which falls well above the critical capacitance values that Chapter 4 calculated. The final design includes extra capacitance to ensure stable performance, since a lack of input and output capacitors can cause instability. By optimizing these capacitances, the overall size of the board and BOM can decrease, making the converter cheaper to build. The inductor should also undergo additional optimization. As discussed in Chapter 4, the buck region sets the critical inductance. Although it is good to have flexibility by having a wide input voltage range, it is a waste to have an inductance that can operate in the buck region when it never reaches the buck region. If a future revision includes a downsized inductor that operates only in the boost region, a larger available collection of inductors becomes more available. This includes inductors that have a larger saturation current so that the converter can achieve a line regulation with a low $\mathrm{V}_{\text {in }}$ of $12 \mathrm{~V}$.

This designed MISO includes additional space for parallel components or for additional features that the MISO could have implemented. This includes space for RC snubbers, Schottky diode in parallel with FETs, parallel inductor $\mathrm{R}_{\text {sense, }}$, additional MOSFETs, additional input and output capacitors, and a couple other small resistors and capacitors that goes with the small signal pins. The size of the board decreases with the removal of these extra pads in the next revision.

Along with the removal of additional space, a future revision should create a better overall layout for a quieter operation. Several locations exist that a new layout can 
improve. First, the gate signal to each FET exhibits unwanted voltage spikes that introduce instability to the control loop. This revision of the MISO uses $4.7 \Omega$ resistors to dampen this noise. These resistors slow down the gate drive, which causes the FETs to have larger switching losses. If this signal became quieter with an improved layout, the new layout could omit the use of these resistors. The output voltage ripple for the MISO200 is slightly larger than specified, as seen in Table 6-1. As stated earlier in this chapter, a shorter feedback trace could lower the output voltage ripple to meet specifications. In addition, the MISO600 board does not have separate analog and power ground, which could result in a quieter ground and a quieter board performance. Lastly, layout can solve the peak temperature $100^{\circ} \mathrm{C}$ on a single MOSFET, as stated earlier in this chapter. Bigger copper pads can act as a bigger heat sink for the MOSFET, which could cause the peak temperature could drop. Other than these specific locations, an improvement could include creating a layout that has fewer crossing traces. A simple solution involves adding two additional layers to the board so that the sensitive traces can exist on a non-power layer, which would reduce the coupled noise. This version of the MISO did not do this due to the additional cost of a four-layer board. Future revisions should consider using a four-layer board for quieter performance.

Overall, the MISO designed in this thesis successfully meets the design requirements as reported in this thesis. It performs efficiently and utilizes equal current sharing. By creating a higher power solution, the applications of the DC House may now extend to urban areas which typically needs large amounts of power to fit their everyday needs. Therefore, the DC House will grow as a more feasible alternative to residential power systems and can develop into a real solution that makes the world greener. 


\section{REFERENCES}

[1] "International energy outlook 2016-World energy demand and economic outlook energy information administration," 2016. [Online]. Available:

http://www.eia.gov/forecasts/ieo/world.cfm. Accessed: Jan. 10, 2017.

[2] "Population," in United States Census. [Online]. Available:

http://www.census.gov/population/international/data/idb/worldpoptotal.php. Accessed: Jan. 10, 2017.

[3] OECD, "Energy poverty," in International Energy Agency, 2017. [Online]. Available: http://www.iea.org/topics/energypoverty/. Accessed: Jan. 10, 2017.

[4] OECD, "WEO - energy access database," in International Energy Agency, 2017. [Online]. Available:

http://www.worldenergyoutlook.org/resources/energydevelopment/energyaccessdat abase/. Accessed: Jan. 10, 2017.

[5] Taufik, "The DC House Project," 2014. [Online]. Available: http://www.calpoly.edu/ taufik/dchouse/projects.html. Accessed: Jan. 10, 2017.

[6] EIA, "International energy outlook 2016-Electricity - energy information administration," 2016. [Online]. Available: http://www.eia.gov/forecasts/ieo/electricity.cfm. Accessed: Jan. 11, 2017.

[7] EESI, "Fossil fuels,". [Online]. Available: http://www.eesi.org/topics/fossilfuels/description. Accessed: Jan. 11, 2017.

[8] energy.gov, "Off-grid or stand-alone renewable energy systems,". [Online]. Available: http://energy.gov/energysaver/grid-or-stand-alone-renewable-energysystems. Accessed: Jan. 14, 2017. 
[9] A. Lantero, "The war of the currents: AC vs. DC power," Energy.gov. [Online]. Available: http://www.energy.gov/articles/war-currents-ac-vs-dc-power. Accessed: Jan. 15, 2017.

[10] T. G. Wilson, "The evolution of power electronics," IEEE Transactions on Power Electronics, vol. 15, no. 3, pp. 439-446, May 2000.

[11] Nithya. ., "MULTI-INPUT DC-DC CONVERTER FOR RENEWABLE ENERGY SOURCES," International Journal of Research in Engineering and Technology, vol. 03, no. 19, pp. 714-719, May 2014.

[12] Z. Li, O. Onar, A. Khaligh, and E. Schaltz, "Design and control of a multiple input DC/DC converter for battery/ultra-capacitor based electric vehicle power system," 2009 Twenty-Fourth Annual IEEE Applied Power Electronics Conference and Exposition, Feb. 2009.

[13] A. Thiyagarajan and B. Gokulavasan, "Design of Four input Buck-Boost DC-DC Converter for Renewable Energy Application," SSRG-IJIE, vol. 1, no. 2, 2014. [Online]. Available: http://docplayer.net/13332578-Design-of-four-input-buckboost-dc-dc-converter-for-renewable-energy-application.html. Accessed: Mar. 6, 2017.

[14] T.-C. Ou, W.-M. Lin, and C.-H. Huang, "A multi-input power converter for hybrid renewable energy generation system," 2009 IEEE PES/IAS Conference on Sustainable Alternative Energy (SAE), Sep. 2009.

[15] R. Zhao and A. Kwasinski, "Multiple-input single ended primary inductor converter (SEPIC) converter for distributed generation applications," 2009 IEEE Energy Conversion Congress and Exposition, Sep. 2009. 
[16] Y. . Chen, Y. . Liu, and S. . Lin, "Double-input PWM DC/DC converter for high/low-voltage sources," IEEE Transactions on Industrial Electronics, vol. 53, no. 5, pp. $1538-1545$, Oct. 2006.

[17] B. Immanuel, S. A, and R. M R, "A Novel Multi Input Converter for Three NonConventional Energy Sources with Reduced Complexity for a Three Phase Induction Motor," in ICEECE'2014, Antalya, Turkey: ICEECE, 2014.

[18] V. Sriniva, E. Kumar, and K. Bhavya, "A Two Input Single Output Z-Sourced DcDc Converter for Renewable Applications," IJMER, vol. 2, no. 5, pp. 3861-3868, 2012.

[19] S. Liu, X. Zhang, H. Guo, and J. Xie, "Multiport DC/DC converter for stand-alone Photovoltaic lighting system with battery storage," 2010 International Conference on Electrical and Control Engineering, Jun. 2010.

[20] S. Mahapatra and A. Tamhane, "DESIGN AND BUILDING OF MULTIPLE INPUT SINGLE OUTPUT DC-DC CONVERTER," IJESRT, Jun. 2015.

[21] C. Wong, "A MULTIPLE-INPUT SINGLE-OUTPUT DC-DC CONVERTER FOR THE DC HOUSE PROJECT," M.S. thesis, Elect. Eng. Dept., Cal Poly Univ., San Luis Obispo, CA, 2011.

[22] O. Jong, "Multiple Input Single Output (MISO) DC-DC Converter for the DC House Project," Sr. Project Report, Elect. Eng. Dept., Cal Poly Univ., San Luis Obispo, CA, 2012.

[23] A. Kwasinski, "Identification of feasible Topologies for multiple-input DC-DC converters," IEEE Transactions on Power Electronics, vol. 24, no. 3, pp. 856-861, Mar. 2009. 
[24] R. Hult, "Renaissance of the edge connector," in Technology, Connector and Cable Assembly Supplier, 2012. [Online]. Available:

http://www.connectorsupplier.com/080712-tech-article-hult-edge-connectors. Accessed: Feb. 15, 2017.

[25] D. Kwan and M. Krug, "Hydro-Electric Generation System for the DC House Project," M.S. thesis, Elect. Eng. Dept., Cal Poly Univ., San Luis Obispo, CA, 2011.

[26] E. Lim and S. Liu, "Wind power generator design for the DC house project," M.S. thesis, Elect. Eng. Dept., Cal Poly Univ., San Luis Obispo, CA, 2011.

[27] L. B. Perez and H. M. Mai, "Photovoltaic System Design for DC House," M.S. thesis, Elect. Eng. Dept., Cal Poly Univ., San Luis Obispo, CA, 2011.

[28] J. E. Chaidez, "DC house modeling and system design," M.S. thesis, Elect. Eng. Dept., Cal Poly Univ., San Luis Obispo, CA, 2011.

[29] J. J. Crowfoot, "Design and modeling of the Cal Poly DC house power distribution system," M.S. thesis, Elect. Eng. Dept., Cal Poly Univ., San Luis Obispo, CA, 2011.

[30] "ABS alternative energy store," 2000. [Online]. Available: http://www.absak.com/library/power-consumption-table. Accessed: Feb. 15, 2017.

[31] M. Muscarella, J. Mitchell, and Taufik, "Design Considerations of Diode Source Protection in Multiple Buck Converter", presented at Proc. of International Conference on Applied Electrical, Electronics, and Informatics Engineering, Pontianak, West Kalimantan, Indonesia, July 2016. 
[32] Linear Technology, "60V Synchronous 4-Switch Buck-Boost Controller with Spread Spectrum,” LT8390 datasheet, 2016.

[33] Altium Designer. Altium, 2017.

[34] "Salary: Electrical Engineer", Glassdoor, 2017. [Online]. Available: https://www.glassdoor.com/Salaries/electrical-engineer-salary-SRCH_KO0,19.htm. [Accessed: 02- Jun- 2017].

[35] "Community Choice Energy | Local Clean Energy Alliance of the Bay Area", Localcleanenergy.org, 2017. [Online]. Available: http://www.localcleanenergy.org/policy-platform/community-choice. [Accessed: 02- Jun- 2017].

[36] "NREL: Energy Analysis - Energy Technology Cost and Performance Data", Nrel.gov, 2017. [Online]. Available: http://www.nrel.gov/analysis/tech_lcoe_re_cost_est.html. [Accessed: 02- Jun2017]. 


\section{APPENDICES}

\section{Appendix A: MISO200 Bill of Materials}

\begin{tabular}{|c|c|c|c|c|}
\hline Designator & Quantity & Value & Description & Part Number \\
\hline C01, C06 & 2 & $1 \mathrm{uF}$ & 0805 Cap & \\
\hline $\mathrm{C} 02$ & 1 & $4.7 \mathrm{uF}$ & 0603 Cap & \\
\hline $\mathrm{C} 03$ & 1 & $0.47 \mathrm{uF}$ & 0603 Cap & \\
\hline C04 & 1 & $3.3 \mathrm{nF}$ & 0603 Cap & \\
\hline $\mathrm{C} 05, \mathrm{C} 07, \mathrm{C} 08$ & 3 & $0.1 \mathrm{uF}$ & 0603 Cap & \\
\hline $\begin{array}{c}\mathrm{C} 09, \mathrm{C} 10, \mathrm{C} 15, \\
\mathrm{C} 16, \mathrm{C} 17, \mathrm{C} 18, \\
\mathrm{C} 23, \mathrm{C} 24\end{array}$ & 4 & $56 \mathrm{uF}$ & $\begin{array}{l}\text { Aluminum } \\
\text { Electrolytic } \\
\text { Capacitor }\end{array}$ & EEHZA1J560P \\
\hline $\begin{array}{l}\text { C11, C12, C13, } \\
\text { C14, C19, C20, } \\
\text { C } 31, \text { C } 32\end{array}$ & 8 & $2.2 \mathrm{uF}$ & 1210 Cap & $\begin{array}{c}\text { GRM32ER72A225KA3 } \\
\text { 5L }\end{array}$ \\
\hline $\mathrm{C} 21, \mathrm{C} 22, \mathrm{C} 25$ & 3 & $10 \mathrm{nF}$ & 0603 Cap & \\
\hline C26, C28 & 0 & NOPOP & 0603 Cap & \\
\hline C29, C30 & 0 & NOPOP & 0805 Cap & \\
\hline R01 & 1 & $4 \mathrm{~m}$ & 2512 Res & CSNL2512FT4L00 \\
\hline R02 & 1 & $18 \mathrm{~m}$ & 2512 Res & RLP73V3AR018FTDF \\
\hline R03 & 1 & $226 \mathrm{k}$ & 0603 Res & \\
\hline R04 & 1 & $14.3 \mathrm{k}$ & 0603 Res & \\
\hline R05 & 1 & $499 \mathrm{k}$ & 0603 Res & \\
\hline R06 & 1 & $21.5 \mathrm{k}$ & 0603 Res & \\
\hline R07 & 1 & $604 \mathrm{k}$ & 0603 Res & \\
\hline $\begin{array}{l}\text { R08, R09, R11, } \\
\text { R12, R29, R32 }\end{array}$ & 6 & $100 \mathrm{k}$ & 0603 Res & \\
\hline R10 & 0 & NOPOP & 0603 Res & \\
\hline R13 & 1 & $511 \mathrm{k}$ & 0603 Res & \\
\hline $\begin{array}{l}\text { R14, R15, R16, } \\
\text { R17 }\end{array}$ & 4 & 4.7 & 0603 Res & \\
\hline
\end{tabular}




\begin{tabular}{|c|c|c|c|c|}
\hline R18, R19 & 2 & $1 \mathrm{k}$ & 0603 Res & \\
\hline R22, R23 & 0 & NOPOP & 0805 Res & \\
\hline R30 & 0 & NO POP & 2512 Res & \\
\hline R27, R28, R31 & 3 & $10 \mathrm{k}$ & 0603 Res & \\
\hline R33 & 1 & $383 \mathrm{k}$ & 0603 Res & \\
\hline U01 & 1 & LT8390 & 28-pin SOP & LT8390EFE\#PBF \\
\hline U02 & 1 & LT1467 & $\begin{array}{l}\text { 16-pin } \\
\text { SOIC }\end{array}$ & LT1467LCS \\
\hline D01, D02 & 0 & NOPOP & 2-Pin SMB & \\
\hline D03 & 1 & $\begin{array}{c}\text { MBR0520LT } \\
1\end{array}$ & 2-Pin SMB & MBR0520LT1 \\
\hline JP01 & 1 & $3 \times 2$ & $\begin{array}{l}\text { Header, 3- } \\
\text { Pin, Dual } \\
\text { row }\end{array}$ & 67997-410HLF \\
\hline JP02, JP03 & 2 & $2 \times 2$ & $\begin{array}{l}\text { Header, 2- } \\
\text { Pin, Dual } \\
\text { row }\end{array}$ & 67997-410HLF \\
\hline L01 & 1 & $22 \mathrm{uH}$ & Inductor & SER2918H-223KL \\
\hline $\begin{array}{c}\text { M01, M02, M03, } \\
\text { M04 }\end{array}$ & 4 & $\begin{array}{c}\text { FDMS86520 } \\
\text { L }\end{array}$ & 5 Pin DFN & FDMS86520L \\
\hline M05, M07 & 0 & NOPOP & 5 Pin DFN & FDMS86520L \\
\hline $\begin{array}{l}\text { CHILD2PAREN } \\
\text { T, GND Input, } \\
\text { Output, } \\
\text { PARENT2CHIL } \\
\text { D }\end{array}$ & 6 & Banana Jack & & Keystone 575-8 \\
\hline EXT SYNC & 1 & $\begin{array}{l}\text { Test Point, } \\
\text { Red }\end{array}$ & & Keystone 5010 \\
\hline Standoffs & 4 & & & \\
\hline Standoff nuts & 4 & & & \\
\hline Header Jumpers & 3 & & & \\
\hline
\end{tabular}




\section{Appendix B: MISO600 Bill of Materials}

\begin{tabular}{|c|c|c|c|c|}
\hline Designator & Quantity & Value & Description & Part Number \\
\hline Cx01, Cx06 & 6 & $1 \mathrm{uF}$ & 0805 Cap & \\
\hline $\mathrm{Cx} 02$ & 3 & $4.7 \mathrm{uF}$ & 0603 Cap & \\
\hline $\mathrm{Cx} 03$ & 3 & $0.47 \mathrm{uF}$ & 0603 Cap & \\
\hline Cx04 & 3 & $3.3 \mathrm{nF}$ & 0603 Cap & \\
\hline $\begin{array}{c}\text { Cx05, Cx } 07, \\
\text { Cx08 }\end{array}$ & 9 & $0.1 \mathrm{uF}$ & 0603 Cap & \\
\hline $\begin{array}{l}\text { Cx09, Cx10, } \\
\text { Cx15, Cx16, } \\
\text { Cx17, Cx18, } \\
\text { Cx23, Cx24 }\end{array}$ & 12 & $56 \mathrm{uF}$ & $\begin{array}{c}\text { Aluminum } \\
\text { Electrolytic } \\
\text { Capacitor }\end{array}$ & EEHZA1J560P \\
\hline $\begin{array}{l}\text { Cx11, Cx12, } \\
\text { Cx13, Cx14, } \\
\text { Cx19, Cx20, } \\
\text { Cx31, Cx32 }\end{array}$ & 24 & $2.2 \mathrm{uF}$ & 1210 Cap & $\begin{array}{c}\text { GRM32ER72A225KA35 } \\
\text { L }\end{array}$ \\
\hline $\begin{array}{c}\mathrm{Cx} 21, \mathrm{Cx} 22, \\
\text { Cx25 }\end{array}$ & 9 & $10 \mathrm{nF}$ & 0603 Cap & \\
\hline Сx26, Сx28 & 0 & NOPOP & 0603 Cар & \\
\hline $\mathrm{Cx} 29, \mathrm{Cx} 30$ & 0 & NOPOP & 0805 Cap & \\
\hline $\mathrm{Rx} 01$ & 3 & $4 \mathrm{~m}$ & 2512 Res & CSNL2512FT4L00 \\
\hline $\mathrm{Rx} 02$ & 3 & $18 \mathrm{~m}$ & 2512 Res & RLP73V3AR018FTDF \\
\hline $\mathrm{Rx} 03$ & 3 & $226 \mathrm{k}$ & 0603 Res & \\
\hline $\mathrm{Rx} 04$ & 3 & $14.3 \mathrm{k}$ & 0603 Res & \\
\hline $\mathrm{Rx} 05$ & 3 & $499 \mathrm{k}$ & 0603 Res & \\
\hline $\mathrm{Rx} 06$ & 3 & $21.5 \mathrm{k}$ & 0603 Res & \\
\hline $\mathrm{Rx} 07$ & 3 & $604 \mathrm{k}$ & 0603 Res & \\
\hline $\begin{array}{l}\mathrm{Rx} 08, \mathrm{Rx} 09, \\
\mathrm{Rx} 11, \mathrm{Rx} 12, \\
\mathrm{Rx} 29, \mathrm{Rx} 32\end{array}$ & 18 & $100 \mathrm{k}$ & 0603 Res & \\
\hline $\mathrm{Rx} 10$ & 0 & NOPOP & 0603 Res & \\
\hline $\mathrm{Rx} 13$ & 3 & $511 \mathrm{k}$ & 0603 Res & \\
\hline
\end{tabular}




\begin{tabular}{|c|c|c|c|c|}
\hline $\begin{array}{l}\mathrm{Rx} 14, \mathrm{R} \times 15, \\
\mathrm{R} \times 16, \mathrm{R} \times 17\end{array}$ & 12 & 4.7 & 0603 Res & \\
\hline Rx18, Rx19 & 6 & $1 \mathrm{k}$ & 0603 Res & \\
\hline $\mathrm{Rx} 22, \mathrm{Rx} 23$ & 0 & NOPOP & 0805 Res & \\
\hline $\mathrm{R} \times 30$ & 0 & NO POP & 2512 Res & \\
\hline $\begin{array}{c}\mathrm{R} \times 27, \mathrm{Rx} 28, \\
\mathrm{R} \times 31\end{array}$ & 9 & $10 \mathrm{k}$ & 0603 Res & \\
\hline $\mathrm{Rx} 33$ & 3 & $383 \mathrm{k}$ & 0603 Res & \\
\hline Ux01 & 3 & LT8390 & 28-pin SOP & LT8390EFE\#PBF \\
\hline Ux02 & 3 & LT1467 & 16-pin SOIC & LT1467LCS \\
\hline Dx01, Dx02 & 0 & NOPOP & 2-Pin SMB & \\
\hline Dx03 & 3 & $\begin{array}{c}\text { MBR0520LT } \\
1\end{array}$ & 2-Pin SMB & MBR0520LT1 \\
\hline JPx01 & 3 & $3 \times 2$ & $\begin{array}{l}\text { Header, 3- } \\
\text { Pin, Dual } \\
\text { row }\end{array}$ & 67997-410HLF \\
\hline Lx01 & 3 & $22 \mathrm{uH}$ & Inductor & SER2918H-223KL \\
\hline $\begin{array}{l}\text { Mx01, Mx02, } \\
\text { Mx03, Mx04 }\end{array}$ & 12 & FDMS86520L & 5 Pin DFN & FDMS86520L \\
\hline Mx05, Mx07 & 0 & NOPOP & 5 Pin DFN & FDMS86520L \\
\hline EXT SYNCx & 3 & $\begin{array}{l}\text { Test Point, } \\
\text { Red }\end{array}$ & & Keystone 5010 \\
\hline $\begin{array}{l}\text { Header } \\
\text { Jumpers }\end{array}$ & 3 & & & \\
\hline
\end{tabular}




\section{Appendix C: MISO200 Efficiency Raw Data}

\begin{tabular}{|c|c|c|c|c|c|c|}
\hline $\begin{array}{l}\text { Load } \\
\text { Step } \\
(\%)\end{array}$ & $\begin{array}{c}\mathrm{P}_{\mathrm{o}} \\
\text { (W) }\end{array}$ & $\begin{array}{l}\mathrm{V}_{\text {in }} \\
(\mathrm{V})\end{array}$ & $\begin{array}{l}\mathrm{I}_{\text {in }} \\
\text { (A) }\end{array}$ & $\begin{array}{l}\mathrm{V}_{\mathrm{o}} \\
(\mathrm{V})\end{array}$ & $\begin{array}{c}\mathrm{I}_{\mathrm{o}} \\
\text { (A) }\end{array}$ & $\begin{array}{c}\text { Efficiency } \\
(\%)\end{array}$ \\
\hline 5 & 10.08 & 24.00 & 0.46 & 48.40 & 0.21 & 91.33 \\
\hline 10 & 20.17 & 24.00 & 0.89 & 48.40 & 0.42 & 94.41 \\
\hline 15 & 30.25 & 24.01 & 1.30 & 48.40 & 0.63 & 96.91 \\
\hline 20 & 40.25 & 24.01 & 1.74 & 48.30 & 0.83 & 96.34 \\
\hline 25 & 50.31 & 24.01 & 2.16 & 48.30 & 1.04 & 97.01 \\
\hline 30 & 60.38 & 24.01 & 2.59 & 48.30 & 1.25 & 97.09 \\
\hline 35 & 70.44 & 24.00 & 3.01 & 48.30 & 1.46 & 97.50 \\
\hline 40 & 80.50 & 24.00 & 3.44 & 48.30 & 1.67 & 97.50 \\
\hline 45 & 90.38 & 24.01 & 3.88 & 48.20 & 1.88 & 97.01 \\
\hline 50 & 100.42 & 24.00 & 4.28 & 48.20 & 2.08 & 97.76 \\
\hline 55 & 110.46 & 24.01 & 4.71 & 48.20 & 2.29 & 97.68 \\
\hline 60 & 120.50 & 24.00 & 5.14 & 48.20 & 2.50 & 97.68 \\
\hline 65 & 130.54 & 24.01 & 5.56 & 48.20 & 2.71 & 97.79 \\
\hline 70 & 140.58 & 24.00 & 6.00 & 48.20 & 2.92 & 97.63 \\
\hline 75 & 150.63 & 24.00 & 6.44 & 48.20 & 3.13 & 97.45 \\
\hline 80 & 160.67 & 24.01 & 6.85 & 48.20 & 3.33 & 97.69 \\
\hline 85 & 170.71 & 24.01 & 7.29 & 48.20 & 3.54 & 97.53 \\
\hline 90 & 180.75 & 24.00 & 7.73 & 48.20 & 3.75 & 97.43 \\
\hline 95 & 190.79 & 24.01 & 8.16 & 48.20 & 3.96 & 97.38 \\
\hline 100 & 200.83 & 24.00 & 8.61 & 48.20 & 4.17 & 97.19 \\
\hline
\end{tabular}




\section{Appendix D: MISO600 Efficiency and Load Sharing Raw Data}

\begin{tabular}{|c|c|c|c|c|c|c|c|c|c|}
\hline $\begin{array}{c}\text { Load } \\
\text { Step } \\
(\%)\end{array}$ & $\begin{array}{c}\mathrm{P}_{\mathrm{o}} \\
(\mathrm{W})\end{array}$ & $\begin{array}{c}\mathrm{V}_{\text {in }} \\
(\mathrm{V})\end{array}$ & $\begin{array}{c}\mathrm{I}_{\text {in }} \\
(\mathrm{A})\end{array}$ & $\begin{array}{c}\mathrm{V}_{\mathrm{o}} \\
(\mathrm{V})\end{array}$ & $\begin{array}{c}\mathrm{I}_{\mathrm{o}} \\
(\mathrm{A})\end{array}$ & $\begin{array}{c}\text { Efficiency } \\
(\%)\end{array}$ & $\begin{array}{c}\mathrm{V}_{1} \\
(\mathrm{mV})\end{array}$ & $\begin{array}{c}\mathrm{V}_{2} \\
(\mathrm{mV})\end{array}$ & $\begin{array}{c}\mathrm{V}_{3} \\
(\mathrm{mV})\end{array}$ \\
\hline 5 & 30.31 & 24.00 & 1.36 & 48.50 & 0.63 & 92.87 & 3.2 & 4.0 & 4.0 \\
\hline 10 & 60.50 & 24.00 & 2.63 & 48.40 & 1.25 & 95.85 & 6.9 & 7.6 & 7.7 \\
\hline 15 & 90.56 & 24.01 & 3.93 & 48.30 & 1.88 & 95.98 & 10.7 & 11.4 & 11.4 \\
\hline 20 & 120.75 & 24.00 & 5.20 & 48.30 & 2.50 & 96.75 & 14.4 & 15.1 & 15.1 \\
\hline 25 & 150.63 & 24.00 & 6.48 & 48.20 & 3.13 & 96.85 & 18.2 & 18.8 & 18.8 \\
\hline 30 & 180.75 & 24.00 & 7.74 & 48.20 & 3.75 & 97.30 & 22.0 & 22.5 & 22.5 \\
\hline 35 & 210.88 & 24.01 & 9.01 & 48.20 & 4.38 & 97.48 & 25.8 & 26.2 & 26.3 \\
\hline 40 & 241.00 & 24.01 & 10.30 & 48.20 & 5.00 & 97.45 & 29.5 & 30.0 & 30.0 \\
\hline 45 & 271.13 & 24.00 & 11.60 & 48.20 & 5.63 & 97.39 & 33.3 & 33.9 & 33.7 \\
\hline 50 & 301.25 & 24.01 & 12.88 & 48.20 & 6.25 & 97.41 & 37.0 & 37.7 & 37.4 \\
\hline 55 & 331.38 & 24.01 & 14.18 & 48.20 & 6.88 & 97.33 & 40.9 & 41.5 & 41.2 \\
\hline 60 & 361.50 & 24.00 & 15.44 & 48.20 & 7.50 & 97.56 & 44.7 & 45.3 & 45.0 \\
\hline 65 & 391.63 & 24.00 & 16.75 & 48.20 & 8.13 & 97.42 & 48.7 & 49.1 & 48.8 \\
\hline 70 & 421.75 & 24.00 & 18.04 & 48.20 & 8.75 & 97.41 & 52.5 & 52.8 & 52.5 \\
\hline 75 & 450.94 & 24.00 & 19.34 & 48.10 & 9.38 & 97.15 & 56.5 & 56.7 & 56.4 \\
\hline 80 & 481.00 & 24.00 & 20.60 & 48.10 & 10.00 & 97.29 & 60.3 & 60.6 & 60.2 \\
\hline 85 & 511.06 & 24.00 & 22.00 & 48.10 & 10.63 & 96.79 & 64.2 & 64.5 & 64.0 \\
\hline 90 & 541.13 & 24.01 & 23.30 & 48.10 & 11.25 & 96.73 & 68.1 & 68.3 & 67.9 \\
\hline 95 & 571.19 & 24.00 & 24.60 & 48.10 & 11.88 & 96.75 & 72.0 & 72.2 & 71.8 \\
\hline 100 & 600.00 & 24.00 & 25.90 & 48.00 & 12.50 & 96.53 & 76.0 & 76.1 & 75.6 \\
\hline
\end{tabular}




\section{Appendix E: MISO1800 Efficiency Raw Data}

\begin{tabular}{|c|c|c|c|c|c|c|c|c|c|c|}
\hline $\begin{array}{l}\text { Load } \\
\text { Step } \\
(\%)\end{array}$ & $\begin{array}{c}\mathrm{P}_{\mathrm{o}} \\
(\mathrm{W})\end{array}$ & $\begin{array}{l}V_{\text {in } 1} \\
(V)\end{array}$ & $\begin{array}{l}V_{\text {in2 }} \\
(V)\end{array}$ & $\begin{array}{l}V_{\text {in } 3} \\
(V)\end{array}$ & $\begin{array}{l}\mathrm{I}_{\text {in1 }} \\
\text { (A) }\end{array}$ & $\begin{array}{l}\mathrm{I}_{\text {in2 }} \\
\text { (A) }\end{array}$ & $\begin{array}{l}\mathrm{I}_{\text {in } 3} \\
\text { (A) }\end{array}$ & $\begin{array}{l}V_{o} \\
(V)\end{array}$ & $\begin{array}{c}\mathrm{I}_{\mathrm{o}} \\
\text { (A) }\end{array}$ & $\begin{array}{c}\text { Efficiency } \\
(\%)\end{array}$ \\
\hline 5 & 90.75 & 24.15 & 24.11 & 24.29 & 1.25 & 1.39 & 1.43 & 48.40 & 1.88 & 92.19 \\
\hline 10 & 181.88 & 24.15 & 24.04 & 24.28 & 2.53 & 2.68 & 2.69 & 48.50 & 3.75 & 95.30 \\
\hline 15 & 271.13 & 24.15 & 24.08 & 24.27 & 3.81 & 3.94 & 3.96 & 48.20 & 5.63 & 95.81 \\
\hline 20 & 362.25 & 24.14 & 24.02 & 24.27 & 5.05 & 5.23 & 5.21 & 48.30 & 7.50 & 96.86 \\
\hline 25 & 452.81 & 24.14 & 24.15 & 24.26 & 6.38 & 6.46 & 6.52 & 48.30 & 9.38 & 96.71 \\
\hline 30 & 542.25 & 24.13 & 24.09 & 24.25 & 7.64 & 7.75 & 7.81 & 48.20 & 11.25 & 96.75 \\
\hline 35 & 632.63 & 24.13 & 24.02 & 24.24 & 8.95 & 9.06 & 9.11 & 48.20 & 13.13 & 96.67 \\
\hline 40 & 723.00 & 24.13 & 24.25 & 24.24 & 10.20 & 10.25 & 10.40 & 48.20 & 15.00 & 96.82 \\
\hline 45 & 813.38 & 24.12 & 24.19 & 24.23 & 11.49 & 11.54 & 11.66 & 48.20 & 16.88 & 96.97 \\
\hline 50 & 903.75 & 24.12 & 24.13 & 24.22 & 12.70 & 12.85 & 12.86 & 48.20 & 18.75 & 97.40 \\
\hline 55 & 994.13 & 24.11 & 24.07 & 24.21 & 14.01 & 14.18 & 14.17 & 48.20 & 20.63 & 97.26 \\
\hline 60 & 1084.50 & 24.11 & 24.00 & 24.20 & 15.31 & 15.51 & 15.48 & 48.20 & 22.50 & 97.18 \\
\hline 65 & 1174.88 & 24.10 & 24.18 & 24.19 & 16.61 & 16.68 & 16.75 & 48.20 & 24.38 & 97.19 \\
\hline 70 & 1265.25 & 24.10 & 24.12 & 24.18 & 17.91 & 18.03 & 18.08 & 48.20 & 26.25 & 97.05 \\
\hline 75 & 1358.44 & 24.09 & 24.05 & 24.17 & 19.27 & 19.41 & 19.42 & 48.30 & 28.13 & 97.00 \\
\hline 80 & 1449.00 & 24.08 & 24.09 & 24.16 & 20.58 & 20.70 & 20.72 & 48.30 & 30.00 & 96.93 \\
\hline 85 & 1536.38 & 24.08 & 24.10 & 24.15 & 21.90 & 22.00 & 22.08 & 48.20 & 31.88 & 96.58 \\
\hline 90 & 1630.13 & 24.07 & 24.02 & 24.15 & 23.25 & 23.40 & 23.41 & 48.30 & 33.75 & 96.63 \\
\hline 95 & 1717.13 & 24.07 & 24.07 & 24.13 & 24.55 & 24.60 & 24.73 & 48.20 & 35.63 & 96.48 \\
\hline 100 & 1807.50 & 24.06 & 24.00 & 24.13 & 25.86 & 26.00 & 26.03 & 48.20 & 37.50 & 96.44 \\
\hline
\end{tabular}




\section{Appendix F: MISO1800 Load Sharing Raw Data}

\begin{tabular}{|c|c|c|c|c|c|c|c|c|c|}
\hline $\begin{array}{c}\text { Load } \\
\text { Step } \\
(\%)\end{array}$ & $\begin{array}{c}\mathrm{V}_{1} \\
(\mathrm{mV})\end{array}$ & $\begin{array}{c}\mathrm{V}_{2} \\
(\mathrm{mV})\end{array}$ & $\begin{array}{c}\mathrm{V}_{3} \\
(\mathrm{mV})\end{array}$ & $\begin{array}{c}\mathrm{V}_{4} \\
(\mathrm{mV})\end{array}$ & $\begin{array}{c}\mathrm{V}_{5} \\
(\mathrm{mV})\end{array}$ & $\begin{array}{c}\mathrm{V}_{6} \\
(\mathrm{mV})\end{array}$ & $\begin{array}{c}\mathrm{V}_{7} \\
(\mathrm{mV})\end{array}$ & $\begin{array}{c}\mathrm{V}_{8} \\
(\mathrm{mV})\end{array}$ & $\begin{array}{c}\mathrm{V}_{9} \\
(\mathrm{mV})\end{array}$ \\
\hline 5 & 3.00 & 3.10 & 3.80 & 4.10 & 4.00 & 3.40 & 3.90 & 3.40 & 4.40 \\
\hline 10 & 6.70 & 6.80 & 7.50 & 7.80 & 7.80 & 7.10 & 7.60 & 7.20 & 8.10 \\
\hline 15 & 10.50 & 10.60 & 11.30 & 11.40 & 11.40 & 10.90 & 11.30 & 11.00 & 11.80 \\
\hline 20 & 14.10 & 14.40 & 15.00 & 15.10 & 15.10 & 14.60 & 15.00 & 14.80 & 15.50 \\
\hline 25 & 17.80 & 18.10 & 18.70 & 18.90 & 18.80 & 18.40 & 18.80 & 18.60 & 19.20 \\
\hline 30 & 21.50 & 21.90 & 22.50 & 22.60 & 22.50 & 22.10 & 22.50 & 22.30 & 22.90 \\
\hline 35 & 25.20 & 25.70 & 26.20 & 26.30 & 26.50 & 25.90 & 26.20 & 26.10 & 26.80 \\
\hline 40 & 29.00 & 29.40 & 30.00 & 30.10 & 30.30 & 29.70 & 29.90 & 29.90 & 30.60 \\
\hline 45 & 32.70 & 33.20 & 33.80 & 33.90 & 34.00 & 33.50 & 33.70 & 33.70 & 34.30 \\
\hline 50 & 36.50 & 37.00 & 37.60 & 37.70 & 37.80 & 37.40 & 37.50 & 37.50 & 38.10 \\
\hline 55 & 40.20 & 40.90 & 41.40 & 41.50 & 41.60 & 41.20 & 41.30 & 41.30 & 41.90 \\
\hline 60 & 44.00 & 44.70 & 45.20 & 45.30 & 45.40 & 45.10 & 45.10 & 45.10 & 45.60 \\
\hline 65 & 47.80 & 48.60 & 49.10 & 49.20 & 49.30 & 49.00 & 49.00 & 49.10 & 49.50 \\
\hline 70 & 51.70 & 52.50 & 52.90 & 53.10 & 53.10 & 52.90 & 52.90 & 52.90 & 53.30 \\
\hline 75 & 55.50 & 56.40 & 56.90 & 57.00 & 57.10 & 56.90 & 56.70 & 56.80 & 57.20 \\
\hline 80 & 59.40 & 60.30 & 60.80 & 60.90 & 61.10 & 60.90 & 60.70 & 60.80 & 61.10 \\
\hline 85 & 63.30 & 64.20 & 64.70 & 64.80 & 65.00 & 64.90 & 64.50 & 64.70 & 65.00 \\
\hline 90 & 67.20 & 68.10 & 68.70 & 68.80 & 69.00 & 68.90 & 68.60 & 68.70 & 68.90 \\
\hline 95 & 71.10 & 72.10 & 72.70 & 72.70 & 72.90 & 72.90 & 72.40 & 72.70 & 72.80 \\
\hline 100 & 75.00 & 76.10 & 76.70 & 76.70 & 76.90 & 76.90 & 76.50 & 76.70 & 76.70 \\
\hline
\end{tabular}




\section{Appendix G: Analysis of Senior Project}

Project Title: Design and Construction of 1800W Modular Multiple Input Single Output Non-Isolated DC-DC Converters

Student's Name: Angelo Gallardo

Advisor's Name: Taufik

1. Summary of Functional Requirements

This project consists of the design and construction of a modular DC-DC power converter that takes multiple inputs and creates one single output. The input takes in a nominal $24 \mathrm{~V}$ input and outputs $48 \mathrm{~V}$ and can operate up to $1800 \mathrm{~W}$ of output power. The converter features current sharing to ensure equal load distribution per module. Each module, which connects to their own separate input, can operate up to $600 \mathrm{~W}$ of output power, and three of these modules create $1800 \mathrm{~W}$.

\section{Primary Constraints}

Due to the maximum output power of $1800 \mathrm{~W}$, component sizing played a role in many of the design decisions. A huge concern involved making sure each component was sized properly so that it would not fail during full load testing, but also so that it would not be oversized and become wasteful.

With $1800 \mathrm{~W}$ of power going through the system, board layout had to take additional measures to ensure that the physical board itself can handle the power without overheating. The layout stage required careful planning on trace widths to ensure that the copper traces can handle the current at full load. 
Layout generally made this project very difficult. Since the LT8390 has many small signal pins working within its control loop, a poorly routed trace could cause the control loop to pick up too much noise and cause failures. This held especially true with the MOSFET gate drivers, which required an external resistor to slow it down.

\section{Economic}

This project brings its share of economic impacts. This new version of the MISO hopes to make the DC House project more attractive as product and hopes to divert people from $\mathrm{AC}$ homes into DC homes. With more attention to DC homes comes more attention to renewable generation, since the MISO and renewable sources must coexist together. This project hopes to increase the market in renewable energy sources by making it more possible to run houses off the $\mathrm{AC}$ grid.

Currently, this MISO serves as a prototype for the final product of the DC House. If the DC House turns into an actual business, where people purchase the MISO, renewable energy sources, and DC loads all in one package, then this project can potentially lead to a profit. Currently, the total cost of components for the MISO600 is about $\$ 75$ per board. Appendix A and B show the bill of materials for the MISO600. The cost to produce a board goes down tremendously during bulk purchasing and manufacturing. Table 5-1 shows the necessary equipment needed for development of this project.

The design of this project took 9 months. The build of a MISO1800 system takes a couple weeks. This includes time for board fabrication, for component acquisition, for soldering, and for system level testing. Data does not exist that describe the lifetime of 
the MISO1800. A cooling system added to the MISO1800 can allow the product to exist for at least 5 - 10 years. NREL data shown in [36] reveal an estimated $\$ 20 / \mathrm{kW}$-year cost for operation and maintenance in a standard <10kW PV system, which the MISO1800 can operate in. Therefore, the MISO1800 requires $\$ 36 / \mathrm{kW}$-year cost in O\&M for $1.8 \mathrm{~kW}$ of operation.

The conclusion of this project leads to additional revisions to improve this project further until it can safely operate in the DC House. Hopefully by this time, the DC House can become a complete product package and can find implementations in homes across the world.

4. If manufactured on a commercial basis:

Osh Park manufactured all the boards created for this thesis project. The cost for the MISO200 equals \$25/board, MISO600 equals \$66/board, and MISO mother board equals $\$ 27 /$ board. For large scale manufacturing, the price of each board drops significantly. The total cost per MISO1800 including components and manufacturing equals $\$ 450 /$ unit. This cost includes all manufacturing labor costs and material cost for each component.

Additional costs include fixed costs such as non-recoverable engineering cost. This project required 9 months of development to create the MISO product. For a design engineering salary of $\$ 60,000 /$ year, as estimated in [34], this equates to $\$ 45,000$. This MISO is built in-house, which requires a person to solder and test each board. Therefore, $\$ 60,000 /$ year covers the salary of a build and test engineer. Facilities are required to build and test the MISO. These facilities include an office and all the necessary equipment to 
solder components to the board and test each board. This analysis estimates $\$ 50,000$ of cost. Therefore, this thesis requires a one-time cost of $\$ 95,000$ and an additional $\$ 60,000 /$ year.

If 1000 devices are sold per year, at the price of $\$ 525$, the estimated profits equal $\$ 525,000$ per year. The cost of 1000 boards equals $\$ 450,000 /$ year, and an additional $\$ 60,000 /$ year covers test engineer salary. After considering a one-time cost of $\$ 95,000$, a break-even point occurs after six years. This does not facture in the significant cost drop due to large scale manufacturing, which would allow the price per device to drop as well to increase marketability.

\section{Environmental}

This project seeks to provide huge environmental upsides. Despite the impacts that electronic manufacturing brings, such as pollution due to factories, this project aims to make the world greener by making renewable energy sources more attractive to use in homes. Since the MISO can provide up to $1800 \mathrm{~W}$ of output power, this can power up houses in urban areas. If these houses use renewable energy sources with this MISO, then they can reduce the electricity that they get from the utilities, which would help reduce the overall usage of fossil fuels in the world. This project seeks to bring environmental improvements by making homes that run only on renewable energy more attainable.

This project also allows multiple renewable sources to combine with each other for one output. This also brings environmental improvements since users can use any renewable energy source. Often old and smaller sources are thrown away since they no 
longer generate a lot of energy. Since any number of sources can connect to the MISO, this project can reduce electronic waste in society.

6. Manufacturability

This project seeks to reduce the challenges during the manufacturability stage. The PCBs designed for this thesis project does not require any complex manufacturing, and therefore any standard PCB manufacturer can make these PCBs. Each component on the board can be easily placed onto to the board with standard reflow ovens and pick and place machines that a standard electronics manufacturer should already have. The MISO1800 requires little effort to install due to the edge connectors on the MISO600.

The board layout of the MISO600 requires little to no complex manufacturing since it uses standard IC pads and surface mount components. Therefore, little to no issues and challenges should occur during its manufacturing,

\section{Sustainability}

One sustainability issue that this project encounters is that one MOSFET heats up hotter than anticipated. At full load, the MOSFET heats up to above $100^{\circ} \mathrm{C}$, which cuts down on its expected lifetime. A short lifetime means that the component becomes a wasteful part of the system. Improving on this, as depicted in Chapter 6, involves either improving the board layout to better sink the heat, or adding a cooling system to reduce its peak temperature. A simple cooling system, such as a small fan, should exist in this system to not only cool down that one MOSFET but cool down the entire system for a longer lifetime to avoid waste. Upgrading this design to fix the MOSFET is sustainable 
since it does not require the remanufacture of the entire board, therefore waste does not accrue.

\section{Ethical}

One ethical implication comes from the manufacturing of each MISO product. Although this MISO aims to improve environmental conditions in the world with the use of renewable energy, it requires semiconductor manufacturing, which degrades the environment during operation. Therefore, this project must go against its goal to improve environmental conditions by using electronics, which requires manufacturing that naturally contributes to the degradation of the environment.

9. Health and Safety

A safety concern arises with this project during operation. Since the output voltage is $48 \mathrm{~V}$, an electrical shock could cause harm to the user during operation. The testing of this project used extra precaution for safety reasons. If this project were to become a real product, an enclosure is needed to protect the user from the electrical components.

10. Social and Political

This project can impact the political sector that deals with utilities and energy generation. If this project causes a push towards renewable energy, then an effect could occur with utility companies and how they handle homes that run solely on renewable energy. More hybrid systems can come out of this project, and so the utilities would have to make more policies regarding the use of hybrid systems with their pre-existing power grid. 
This project can impact energy generation companies such as ExxonMobil and BP by harming their sales. Since this project creates a power system that runs solely on renewable power, it encourages users to stray away from oil and gas companies, which could cause these companies to lose profit. This can indirectly impact political policy, since the government might have to step in to provide help for any oil and gas company that could face bankruptcy. This especially can hold true for bigger oil and gas companies that have political power and can lobby for changes in energy generation policy. The state or federal government could possibly enact policies regarding electricity generation and how much tax goes into running an off-grid system.

Lastly, this project can have impact at the community level. Community Choice Energy [35] is an organization that allows homeowners the option to purchase energy from either renewable energy generating facilities or from the traditional utilities. This project can impact organizations like this by providing another way to generate renewable energy in a cost-effective way. This organization exists because homeowners find it unreasonable to purchase products that allow renewable energy generation at the home level. It also exists to get people aware of renewable and to incentive them on investing in renewables. This project shows a cheaper way to create renewable energy generation for homes and thus can impact organizations like the Community Choice Energy to hopefully spread renewable generation to more homes.

\section{Development}

This project uses Altium Designer [33] for each layout of the boards. I had to learn this tool on the spot to create the layout for each MISO board in this thesis. From the start, I knew I had to create a hardware solution and therefore I had to eventually 
create a board layout. The design of the MISO power converter came easy to me since the power electronic classes go over how to design a power converter. However, the power electronic classes, and nearly every other EE class at Cal Poly, failed to mention how board layout works. Therefore, I spent most of my initial design time learning how to use Altium Designer and how to make correct design considerations during the actual layout process.

For instance, one thing I learned was how to properly route power traces. I found calculators online that calculated the width a trace should have depending on the current it carries and the expected temperature rise on the trace. With this knowledge, I could route power traces much larger so the board's temperature stays relatively close to ambient temperature, as seen in the thermal pictures shown in Chapter 5.

Another specific layout technique that I learned involved creating custom footprints to best serve my needs. Each component requires a specific footprint, but sometimes the manufacturer or Altium Designer did not have the right footprint for my component. Therefore, I learned how to create footprints through Altium Designer and how to properly read datasheets so I can size the pad properly so the component can fit onto the board. 